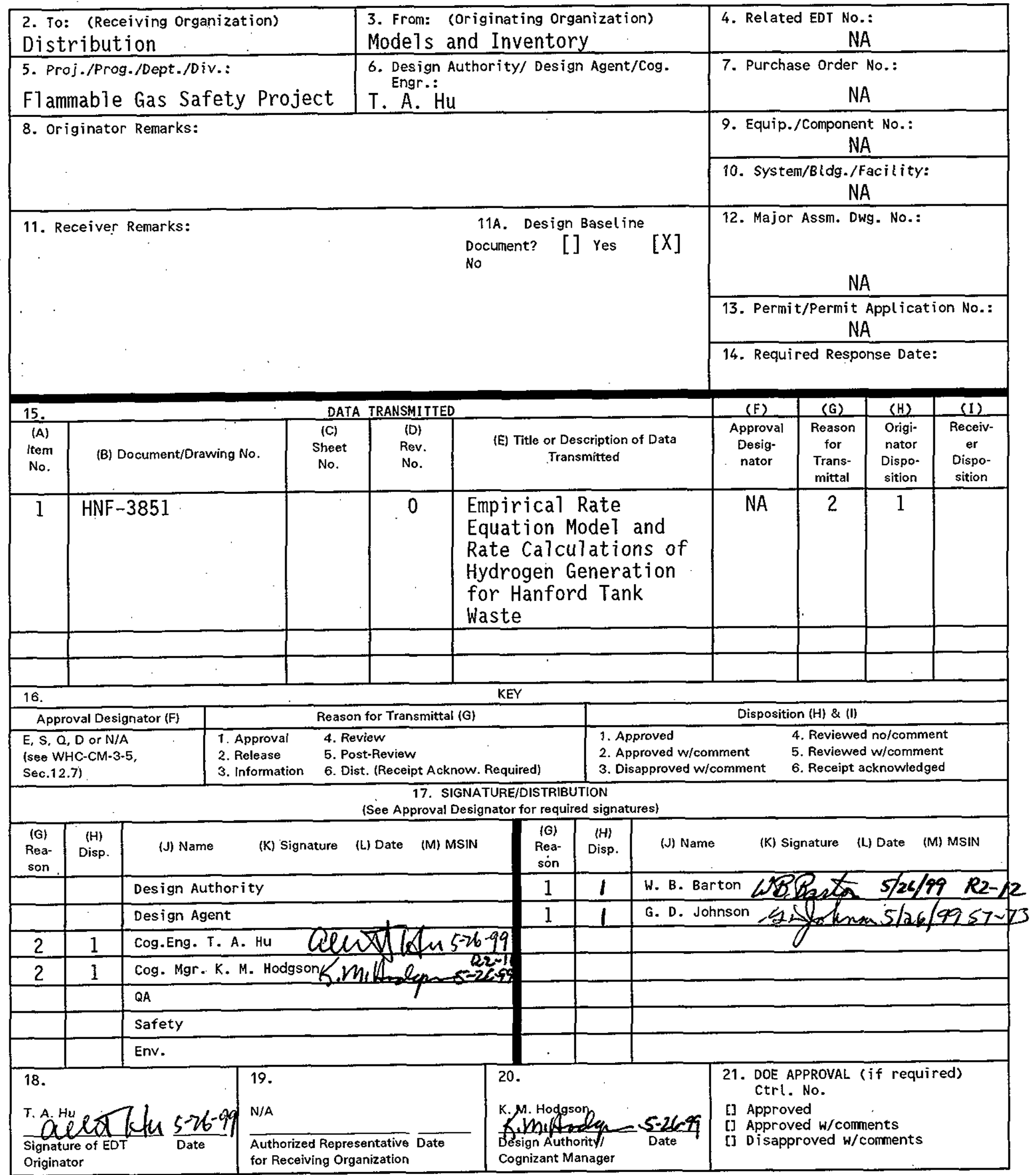




\section{Empirical Rate Equation Model and Rate Calculations of Hydrogen Generation for Hanford Tank Waste}

T. A. Hu

Lockheed Martin Hanford, Corp., Richland, WA 99352

U.S. Department of Energy Contract DE-AC06-96RL13200

EDT/ECN: EDT-626581

UC: 2070

Org Code: 74B40

B\&R Code: EW 3120074

Charge Code: 101898

Total Pages: 75

Key Words: Hydrogen Generation, Flammable Gas, Rate Equation Model, Hanford Tank Waste

Abstract: Empirical rate equations are derived to estimate hydrogen generation based on chemical reactions, radiolysis of water and organic compounds, and corrosion processes. A comparison of the generation rates observed in the field with the rates calculated for twenty eight tanks shows agreement within a factor of two to three.

TRADEMARK DISCLAIMER. Reference herein to any specific commercial product, process, or service by trade name, trademark, manufacturer, or otherwise, does not necessarily constitute or imply its endorsement, recommendation, or favoring by the United States Government or any agency thereof or its contractors or subcontractors.

Printed in the United States of America. To obtain copies of this document, contact: Document Control Services, P.0. Box 950, Mailstop H6-08, Richland WA 99352, Phone (509) 372-2420;

Fax (509) 376-4989.
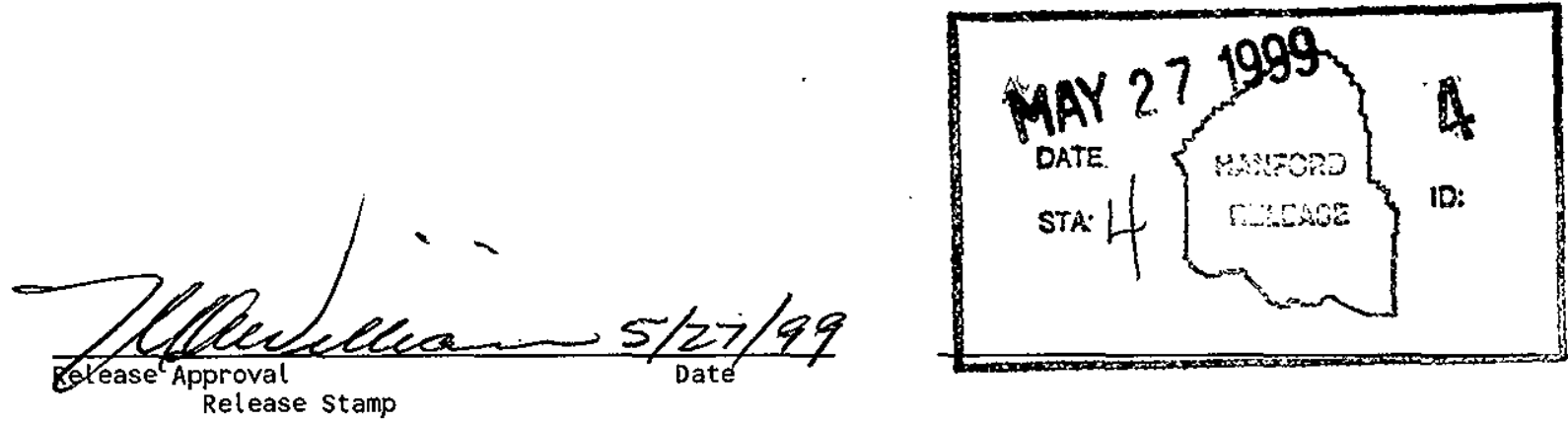

\section{Approved for Public Release}


HNF-3851

Revision 0

\section{Empirical Rate Equation Model and Rate Calculations of Hydrogen Generation for Hanford Tank Waste}

T. A. Hu

Lockheed Martin Hanford Corporation

Date Published

May 1999

Prepared for the U.S. Department of Energy

Assistant Secretary for Environmental Management

Project Hanford Management Contractor for the

U.S. Department of Energy under Contract DE-AC06-96RL13200

Approved for public release; distribution is unlimited 


\title{
Empirical Rate Equation Model and Rate Calculations of Hydrogen Generation for Hanford Tank Waste
}

\begin{abstract}
Hydrogen is the major flammable gas observed in tank dome spaces at the U.S. Department of Energy Hanford Site. Empirical rate equations are derived to estimate hydrogen generation based on chemical reactions, radiolysis of water and organic compounds, and corrosion processes. These equations take into account the dependence of the rate on tank waste compositions, temperature, radiation dose rate, liquid fraction etc. The numerical parameters are established by the analysis of gas generation kinetic data from actual waste samples, tank field surveillance data and tank waste characterization data. A comparison of the generation rates observed in the field with the rates calculated for twenty eight tanks shows agreement within a factor of two to three. The model serves as an useful tool to evaluate flammable gas issues to support operations.
\end{abstract}




\section{Acknowledgement}

The author wishes to thank Dr. James Person of Numatec Hanford Corporation for his significant contribution to this project. During the course of data analysis and model development, the author has had a number of lengthy and in-depth discussions with him, and he always offered brilliant ideas and professional opinions to initiate thought and resolve confusion. The author also would like to thank Dr. Kent Hodgson and Mr. Blaine Barton for their full support and comments on this project, and to thank Dr. Leon Stock for his comments on the manuscripts. Finally, the author would like to thank Ms. Karen Hennesay for her enthusiasm and patience in editing this report. 


\section{TABLE OF CONTENTS}

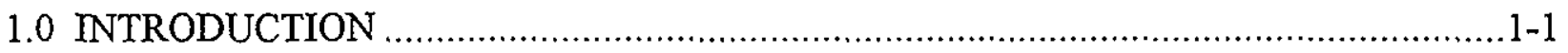

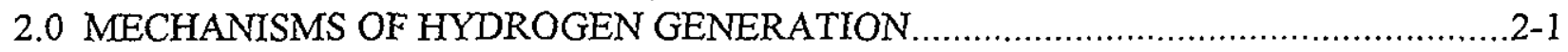

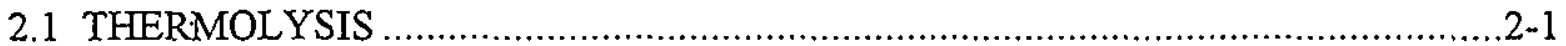

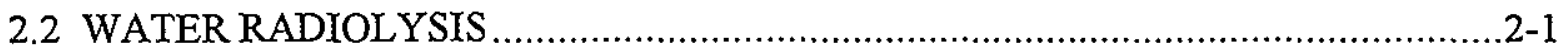

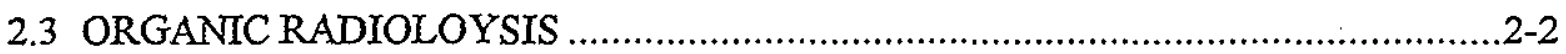

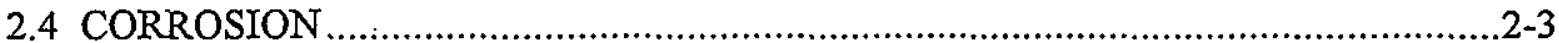

3.0 HYDROGEN GENERATION RATES FROM TANK WASTE SAMPLES .....................3-1

3.1 LABORATORY MEASURED HYDROGEN GENERATION RATES......................3-1

3.2 TANK-BY-TANK ANALYSIS OF THERMAL AND RADIOLYSIS RATES ..........3-4

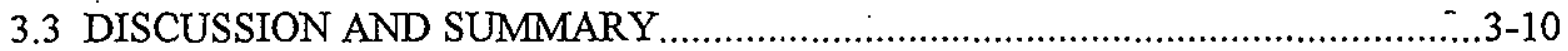

4.0 GLOBAL ANALYSIS AND EMPIRICAL RATE EQUATION MODEL .......................4-1

4.1 RATE EQUATION FOR THERMOLOYSIS …...................................................

4.1.1. Preliminary Thermal Rate Equation Based on Pre-exponential Term Analysis .4-2

4.1.2. Final Global Thermal Rate Equation Analysis.............................................4-10

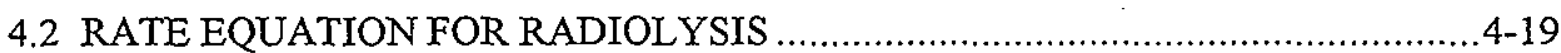

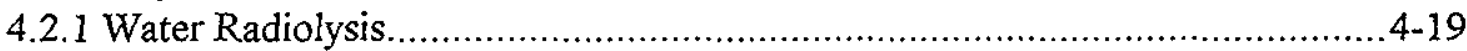

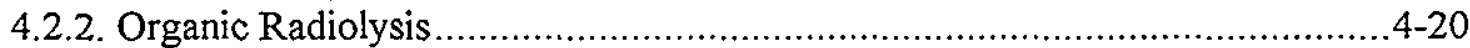

4.2.3. Global Radiolysis Rate Equation Analysis ...............................................4-21

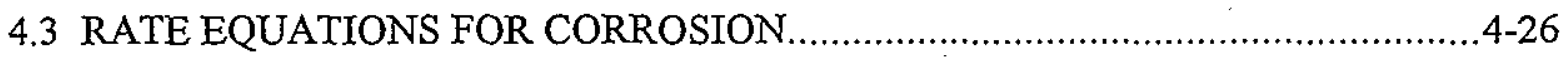

4.4 SUMMARY AND DISCUSSION OF EMPIRICAI RATE EQUATIONS .............4-27

5.0 COMPARISON OF FIELD OBSERVED AND MODEL CALCULATED RATES ..........5-1

5.1 MODEL CALCULATED HYDROGEN GENERATION RATES OF

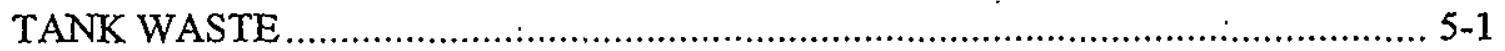

5.2 FIELD OBSERVED HYDROGEN GENERATION RATES OF TANK WASTE .....5-3

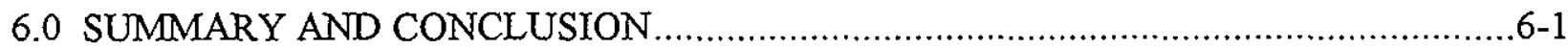

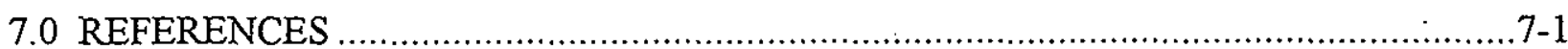




\section{LIST OF TABLES}

Table 3-1. Laboratory Measurements of Hydrogen Generation Rates with or without External Radiation at Different Temperature

Table 3-2. Energy of Activation and Pre-exponential Term for Thermal Gas Generation for Seven Tanks.

Table 3-3. Arrhenius Parameters from the Effective Radiolysis Rates Analysis

Table 3-4. Calculated G-Value from the Radiolytic Rate Analysis of Hydrogen Generation....3-10

Table 4-1. Activation Energies from Thermal Studies on Tank Waste Samples

Table 4-2. Kinetic Data of Hydrogen Generation and Waste Constituents 4-4

Table 4-3. Water Content of Samples and Calculated $A_{\text {Liq }}$ Values 4-7

Table 4-4. Fitting Results of $\mathrm{A}_{\mathrm{Liq}}$ with [TOC][Al] $]^{0.4}$ 4-9

Table 4-5. Input Variables for Normalized Thermal Rates Analysis

Table 4-6. Comparison of the Results of Linear Fit with As Reported and Normalized Thermal Rates with $[\mathrm{TOC}],[\mathrm{Al}]^{0.4}$ and $\mathrm{L}_{\mathrm{f}}$. 4-11

Table 4-7. Normalized Thermal Rates With or Without Reactivity Coefficient $r_{f}$ 4-14

Table 4-8. The Parameters for The Thermal Rate Equation from the Global Fit of the Normalized Thermal Rate Analysis 4-18

Table 4-9. Radiolysis Rates Analysis Parameters.

Table 4-10. Global Fit of Organic Radiolysis at Different Water Radiolysis Default Values .....4-23

Table 4-11. Calculated Radiolysis $\mathrm{G}$-value and Rate at $\mathrm{G}_{\mathrm{H} 2 \mathrm{O}}=0.005$ 4-25

Table 5-1. The Model-Calculated Hydrogen Generation Rate $5-2$

Table 5-2. Tank 241-AY-102 Hydrogen Concentration, Vent Rate, and Hydrogen Release Rate

Table 5-3. Field-Estimated Hydrogen Accumulation Rate, Release Rate, and Generation Rate for Hanford Tank Waste $5-7$

Table 5-4. Comparison of Rates Between Model-Calculated and Field-Observed $5-9$

\section{LIST OF FIGURES}

Figure 3-1. Thermal Rate Data from Tank 241-AN-105 Data (Person 1998). $3-4$ 
Figure 3-2. Laboratory Measurements of Hydrogen Generation From Tank 241-S-106 in the Presence of External Radiation (King and Bryan 1998a).

Figure 3-3. Laboratory Measurements of Hydrogen Generation from Tank 241-A-101 in the Presence of External Radiation (King and Bryan 1998b)

Figure 3-4. Radiolysis Rate Analysis Plot as $\ln ($ Rate) Versus 1/T for Tank 241-S-106 $3-8$

Figure 3-5. Typical Radiolysis Rate Analysis from Tank 241-A-101 (Data Taken from King and Bryan 1998b)

Figure 4-1. A Plot of Total Gas Reaction Rate as a Function of Sodium Aluminate in a Simulated Waste (Delegard 1980). 4-2

Figure 4-2. Preliminary Thermal Analysis: The Fit of reported A-value with the Product of [TOC] and [Al] from Tanks 241-SY-101, 241-SY-103, 241-AN-105, and 241-S-102

Figure 4-3. Preliminary Thermal Analysis: The Fit of $A_{\text {liquid }}$ with the $[\mathrm{TOC}] \times[\mathrm{Al}]^{0.4}$ from Tanks 241-SY-101, 241-SY-103, 241-AN-105, and 241-S-102 Data. 4-8

Figure 4-4: The Relationship Between Logarithm of Reported Thermal Rates and the Inverse of Temperature (1/T) for Tanks 241-A-101, 241-AN-105, 241-AW-101, 241-SY-103, 241-S-102, and 241-S-106. $4 \times 12$

Figure 4-5. The Relationship of Logarithm of Normalized Thermal and the Inverse of Temperature (1/T ) for Tanks 241-A-101, 241-AN-105, 241-AW-101, 241-SY-103, 241-S-102, and 241-S-106.

Figure 4-6. Plot of the Relationship of the Logarithm of Normalized Thermal Rates with Reactivity Coefficient Per [TOC] Versus the Inverse of Temperature From Tanks 241-AW-101, 241-AN-105, 241-SY-103, 241-A-101, 241-S-102, and 241-S-106

Figure 4-7. Comparison of the Ratio of Calculated to Laboratory Thermal Rates With and Without reactivity coefficients $r_{f}$ for Tanks 241-AW-101, 241-SY-103, 241-A-101, 241-S-102, and 241-S-106.

Figure 4-8. Normalized Radiolysis Rate Analysis with $\mathrm{G}_{\mathrm{H} 2 \mathrm{O}}=0.005$ for the Data from Tanks 241AW-101, 241-SY-103, 241-A-101, 241-S-102, and 241-S-106.

Figure 5-1. The Hydrogen Release Rate of Tank 241-AY-102 From Continuous Field Monitoring Data of Hydrogen Concentration and Headspace Vent Rate.

Figure 5-2. The Hydrogen Release Rate, Hydrogen Concentration, and Vent Rate in the Headspace of Tank 241-AY-102. 


\section{LIST OF TERMS}

A

A-Value

$\mathrm{A}_{\mathrm{H} 2}$

$a_{\text {rad }}$

$a_{\text {thm }}$

$A_{\text {wetted }}$

[Al]

cfm

cfd

DST

EDTA

$\mathrm{E}_{\mathrm{rad}}$

$E_{\text {thm }}$

G-Value

$\left(\mathrm{G}_{\mathrm{H} 2 \mathrm{O}}\right)_{\text {sat }}$

[ $\left.\mathrm{H}_{2}\right]$

$\mathrm{H}_{\text {load }}$

$\mathrm{H}_{2} / 100 \mathrm{eV}$

HEDTA

HGR

$\mathrm{J} / \mathrm{mole} /{ }^{\circ} \mathrm{K}$

$\mathrm{kJ} / \mathrm{mole}$

$\mathrm{L}_{f}$

$\mathrm{L}_{\mathrm{g}}$

$\mathrm{mol} / \mathrm{kg} / \mathrm{day}$

moles/L

$\left[\mathrm{NO}_{3}{ }^{-}\right]$

$\left[\mathrm{NO}_{2}{ }^{-}\right]$

$(\mathrm{P} / \mathrm{T})_{\text {waste }}$

ppm .

$\mathrm{R}$

$\mathrm{R}_{\text {corr }}$

$\mathrm{r}_{\mathrm{f}}$

RGS

SHMS

SST

TCD

TCR

[TOC]

$(\mathrm{T} / \mathrm{P})_{\text {headspace }}$

TWRS

wt $\%$ surface area $\left(\mathrm{pi} \times \mathrm{r}^{2}\right)$ of the tank.

pre-exponential term in the Arrhenius behavior of gas generation rate hydrogen accumulation rate $\left(\mathrm{ft}^{3} / \mathrm{min}\right.$ or $\left.\mathrm{cfm}\right)$

pre-exponential factor of organic radiolysis rate

pre-exponential factor of the thermal rate

area of steel exposed to moisture-containing waste $\left(\mathrm{ft}^{2}\right)$

aluminum concentration in liquid waste (wt\%)

cubic feet per minute

cubic feet per day

double-shell tank

Ethylenediaminetetraacetic acid

activation energy for organic radiolysis

activation energy for thermal reaction

A constant in the radiolysis rate equation of gas generation

default water radiolysis $\mathrm{G}$ under high salts

hydrogen volume fraction in the trapped gas

total heat load of the tank (Watt $/ \mathrm{kg}$ )

Number of $\mathrm{H}_{2}$ yield per $100 \mathrm{eV}$ in radiolysis

Hydroxyethylethylenediaminetriacetic acid

hydrogen generation rate

Joules per mole per degree Kelvin

kiloJoule per mole

liquid weight fraction in the waste (unitless)

growth rate of waste level ( $\mathrm{ft} / \mathrm{min}$ )

moles per kilogram per day

moles per liter

nitrate ion concentration in the liquid waste (moles/L)

nitrite ion concentration in the liquid waste (moles/L)

ratio of gas pressure $\mathrm{P}$ and temperature $T$ within the waste.

parts per million

gas constant

Hydrogen generation correspond to corrosion rate per unit area

TOC reactivity coefficient

retained gas sampler

Standard Hydrogen Monitoring System

single-shell tank

Tank Characterization Database

tank characterization report

concentration of total organic carbon in the liquid waste (wt\%)

ratio of temperature and pressure at the tank headspace.

Tank Waste Remediation System

weight percent 


\subsection{INTRODUCTION}

Gas generation in high-level radioactive tank waste is one of the major safety issues at the Hanford Site. The gases generated from tank waste are primarily hydrogen, nitrogen, nitrous oxide, ammonia, and methane. Understanding gas generation and the ability to predict the gas generation rates are important for controlling the flammable gas hazard during interim storage and for planning for future activities such as waste transfer, retrieval, and treatment.

Laboratory studies (Ashby et al. 1992, 1993, and 1994; Barefield et al. 1995 and 1996; Bryan et al. 1992; Bryan and Pederson 1994; Delegard 1980; Meisel et al. 1991a, 1991b, 1991c, and 1993; Person 1996) on gas generation from simulated waste samples provide good information about the mechanisms of the gas generation in the waste. The hydrogen generation rates from actual waste samples have been measured for several tanks (Person 1996 and 1998; Bryan et al. 1996; King et al. 1997; Bryan and King 1998; King and Bryan 1998a and 1998b). These kinetic data were used to determine Arrhenius parameters. Pederson and Bryan (1996) have prepared a good review of this topic.

In addition, the tank waste characterization program has provided a vast amount of information for the development of a reliable model, including. (1) tank waste characterization data from core and grab sampling (Schaffer 1997); (2) gas composition results from the retained gas sampler (Shekarriz et al. 1997; Mahoney et al. 1997); (3) tank headspace vent rate studies (Huckaby et al. 1997 and 1998; Sklarew and Huckaby 1998), and (4) vapor sampling data of tank dome space by the Standard Hydrogen Monitoring Systems (SHMS) and related grab samples (McCain and Bauer 1998).

Several models have been previously proposed to estimate the hydrogen generation rate (Hopkins 1994, Graves 1994, Pederson and Bryan 1996, Hu 1997). The approach has been to estimate the rate of gas generation by relating the measured generation rate from either simulated or actual waste samples to specific tank waste chemical constituents and physical conditions. Hopkins (1994) provided a complete set of equations to estimate the hydrogen generation rate from thermal chemical reactions, radiolysis, and corrosion. Graves (1994) provided a very similar model using slightly different scaling factors in the thermal rate equations. In these models, the thermal rate equation follows the Arrhenius behavior but the radiolysis rate is proportional to radiation with a constant G-value of $0.1 \mathrm{H}_{2} / 100 \mathrm{eV}$. Both Hopkins (1994) and Graves (1994) used simulated waste as a baseline for scaling.

Pederson and Bryan (1996) adopted Hopkins' thermal rate equation, and proposed a [TOC]dependent equation for organic radiolysis and a constant $\mathrm{G}$-value of $0.031 \mathrm{H}_{2} / 100 \mathrm{eV}$ for water radiolysis, which was first suggested by Meisel and coworkers (1993). In the Pederson and Bryan (1996) model, both thermal and radiolysis rate parameters were derived from tank 241-SY-103 waste samples (Bryan et al. 1996). They have shown good agreement between model-calculated rates and field-estimated rates when applied to tank 241-SY-101. Hu (1997) modified this model (Pederson and Bryan 1996) by adding terms for water radiolysis when the salt concentrations were low and for liner corrosion, and applied the extended model to double-shell tanks (DSTs). 
The calculated rates show good agreement with field data. However, when applying the model (Hu 1997) to calculate generation rates for single-shell tanks (SSTs), the ratio of modelcalculated rate to filed-estimated rate ranged from 0.75 to 26.5 (Peurrung et al. 1998). It was concluded that this large variation resulted, in part, from the exclusive use of rate data from tank 241-SY-103 to parameterize the model. This deficiency has been addressed in this report.

In this work, including the preliminary work (Hu et al. 1998), a newly developed and validated empirical model to estimate the hydrogen generation rate for SST and DST tank waste is presented and discussed. This model offers a more complete set of empirical rate equations to simulate both thermolytic and radiolytic effects on the hydrogen generation rate and incorporates the hydrogen generation rate from tank liner corrosion. Although coherent with the previously proposed models, the model has several new features: (1) it provides a set of empirical kinetic rate equations rather than a rate-scaling approach; (2) it has a temperature-dependent radiolysis rate equation (3) it is based on a large body of laboratory-measured rates from actual waste samples rather than a single simulated waste sample or 241-SY-103 waste samples; and (4) it has been applied to 33 of the most active gas generating DSTs and SSTs. The results are in good agreement with the field observations.

Model development was divided into three subtasks. The first subtask was the detailed analysis of all hydrogen generation rates from actual waste samples for each individual tank. The main thrust of this tank-by-tank approach was to evaluate the temperature-dependent rates measured in the presence of the external radiation. The activation energy, pre-exponential A-value for the thermal reactions, and the effective G-value for the radiolysis are derived for individual tanks. This work established the rate behavior, tank by tank, and formalized the individual elements of the model.

The second subtask was to analyze the available laboratory rate data as a whole. A preliminary global analysis of the pre-exponential term of Arrhenius equations for thermal rates and of the radiolysis G-values was conducted first to identify the rate-dependent variables and establish the framework of the model (Hu et al., 1998). The model was finalized by performing global analysis on all available thermolysis and radiolysis rates. The parameters of the final rate equations were obtained from this global analysis of laboratory and field observations. The rate constants and activation energies were determined for the thermal rate equation. The effective radiolysis reaction rate was computed in two parts, water radiolysis and organic radiolysis. The G-values for both water and organic reactions are computed as a function of tank waste compositions. Corrosion rates are formulated from the tank liner corrosion rate and the area of wetted surface.

Finally, the rate equations were used to calculate the hydrogen generation rate for a number of SSTs and DSTs, and the results were compared with the field data. The field data were also used to fine tune the parameters of the rate equations. The hydrogen generation rates for the crusts (top thin solid layer), convective (liquid), and nonconvective (solid) waste layers for all twentyeight tanks were calculated. These layer-by-layer calculations reveal differences between layers and can be compared with the hydrogen release and accumulation rates estimated from field data. 
This report is organized as follows. A brief review of hydrogen gas generation chemistry is given in Section 2. The hydrogen generation rates analyzed for individual tank are given in Section 3. A global analysis of the measured generation rates and the development of the model are given in Section 4. Calculated generation rates and field generation rates are compared in Section 5. Summary and conclusions are given in Section 6. References are given in Section 7. 
HNF-3851 Rev. 0

This page intentionally left blank. 
HNF-3851 Rev. 0

\subsection{MECEANISMS OF HYDROGEN GENERATION}

Laboratory studies on the pathways for hydrogen generation in tank waste by radiolysis, thermolysis, and corrosion processes are summarized in following subsections.

\subsection{THERMOLYSIS}

In a study of tank 241-SY-101 simulant, Delegard (1980) reported that $\mathrm{N}_{2}, \mathrm{~N}_{2} \mathrm{O}$, and $\mathrm{H}_{2}$ generation was caused by the oxidative degradation of the complexant hydroxyethylethylenediaminetriacetate ion (HEDTA) but not by ethylenediaminetetraacetate ion (EDTA). Studies of gas generation indicate the observed reaction rates depend on temperature and follow Arrhenius behavior, in which the rate increases exponentially with temperature.

$$
\text { Rate }_{\text {thm }}=\mathbf{A} \mathbf{e}^{-\mathrm{E} / \mathrm{RT}}
$$

where $A$ is a constant and $E$ is the activation energy.

Delegard (1980) found an activation energy of $102.5 \mathrm{~kJ} / \mathrm{mole}$ for the simulant and that the gas generation rates were dependent on the concentrations of the organic solutes, nitrite, hydroxide, and aluminate ion. Ashby et al. (1994) also reported aluminate ion enhanced the decomposition of glycolate in the tank 241-SY-101 simulated waste. Barefield et al. (1995, 1996) found that aluminate and nitrite ions are important in initiating the decomposition. More than half a dozen activation energies for hydrogen generation have been reported. Depending on the identity of the organic component, the values vary considerably, ranging from $41 \mathrm{~kJ} / \mathrm{mole}$ (Meisel et al. 1993) to $126 \mathrm{~kJ} / \mathrm{mole}$ (Ashby et al. 1994).

In addition to water radiolysis, Ashby et al. (1992, 1993, 1994) suggested that formaldehyde, a decomposition product of HEDTA and EDTA, was an important organic source of hydrogen. Formaldehyde can react with base to form hydrogen and formate ion:

$$
\mathrm{H}_{2} \mathrm{CO}+\mathrm{H}_{2} \mathrm{O}\left(\mathrm{OH}^{-}\right) \rightarrow \mathrm{HCOO}^{-}+\mathrm{H}_{2}
$$

Similar reactions occur with other aldehydic aging products such as glyoxylate ion.

\subsection{WATER RADIOLYSIS}

In radiation-induced reactions, hydrogen generation can arise from the direct radiolysis of water and by hydrogen abstraction from organic solutes. The radiolysis of water generates highly reactive species, such as the solvated electron $\left(\mathrm{e}_{\mathrm{aq}}{ }^{-}\right)$; hydrogen atom $(\mathrm{H})$; and the hydroxyl 
radical $\mathrm{OH} \cdot($ Spinks and Woods 1990$)$ as shown

$$
\mathrm{H}_{2} \mathrm{O}+\text { radiation } \rightarrow \mathrm{H} \cdot+\mathrm{H}^{+}+\mathrm{OH} \cdot+\mathrm{e}_{2 \mathrm{q}}^{-} \text {etc. }
$$

Typical reactions to form hydrogen are shown.

$$
\begin{aligned}
& \mathrm{e}_{\mathrm{aq}}{ }^{-}+\mathrm{H} \cdot+\mathrm{H}_{2} \mathrm{O} \rightarrow \mathrm{H}_{2}+\mathrm{OH} \cdot \\
& \mathbf{H} \cdot+\mathrm{H}^{\cdot} \rightarrow \mathrm{H}_{2}
\end{aligned}
$$

Water radiolysis is suppressed by the salts. For Hanford wastes containing high concentrations of nitrate and nitrite ions, the products of water radiolysis (see Equation 2-4) are scavenged as

$$
\begin{aligned}
& \mathrm{e}_{\mathrm{aq}}{ }^{-}+\mathrm{NO}_{3}{ }^{-} \rightarrow \mathrm{NO}_{3}{ }^{2-} \\
& \mathrm{H} \cdot+\mathrm{NO}_{2}{ }^{-} \rightarrow \mathrm{NO}+\mathrm{OH}^{-}
\end{aligned}
$$

The nitrate and nitrite ions consume the solvated electron and hydrogen atom and dramatically reduce hydrogen generation by water radiolysis.

\subsection{ORGANIC RADIOLOYSIS}

The hydrogen radical from water radiolysis can abstract $\mathrm{H}$ atoms from organic constituents to initiate the oxidation reaction of organic complexants and solvents and form hydrogen gas

$$
\mathbf{H} \cdot \mathbf{R}-\mathbf{H} \rightarrow \mathbf{H}_{2}+\mathbf{R} \cdot
$$

where R-H represents an organic component with a hydrogen atom, as shown in the reaction of HEDTA:

$$
\begin{aligned}
& \mathrm{H} \cdot+\mathrm{RN}\left(\mathrm{CH}_{2} \mathrm{CO}_{2}^{-}\right) \mathrm{CH}_{2} \mathrm{CH}_{2} \mathrm{OH} \rightarrow \mathrm{H}_{2}+\left(\mathrm{RN}\left(\mathrm{CH}_{2} \mathrm{CO}_{2}^{-}\right) \mathrm{CHCH}_{2} \mathrm{OH}\right) \\
& \text { Where R }=\left(\mathrm{CH}_{2} \mathrm{CO}_{2}^{-}\right)_{2} \mathrm{NCH}_{2} \mathrm{CH}_{2}
\end{aligned}
$$


The ensuing decomposition processes in which HEDTA is converted into ED3A leads to formaldehyde, and additional hydrogen is generated by its oxidation to formate ion.

\subsection{CORROSION}

Hydrogen gas can be produced by the interaction of caustic liquids with the carbon steel of the tank walls. The chemical reaction for corrosion of steel is

$$
2 \mathrm{H}_{2} \mathrm{O}+\mathrm{Fe} \rightarrow \mathrm{Fe}(\mathrm{OH})_{2}+\mathrm{H}_{2}
$$

In a high salt environment, such as Hanford tank waste, the corrosion process can be more complex (Anantatmula et al. 1994; Ondrejcin, et al. 1979). However, corrosion contributes only modestly to hydrogen generation and will not be discussed further. 
HNF-3851 Rev. 0

This page intentionally left blank. 


\subsection{HYDROGEN GENERATION RATES FROM TANK WASTE SAMPLES}

Gas generation rates of waste samples from several tanks were measured to assess the relative importance of thermolysis and radiolysis at Pacific Northwest National Laboratory (King and Bryan 1998b and associated references) and 222-S Laboratory (Person 1996, 1998) at the Hanford Site. The thermal generation rates for each tank waste follow Arrhenius behavior quite nicely. The study of the influence of radiation on the gas generation rate for tank 241-SY-103 waste (Pederson and Bryan 1996) found that the radiolysis rate was temperature independent. However, additional studies found that the radiolysis rates for tank 241-AW-101 (Bryan and King 1998), tank 241-S-106 (King and Bryan 1998a), and tank 241-A-101 (King and Bryan 1998b) were temperature-dependent.

Temperature-dependent radiolysis G-values are also observed in the simulated waste studies (Meisel et al. 1993 and Camaioni et al. 1996). Meisel et al (1993) found that the radiolysis G-value at $60^{\circ} \mathrm{C}$ is higher than at $30^{\circ} \mathrm{C}$ for several solutes. The activation energies for the hydrogen abstraction reaction range from 4 to $39 \mathrm{~kJ} / \mathrm{mole}$. In the tank waste simulants SY-SIM-94C aging experiment, Camaioni et al. (1996) show that the radiolysis $\mathrm{G}$-values are $0.09,0.11,0.28$ at temperatures of 50,70 , and $90^{\circ} \mathrm{C}$, respectively. The activation energy derived from that study is about $27 \mathrm{~kJ} / \mathrm{mole}$.

As shown in the following analysis, the radiolysis rate is temperature-dependent. Whether this temperature-dependent behavior can be observed or not is dependent on the relative magnitude of the thermolysis and radiolysis components of the total rate. The analysis of radiolysis rates shows the observed radiolysis rates are not only temperature-dependent but also follow Arrhenius behavior. The results suggest that the observed radiolysis rates are the result of thermal reactions of organic molecules, e.g., formaldehyde, formed in radiolytically induced reactions.. The temperature-dependent G-values and the activation energies of the radiation-enhanced chemical reactions are derived for each individual tank in the following sections.

\subsection{LABORATORY MEASURED HYDROGEN GENERATION RATES}

Bryan et al. (1996) and Person (1996) assessed the thermal contribution to the gas generation rate by measuring the rate of pressure increase in the reaction vessel when the waste samples are heated and maintained at different temperatures. The individual gas generation rates were determined based on the percentage of the gas in the sample (from the mass spectroscopy results of the sample) multiplied by the total gas generation rate. The rate measured at different temperatures is referred to as the thermolysis rate. The radiation effect from self-dose is very small compared to the thermolysis contribution for the temperatures used in the study. For the radiation contribution, the gas generation rates are measured at different temperatures while irradiating the samples with relatively large external radiation dosages to enhance the radiolytic reaction. At least two samples are subjected to each condition examined.

Table 3-1 lists the measured rates from seven tanks with or without external radiation at different 
temperatures, and the differences between the two measured rates. The rate measured without external radiation is referred to as the thermal rate. The effective radiolysis rate is defined as the difference between the rates measured with and without external radiation.

Table 3-1. Laboratory Measurements of Hydrogen Generation Rates with or without External Radiation at Different Temperature (2 Sheets)

\begin{tabular}{|c|c|c|c|c|}
\hline Tanks. & Temperature & 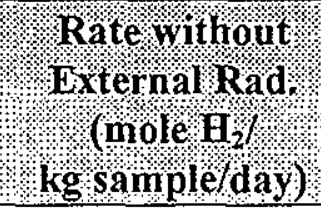 & 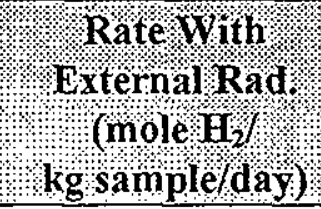 & 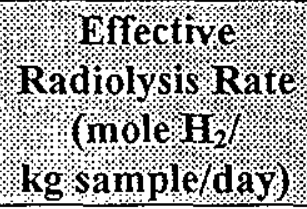 \\
\hline \multirow{6}{*}{$241-A-101^{1}$} & 60 & $6.90 \mathrm{E}-07$ & $6.80 \mathrm{E}-06$ & $6.11 \mathrm{E}-06$ \\
\hline & 60 & $8.70 \mathrm{E}-07$ & 8.90E-06 & $8.03 E=06$ \\
\hline & 90 & 9.60E-06 & $4.60 \mathrm{E}-05$ & $3.64 \mathrm{E}-05$ \\
\hline & 90 & $1.10 \mathrm{E}-05$ & $4.90 \mathrm{E}-05$ & $3.80 \mathrm{E}-05$ \\
\hline & 120 & $1.70 \mathrm{E}-04$ & $2.60 \mathrm{E}-04$ & $9.00 \mathrm{E}-05$ \\
\hline & 120 & $1.80 \mathrm{E}-04$ & $2.80 \mathrm{E}-04$ & $1.00 \mathrm{E}-04$ \\
\hline \multirow{8}{*}{$241-S-102^{2}$} & 60 & $1.20 \mathrm{E}-06$ & $1.0 .60 \mathrm{E}-05$ & $1.48 \mathrm{E}-05$ \\
\hline & 60 & $1.70 \mathrm{E}-06$ & $1.0 .50 \mathrm{E}-05$ & 1.33E-05 \\
\hline & 80 & $7.00 \mathrm{E}-06$ & $3.20 \mathrm{E}-05$ & $2.50 \mathrm{E}-05$ \\
\hline & 80 & 7.30E-06 & $2.80 \mathrm{E}-05$ & $2.07 \mathrm{E}-05$ \\
\hline & 100 & $2.70 \mathrm{E}-05$ & $9.60 \mathrm{E}-05$ & $6.90 \mathrm{E}-05$ \\
\hline & 100 & $2.70 \mathrm{E}-05$ & $9.50 \mathrm{E}-05$ & $6.80 \mathrm{E}-05$ \\
\hline & 120 & $1.60 \mathrm{E}-04$ & $2.70 \mathrm{E}-04$ & $1.10 \mathrm{E}-04$ \\
\hline & 120 & $2.20 \mathrm{E}-04$ & $2.70 \mathrm{E}-04$ & $5.00 \mathrm{E}-05$ \\
\hline \multirow{6}{*}{$241-\mathrm{S}-106^{3}$} & 60 & $1.10 \mathrm{E}-06$ & $9.90 \mathrm{E}-06$ & $8.80 \mathrm{E}-06$ \\
\hline & 60 & $1.20 \mathrm{E}-06$ & $1.0 .00 \mathrm{E}-05$ & $8.80 \mathrm{E}-06$ \\
\hline & 90 & $9.40 \mathrm{E}-06$ & $3.60 \mathrm{E}-05$ & $2.66 \mathrm{E}-05$ \\
\hline & 90 & $1.40 \mathrm{E}-05$ & $4.30 \mathrm{E}-05$ & $2.90 \mathrm{E}-05$ \\
\hline & 120 & $5.50 \mathrm{E}-05$ & $1.0 .70 \mathrm{E}-04$ & $1.15 \mathrm{E}-04$ \\
\hline & 120 & $8.70 \mathrm{E}-05$ & 1.0.70E-04 & $8.30 \mathrm{E}-05$ \\
\hline 241-AN-105 & 61 & $5.34 \mathrm{E}-06$ & $\mathrm{n} / \mathrm{a}$ & $\mathrm{n} / \mathrm{a}$ \\
\hline
\end{tabular}


HNF-3851 Rev. 0

Table 3-1. Laboratory Measurements of Fydrogen Generation Rates with or without External Radiation at Different Temperature (2 Sheets)

\begin{tabular}{|c|c|c|c|c|}
\hline 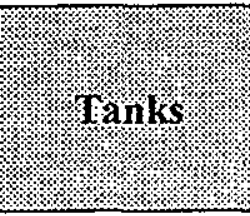 & $\begin{array}{l}\text { Temperature } \\
(9) \\
(0)\end{array}$ & 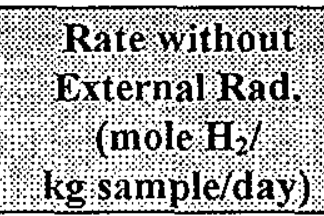 & $\begin{array}{l}\text { Rate With } \\
\text { External Rad. } \\
\text { (mole H, } \\
\text { kg sample/day) }\end{array}$ & $\begin{array}{l}\text { Effective } \\
\text { Radiolysis.Rate } \\
\text { (moleH } \\
\text { kg sample/day) }\end{array}$ \\
\hline \multirow{7}{*}{$241-\mathrm{AN}-105^{4}$} & 58 & $4.79 \mathrm{E}-06$ & $\mathrm{n} / \mathrm{a}$ & $\mathrm{n} / \mathrm{a}$ \\
\hline & 82 & $3.01 E-05$ & $\mathrm{n} / \mathrm{a}$ & $\mathrm{n} / \mathrm{a}$ \\
\hline & 78 & $2.23 \mathrm{E}-05$ & $\mathrm{n} / \mathrm{a}$ & $\mathrm{n} / \mathrm{a}$ \\
\hline & 102 & $1.97 \mathrm{E}-04$ & $\mathrm{n} / \mathrm{a}$ & $\mathrm{n} / \mathrm{a}$ \\
\hline & 96 & $1.25 \mathrm{E}-04$ & $\mathrm{n} / \mathrm{a}$ & $\mathrm{n} / \mathrm{a}$ \\
\hline & 103 & $1.72 \mathrm{E}-04$ & $\mathrm{n} / \mathrm{a}$ & $\mathrm{n} / \mathrm{a}$ \\
\hline & 96 & $7.38 \mathrm{E}-05$ & $\mathrm{n} / \mathrm{a}$ & $\mathrm{n} / \mathrm{a}$ \\
\hline \multirow{10}{*}{$241-S Y-103^{5}$} & 60 & $7.20 \mathrm{E}-06$ & $2.80 \mathrm{E}-05$ & $2.08 \mathrm{E}-05$ \\
\hline & 60 & $9.10 \mathrm{E}-06$ & $2.50 \mathrm{E}-05$ & $1.59 \mathrm{E}-05$ \\
\hline & 75 & $2.50 \mathrm{E}-05$ & $4.00 \mathrm{E}-05$ & $1.30 \mathrm{E}-05$ \\
\hline & 75 & $2.70 \mathrm{E}-05$ & $3.40 \mathrm{E}-05$ & $9.00 \mathrm{E}-06$ \\
\hline & 90 & $7.20 \mathrm{E}-05$ & $8.50 \mathrm{E}-05$ & $1.20 \mathrm{E}-05$ \\
\hline & 90 & 7.30E-05 & $8.30 \mathrm{E}-05$ & $1.10 \mathrm{E}-05$ \\
\hline & 105 & 2.80E-04 & $2.20 \mathrm{E}-04$ & $-6.00 E-05$ \\
\hline & 105 & $4.60 \mathrm{E}-04$ & 2.50E-04 & $-2.10 \mathrm{E}-04$ \\
\hline & 120 & $1.10 \mathrm{E}-03$ & $6.70 \mathrm{E}-04$ & $-4.30 \mathrm{E}-04$ \\
\hline & 120 & $1.20 \mathrm{E}-03$ & 8.00E-04 & $-4.00 \mathrm{E}-04$ \\
\hline \multirow{6}{*}{$241-A W-101^{6}$} & 60 & $8.80 \mathrm{E}-06$ & 1.0.20E-04 & $1.11 \mathrm{E}-04$ \\
\hline & 60 & $9.00 \mathrm{E}-06$ & $1.0 .00 \mathrm{E}-04$ & $9.10 \mathrm{E}-05$ \\
\hline & 90 & $1.60 \mathrm{E}-04$ & $5.60 \mathrm{E}-04$ & $4.00 \mathrm{E}-04$ \\
\hline & 90 & $1.70 \mathrm{E}-04$ & $4.40 \mathrm{E}-04$ & $2.70 \mathrm{E}-04$ \\
\hline & 120 & $2.20 \mathrm{E}-03$ & 2.00E-03 & $-1.89 \mathrm{E}-04$ \\
\hline & 120 & $2.30 \mathrm{E}-03$ & $2.00 \mathrm{E}-03$ & $-3.01 \mathrm{E}-04$ \\
\hline
\end{tabular}

${ }^{1}$ King and Bryan (1998b)

${ }^{2}$ King et. al. (1997)

${ }^{3}$ King and Bryan (1998a)

${ }^{4}$ Person (1998)

'Bryan et al. (1996)

${ }^{6}$ Bryan and King (1998) 
HNF-3851 Rev. 0

In general, the rate should reach a steady generation rate in a few hours and remain constant at a given temperature. The rate could decrease because the source fuel is gradually used up. In the following analysis, the highest average rates at each temperature are selected for each tank in Table 3-1. Tanks 241-AW-101 and 241-SY-103 have negative radiolysis rates at higher temperatures.

\subsection{TANK-BY-TANK ANALYSIS OF THERMAL AND RADIOLYSIS RATES}

The thermal rates (i.e., measured without external radiation) follow Arrhenius behavior,

$$
\text { Rate }_{t h m}=\mathbf{A}_{\text {thm }} \times \mathbf{e}^{-(\mathrm{Ethm} / \mathrm{RT})}
$$

Where $E_{t h m}$ is the effective activation energy for thermal reaction.

$A_{t h m}$ is the pre-exponential term.

The thermal activation energy and pre-exponential A-value are obtained from the slope and intercept of each Arrhenius analysis, as shown for tank 241-AN-105 in Figure 3-1.

Figure 3-1. Thermal Rate Data from Tank 241-AN-105 Data (Person 1998).

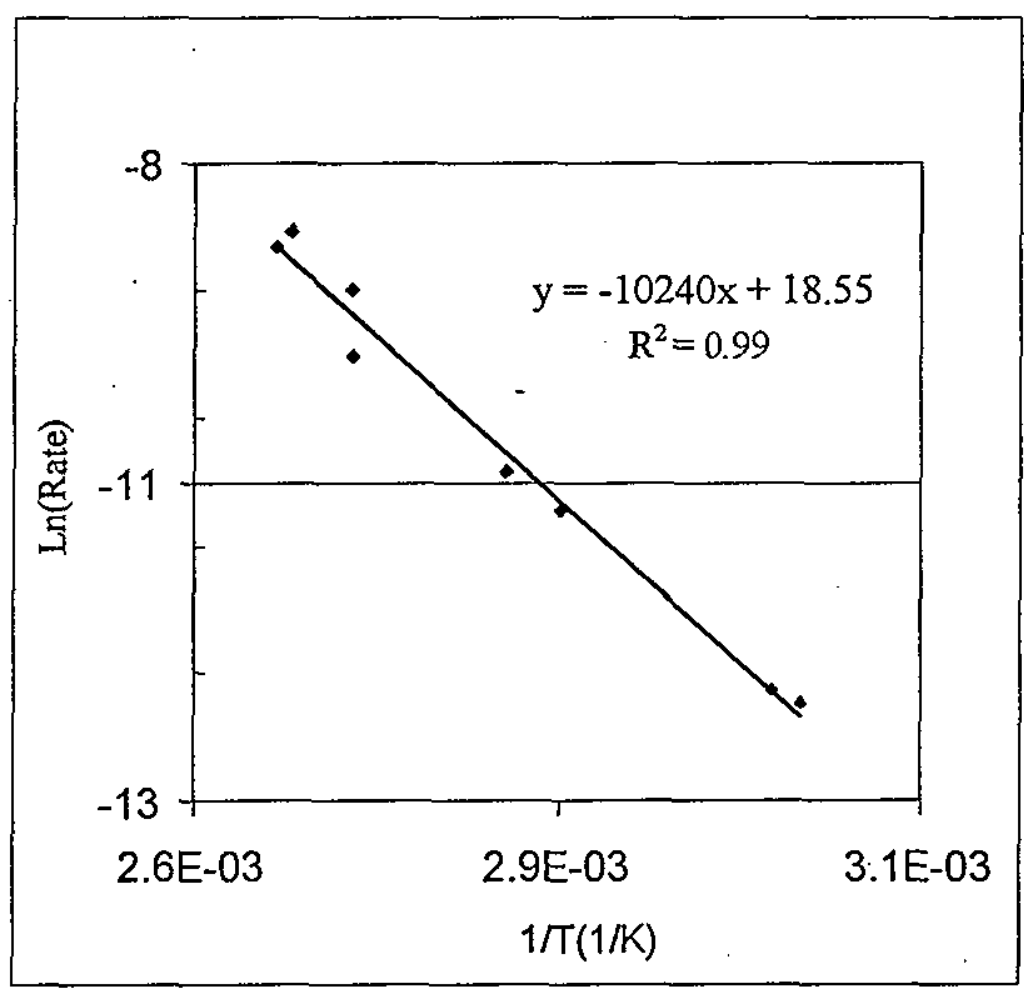


HNF-3851 Rev. 0

In the thermal rate analysis, the self-dose radiation is so small that the radiation enhancement can be neglected. The thermal activation energy and the pre-exponential term quoted from the reports are listed in Table 3-2. The standard deviation of each value in Table 3-2 is given (where available) in the parenthesis.

Table 3-2. Energy of Activation and Pre-exponential Term for Thermal Gas Generation for Seven Tanks

\begin{tabular}{|c|c|c|}
\hline Tanks & Gain & $\ln (\mathbf{A})$ \\
\hline $241-\mathrm{A}-101^{1}$ & $101(8)$ & $22(3)$ \\
\hline $241-\mathrm{S}-102^{2}$ & $91(7)$ & $19(3)$ \\
\hline $241-\mathrm{S}-106^{3}$ & $73(6)$ & $12(2)$ \\
\hline $241-\mathrm{AW}-101^{4}$ & $102(3)$ & $25(1)$ \\
\hline $241-\mathrm{AN}-105^{5}$ & $89.0(6)$ & $20(2)$ \\
\hline $241-\mathrm{SY}-101^{6}$ & 94 & 21 \\
\hline $241-\mathrm{SY}-103^{7}$ & $91(9)$ & $21(3)$ \\
\hline
\end{tabular}

${ }^{1}$ King and Bryan (1998b)

${ }^{2}$ King et. al. (1997)

${ }^{3}$ King and Bryan (1998a)

${ }^{4}$ Bryan and King (1998)

Serson (1998)

${ }^{6}$ Person (1996) This is one temperature measurement

${ }^{7}$ Bryan et al. (1996)

To assess the radiation effect, the generation rates are measured in the presence of external radiation at different temperature. The effective radiolysis rates referred as the rate difference with and without external radiation are listed in the last column of Table 3-1. Figures 3-2 and 3-3 illustrate the hydrogen generation rates for samples from tanks $241-\mathrm{S}-106$ and $241-\mathrm{A}-101$. In the figure, each column represents the total generation rate measured in the presence of external radiation at different temperatures. Each column is divided into two parts. The bottom portion represents the rate with no external radiation and is referred to as the thermolysis rate. The top portion is the effective radiolysis rate, which is the difference with and without external radiation. It is clear that the thermolysis rates, the effective radiolysis rates, and even the total rates increase as function of temperature for both tanks. It is also observed that the generation rate is dominated by radiolysis for tank 241-S-106 while in tank 241-A-101 the thermolysis rate dominates.

Although five tanks have been studied, only the data from tanks 241-S-106, 241-S-102, and 241-A-101 have a sufficient statistical basis to permit determination of the rate parameter (e.g., $A_{\text {rad }}$ and $\left.E_{\mathrm{rad}}\right)$. For tank 241-AW-1.01, the radiolysis rate is a negative value at $120^{\circ} \mathrm{C}$ (Table $\left.3-1\right)$ and is not usable. The activation energy and pre-exponential term of tank 241-AW-101 were 
determined by the rates at $90^{\circ} \mathrm{C}$ and $60^{\circ} \mathrm{C}$. For tank $241-\mathrm{SY}-101$, the radiolysis rates measured at 60 and $75^{\circ} \mathrm{C}$ are very similar while the rates measured at $90^{\circ} \mathrm{C}$ are indistinguishable with or without external radiation.

Figure 3-2. Laboratory Measurements of Hydrogen Generation From Tank 241-S-106 in the Presence of External Radiation (King and Bryan 1998a)

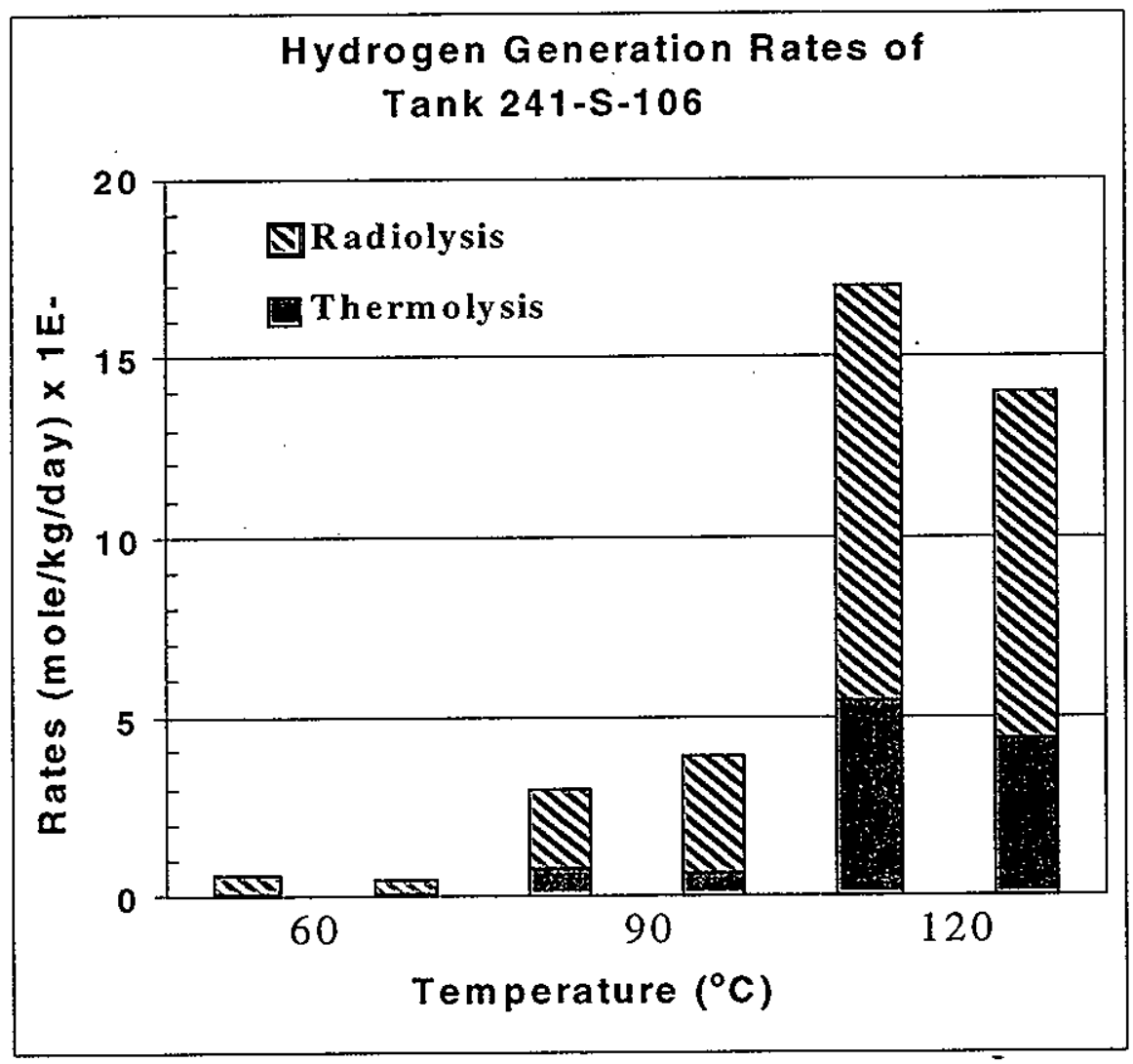

Previous models have assumed that the radiolysis rate is proportional to the radiation dose with a constant G-value (Spinks and Woods 1990)

$$
\text { Rate }_{\text {rad }}=\text { G } \times \text { Rad-dose }
$$

However, the observed effective radiolysis rate is temperature-dependent. This means that the effective G-value is temperature-dependent . A large portion of the hydrogen generated in the tank is the by-product of multi-step chemical reactions that produce formaldehyde and other intermediates. 
HNF-3851 Rev. 0

Figure 3-3. Laboratory Measurements of Hydrogen Generation from Tank 241-A-101 in the Presence of External Radiation (King and Bryan 1998b)

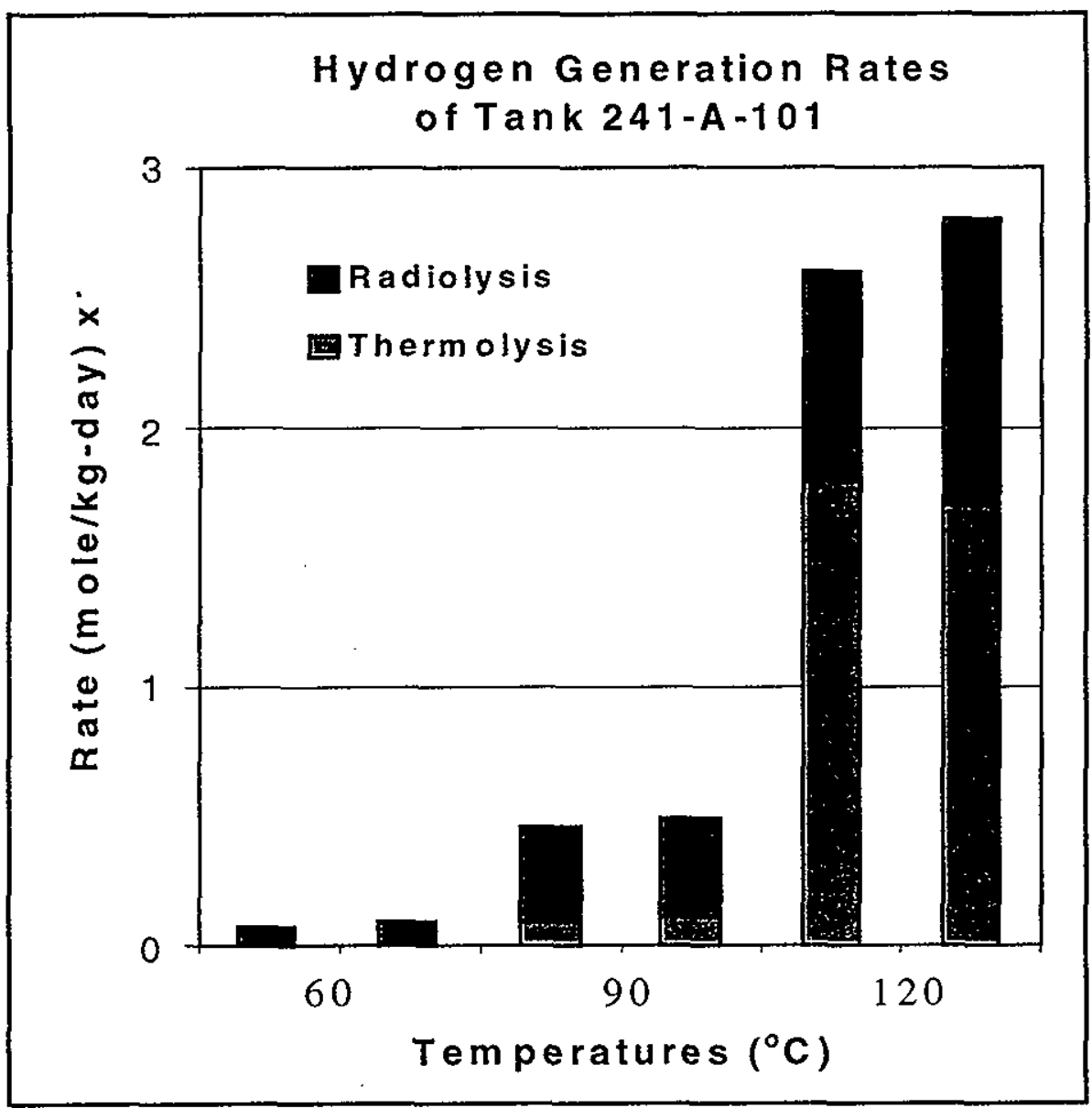

Hydrogen is generated from formaldehyde and these intermediates; thus, hydrogen is a product of the multi-step thermal organic reactions. The radiolytic reactions are thereby coupled to thermal chemical reactions.

The observed effective radiolysis rates, as listed in Table 3-1, are analyzed as follows,

Rate $_{\text {rad }}=\mathbf{A}_{\text {rad }} \times \mathbf{e}^{-(\mathrm{Erad} / \mathrm{RT})}$

Where $E_{\text {rad }}$ is the activation energy for radiolysis.

$A_{\text {rad }}$ is the pre-exponential term for radiolysis 
HNF-3851 Rev. 0

Figure 3-4. Radiolysis Rate Analysis Plot as $\ln ($ Rate) Versus 1/T for Tank 241-S-106 (King and Bryan 1998a)

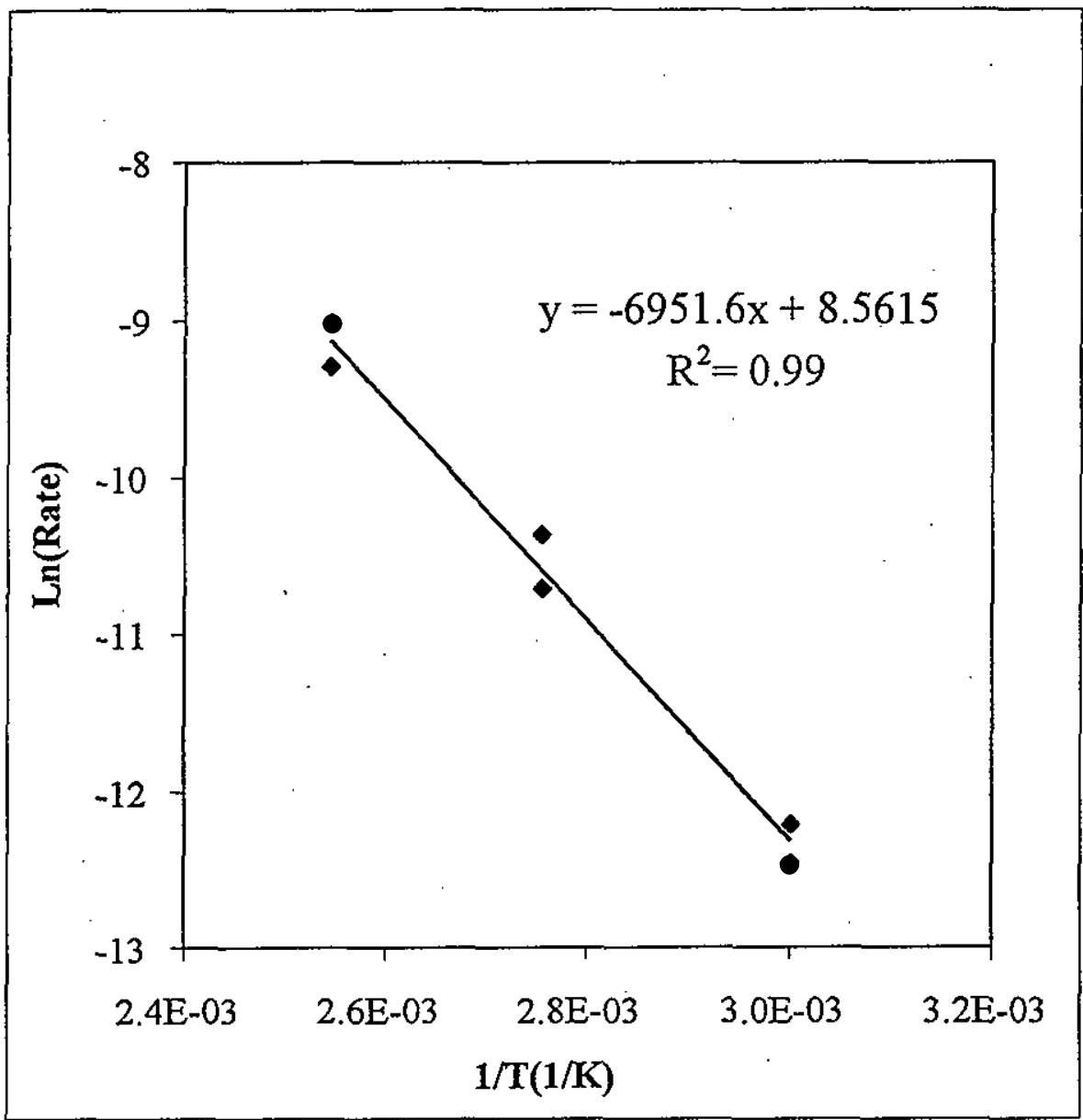

A linear fit of the logarithm of the radiolysis rate versus the inverse of the temperature provides the parameters of $A_{\text {rad }}$ and $E_{\text {rad }}$ as shown in Figure 3-4 for tank 241-S-106. The radiolytic rates show a good correlation with temperature $\left(R^{2}=0.99\right)$. The activation energy and pre-exponential term for the radiolysis can be obtained from the slope and intercept, respectively. Note that the radiolysis rate is the rate measured with external radiation minus the thermal rate calculated from the fit of thermal rate. The slope and intercept, which are used to calculate the activation energy and the pre-exponential factor respectively, and the associated statistical parameters are listed in Table 3-3. The results for tank 241-AW-101 are based on the rates at 60 and $90^{\circ} \mathrm{C}$. The radiolysis rate at $120^{\circ} \mathrm{C}$ is negative and is not usable. The effective activation energy ranged from $39 \mathrm{~kJ} / \mathrm{mole}$ for tank 241-AW-101 to $60 \mathrm{~kJ} / \mathrm{mole}$ for tank 241-S-106, and the correlation's coefficient ranges from 0.94 to 0.99 . 
HNF-3851 Rev. 0

Table 3-3. Arrhenius Parameters from the Effective Radiolysis Rates Analysis

\begin{tabular}{|c|c|c|c|c|c|}
\hline : 14nkss: & Parameters & Slope & Intercept & (6IJ) & (moledrg-day) \\
\hline \multirow{3}{*}{ 241-A-101 } & Values & -6095.72 & 6.47 & 50.68 & 645 \\
\hline & Yncertainty. & 287.73 & 0.80 & 2.39 & 2 \\
\hline & overallir? & \multicolumn{4}{|c|}{0.99} \\
\hline \multirow{3}{*}{$241-S-102$} & V.âlues & -5769.59 & 5.57 & 47.97 & 263 \\
\hline & Uncertarning & 336.80 & 0.93 & 2.80 & 3 \\
\hline & overallar & \multicolumn{4}{|c|}{0.98} \\
\hline \multirow{3}{*}{$241-S-106$} & Valines : & -7201.13 & 9.09 & 59.87 & 8829 \\
\hline & Wrncentaninty & 273.54 & 0.76 & 2.27 & 2 \\
\hline & overalla & \multicolumn{4}{|c|}{0.99} \\
\hline \multirow{3}{*}{ 241-AW-101 } & - Yalues & -4667.35 & 4.81 & 38.81 & 123 \\
\hline & troertainty & 848.43 & 2.44 & 7.05 & 12 \\
\hline & oyeraller & \multicolumn{4}{|c|}{0.94} \\
\hline
\end{tabular}

A temperature-dependent formula for $\mathrm{G}$ can be obtained by combining Equations 3-2 and 3-3:

$$
G=\left(A_{\text {rad }} / \text { Rad-dose } \times C F\right) \times e^{-\left(E_{r a d} / R T\right)}
$$

Where $\mathrm{G}$ is the yield of radiolysis $\left(\mathrm{H}_{2} / 100 \mathrm{eV}\right)$

$E_{\text {rad }}$ is the effective activation energy for the radiolysis process (mole/kJ).

$\mathrm{A}_{\mathrm{rad}}$ is the pre-exponential term for radiolysis (mole/kg-day).

Rad-dose is the applied external radiation dose rate $(\mathrm{R} / \mathrm{hr})$

$\mathrm{CF}$ is the conversion factor $4.02 \mathrm{E}+07\left((\mathrm{~mole} / \mathrm{kg}\right.$-day $\left.) /\left(\mathrm{H}_{2} / 100 \mathrm{eV}\right)(\mathrm{R} / \mathrm{hr})\right)$

Using the effective activation energy $E_{\mathrm{rad}}$ and the pre-exponential $\mathrm{A}_{\mathrm{rad}}$ listed in Table 3-3, and the external dose used in the measurement, the effective $G$-values for the radiation enhanced reaction rates at each temperature can be calculated for each tank and are given in Table 3-4. Notice that the observed G-value can be as low as 0.005 at $60^{\circ} \mathrm{C}$ from tank $241-\mathrm{S}-106$. This value is much lower than the water radiolysis default value of 0.031 from simulant study (Meisel et al. 1993). 


\section{Error}

An error occurred while processing this page. See the system log for more details. 
the rate measured with and without external radiation and is referred to as the effective radiolysis rate, is temperature-dependent and also follows Arrhenius behavior. It can be interpreted as the combination of thermal and radiation reactions. Thus, the observed effective radiolysis rates are analyzed as a function of the radiation dose-rate, where the $\mathrm{G}$-value is temperature dependence and expresses in terms of an effective activation energy as shown in Equation 3-4. The activation energies for the radiolytic rate ranged from $39 \mathrm{~kJ} / \mathrm{mole}$ to $60 \mathrm{~kJ} / \mathrm{mole}$, about half the thermal activation energies compared to the activation energy found in simulants studies, which are 4 to $39 \mathrm{~kJ} / \mathrm{mole}$ by Meisel et al. (1993).

The Arrhenius relationship for the thermal rate and the effective radiolysis rate are demonstrated in Figure 3-5 using tank 241-A-101 data. At low temperature, the radiolysis rate is dominant. But when the temperature is increased to $100^{\circ} \mathrm{C}$, the thermal rate is the same as the radiolysis rate, and above that temperature, the thermal rate dominates.

Figure 3-5. Typical Radiolysis Rate Analysis from Tank 241-A-101 (Data Taken from King and Bryan 1998b)

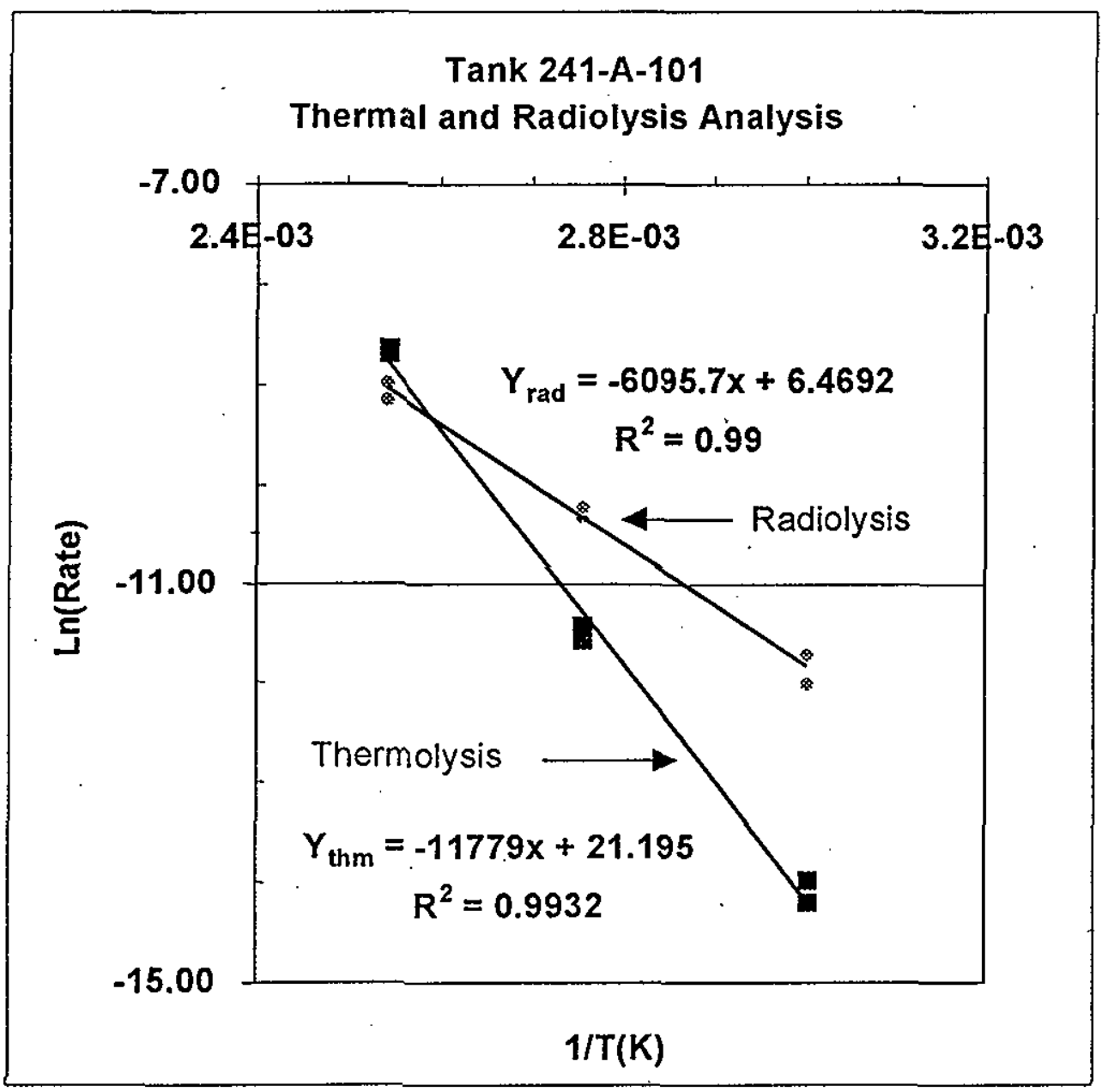


For tank 241-AW-101, the rates measured in the absence and in the presence of external radiation are indistinguishable at $120^{\circ} \mathrm{C}$. Calculations suggest that organic fuel consuming by radiolysis effect under these conditions are a lot faster than thermolysis. For tank 241-SY-103 samples, the radiolysis rate seems about the same at 60,75 , and $90^{\circ} \mathrm{C}$, and then becomes negative at 105 , and $120^{\circ} \mathrm{C}$. The results are totally different from the behavior of other tanks. At this time it is not possible to explain these results, but again it is possible that the fuel has been depleted to show the radiolysis effect at $90^{\circ} \mathrm{C}$ and above, and thus, the rates become too low to show Arrhenius behavior. 
HNF-3851 Rev. 0

\subsection{GLOBAL ANALYSIS AND EMPIRICAL RATE EQUATION MODEL}

Several teams have carried out laboratory studies of gas generation with waste simulants and waste samples. The ultimate goal of this work is to define the rules governing hydrogen generation so that the generation rates for any waste condition can be predicted.

Efforts have been made to create an empirical model of hydrogen generation. Hopkins (1994) based his rate equations on the study of tank 241-SY-101 waste simulant. Later, Graves (1994) presented a similar version of the equations used by Hopkins. During this early stage, only simulated waste data were available for modeling. Subsequently, gas generation studies using actual waste samples were conducted for tank 241-SY-101 (Person 1996) and 241-SY-103 (Bryan et al. 1996). Pedersen and Bryan (1996) modified the model and obtained the parameters for the equations using the generation rate data from waste samples from tank 241-SY-103. More recently, $\mathrm{Hu}$ (1997) extended this model adding water radiolysis and corrosion to calculate the generation rates for double-shell tanks. In that study (Hu 1997), the field-derived and modelcalculated generation rates for seven tanks agreed within a factor of 2 .

As additional information for wastes in SST's and DSTs became available, it became evident that a more general approach would be necessary to model hydrogen generation. Hu et al. (1998) integrated and analyzed the available data for four DSTs to derive a general thermal rate equation as a function of tank waste conditions incorporating Arrhenius A-values, activation energies, and radiolysis parameters. That analysis was successful because the available data were from four tanks having similar thermal activation energies. The preliminary analysis provided good results, led to a methodology for handling the laboratory data, and established a framework for the desired rate equation that has been exploited in this report.

The rate equations from the previous work (Hu et al.1998) has been upgraded based on the availability of more hydrogen generation data from waste samples. As shown in Section 3.0, the effective radiolysis rate is temperature-dependent, and follows Arrhenius behavior. In addition, in this study, both thermal and radiolysis generation rates data are used and, thus both activation energy and pre-exponential factor can be extrapolated from the analysis. The procedure and rate equation development will be discussed in the following sections.

\subsection{RATE EQUATION FOR THERMOLOYSIS}

Preliminary analysis of the thermal rate (Hu et al. 1998) is discussed in Section 4.1.1 to establish the framework for the thermal rate equation. The thermal rate equation is then finalized by the analysis of data from six tanks in Section 4.1.2. The thermal rate follows Arrhenius behavior and is proportional to the total organic carbon concentration and aluminate ion concentrations. A reactivity coefficient, $\mathrm{r}_{\mathrm{f}}$, was evaluated for the organic carbon in each tank. This parameter was used together with the other data to determine the rate parameters and activation energies leading to the best overall statistical agreement. 


\subsubsection{Preliminary Thermal Rate Equation Based on Pre-exponential Term Analysis}

As discussed in Section 2.0, the thermal generation rates in the simulated waste studies follow Arrhenius behavior, increasing exponentially as temperature increases, and exhibit approximately first-order dependence on the organic solutes, aluminate, nitrite, and hydroxide concentrations. Figure 4-1 shows the linear dependence of the total gas generation rate for tank 241-SY-101 (Delegard 1980) on the aluminate ion.

Figure 4-1. A Plot of Total Gas Reaction Rate as a Function of Sodium Aluminate in a Simulated Waste (Delegard 1980)

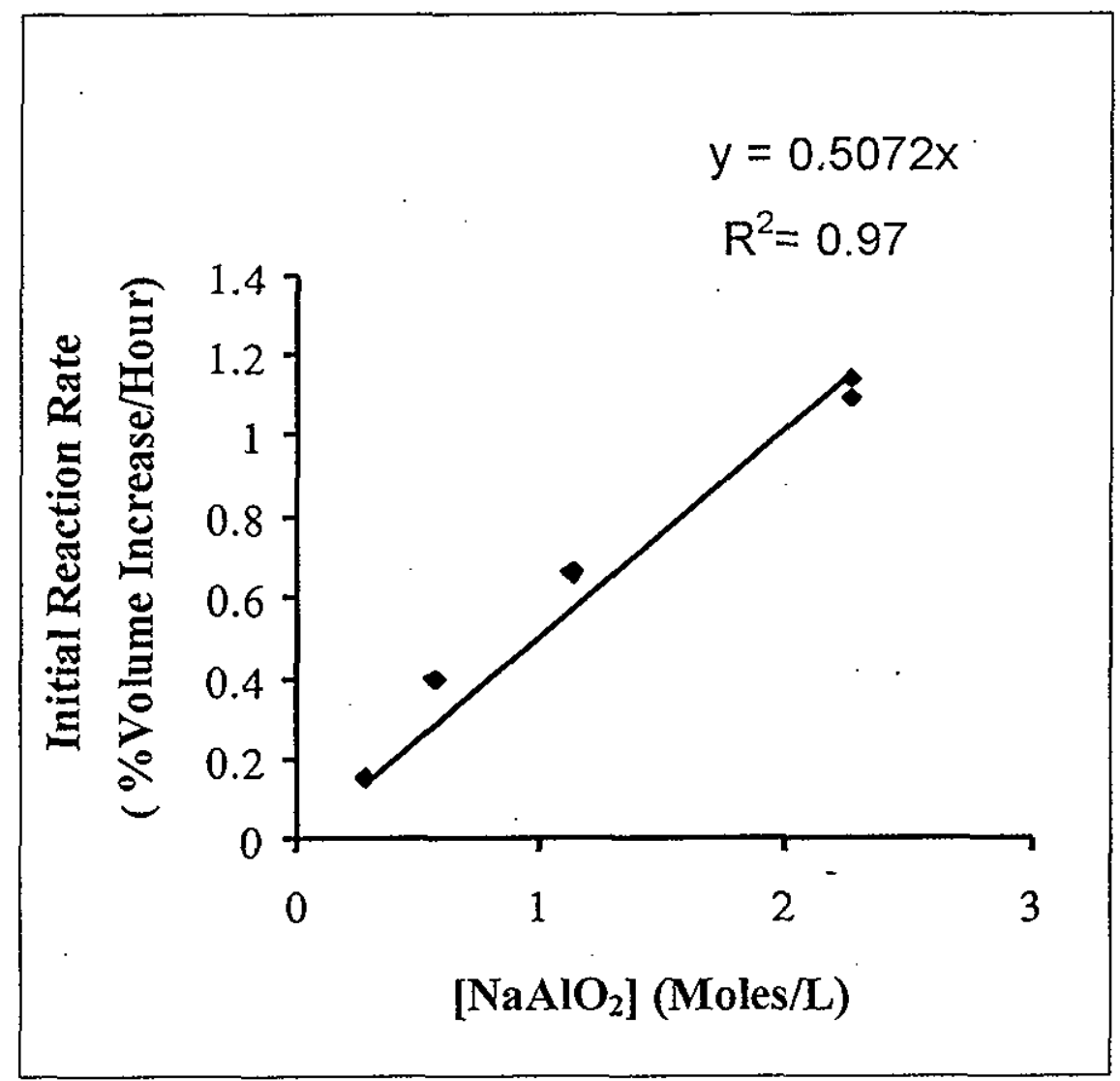

The results for the hydroxide ion and nitrite ion were more complex. For example, the rate is independent of nitrite when its concentration is higher than 0.5 molar; the rate decreases when the hydroxide concentration is higher than 1.6 molar (Delegard 1980).

The gas generation data for waste samples from tanks 241-SY-101, 241-SY-103, 241-AN-105, and 241-S-102 were used to establish the parameters for the thermal generation of gas. Table 4-1 
lists the activation energy from the thermal studies on gas generation for tanks 241-SY-101, 241-SY-103, 241-AN-105, and 241-S-102 (Person 1996, 1998; Bryan et al. 1996; King et al. 1997)

Table 4-1. Activation Energies from Thermal Studies on Tank Waste Samples

\begin{tabular}{|c|c|c|c|c|}
\hline Tanks & $(1 / 1 / m o l e)$ & (ivimole) & (ivimole) & gotal Gas (arnole) \\
\hline $241-S Y-101^{1}$ & 94 & 95 & 91 & 95 \\
\hline $241-S Y-103^{2}$ & $91(9)$ & $116.7(9)$ & $84(10)$ & $96(6)$ \\
\hline $241-\mathrm{AN}-105^{3}$ & 89 & 107 & 136 & 97 \\
\hline $241-\mathrm{S}-102^{4}$ & $91(7)$ & $79(11)$ & $127(70)$ & $95(8)$ \\
\hline
\end{tabular}

'Person (1996)

${ }^{2}$ Bryan et. al. (1996)

${ }^{3}$ Person (1998)

${ }^{4}$ King et. al. (1997)

As shown in Table 4-1, the activation energy for hydrogen varies from 89.0 to $94 \mathrm{~kJ} / \mathrm{mole}$. The difference among these activation energies is within the level of measurement uncertainty and center around $91 \mathrm{~kJ} / \mathrm{mole}$. The similarity of the activation energies suggests that the dominant pathways for these tanks are quite similar and implies that the hydrogen generation rate can be modeled. In addition, hydrogen is almost insoluble making the modeling of hydrogen release less complex by avoiding modeling gas transport from liquid phase to the dome space. In contrast, as shown in Table 4-1, the activation energies of nitrous oxide and nitrogen vary from 79 to 128 $\mathrm{kJ} /$ mole and from 84 to $136 \mathrm{~kJ} / \mathrm{mole}$ respectively. These results indicate that the pathways leading to nitrogen-containing gas may be quite different from tank to tank. Stock and Pederson (1997) also pointed out that there are many pathways for generating nitrogen-containing molecules. Ammonia, one of the major products, is very soluble, and was not measured in the gas generation experiments.

The remainder of this section will focus on the kinetic data of hydrogen generation. Table 4-2 lists the hydrogen generation data and the concentration of TOC and $\mathrm{Al}$, which are possible ratedependent constituents as indicated from simulant studies (e.g., Meisel et al. 1993) and dilution study of tank 241-SY-101 (Person 1996). Other possible rate-dependent constituents have been examined without success in finding correlation with current rate data. 
HNF-3851 Rev. 0

Table 4-2. Kinetic Data of Hydrogen Generation and Waste Constituents

\begin{tabular}{|c|c|c|c|c|}
\hline (: Tanks: & $(\mathrm{HJ} / \mathrm{mole})$ & (mole/lig-day) & $\begin{array}{l}\text { TOC } \\
(\mathrm{w} / \%)\end{array}$ & (2) \\
\hline 241-SY-101 & $94.0^{1}$ & $15.8 \mathrm{E}+08^{1}$ & 1.07 & 3.2 \\
\hline 241-SY-103 & $91.3^{2}$ & $14.0 \mathrm{E}+08^{2}$ & 0.74 & 2.8 \\
\hline 241-AN-105 & $89.0^{3}$ & $5.88 \mathrm{E}+08^{3}$ & 0.28 & 2.9 \\
\hline 241-S-102 & $91.7^{4}$ & $2.10 \mathrm{E}+08^{4}$ & 0.23 & 2.1 \\
\hline
\end{tabular}

${ }^{1}$ Person (1996)

${ }^{2}$ Bryan et al. (1996)

${ }^{3}$ Person (1998)

${ }^{4} \mathrm{King}$ et al. (1997)

${ }^{5}$ Data from current tank characterization report

The rate equation for a bimolecular reaction can be written as a function of concentration of reactants and the rate constant, as follows,

$$
\begin{aligned}
& \text { Rate }=k \times[X]^{\mathrm{m}} \times[\mathrm{Y}]^{\mathrm{n}} \\
& \text { with } \mathrm{k}=\mathbf{a} \times \mathrm{e}^{-(\mathrm{E} a / \mathrm{R} T)}
\end{aligned}
$$

Where $[X]$ and $[Y]$ are the concentration of the reactants $X$ and $Y$, respectively $m$ and $n$ are the reaction order of the reactants $X$ and $Y$, respectively $E_{a}$ is the activation energy of the reaction $\mathrm{k}$ is the rate constant $\mathrm{a}$ is the pre-exponential term of the rate constant

By comparing Equations 4-1 and 3-1, the pre-exponential term $A_{\text {thm-value is mathematically }}$ equivalent as follows,

$$
\mathbf{A}_{\mathrm{thm}}=\mathbf{a} \times[\mathbf{X}]^{\mathrm{m}} \times[\mathbf{Y}]^{\mathrm{n}}
$$

Thus, the reported A-values in the gas generation studies can be related to the concentrations of reactants and contain information about the concentration dependence. In the study of the effect of sodium hydroxide dilution on thermal rate in tank 241-SY-101 wastes, Person (1996) found that a dilution that lowered the solution concentrations to 0.65 of their undiluted values resulted in the rate being 52 to 58 percent of the undiluted rate. Note that the dilution causes a smaller 
decrease in the thermal rate than would be predicted by the product of two first-order dependencies (i.e., $0.55 \pm 0.03>0.65 \times 0.65=0.42$ ). These results indicate there are no more than two species with first-order dependencies; probably there is one species with a first-order dependence and one or more species with a fractional order dependence. The results from simulated waste (e.g. Delegard 1980, Meisel et al. 1993), suggest TOC and Al have first order rate-dependence.

To examine this feature, the data in Table 4-2 were used to evaluate the dependence of the reported A-values on [TOC] and [Al], Figure 4-2. It appears that A-values are reasonably linearly dependent on the product of [TOC] and [Al]. These A-values are in the unit of moles of $\mathrm{H}_{2}$ generated per kilogram of waste sample per day without considering the differences of liquid fractions among samples.

Figure 4-2. Preliminary Thermal Analysis: The Fit of reported A-value with the Product of [TOC] and [AI] from Tanks 241-SY-101, 241-SY-103, 241-AN-105, and 241-S-102

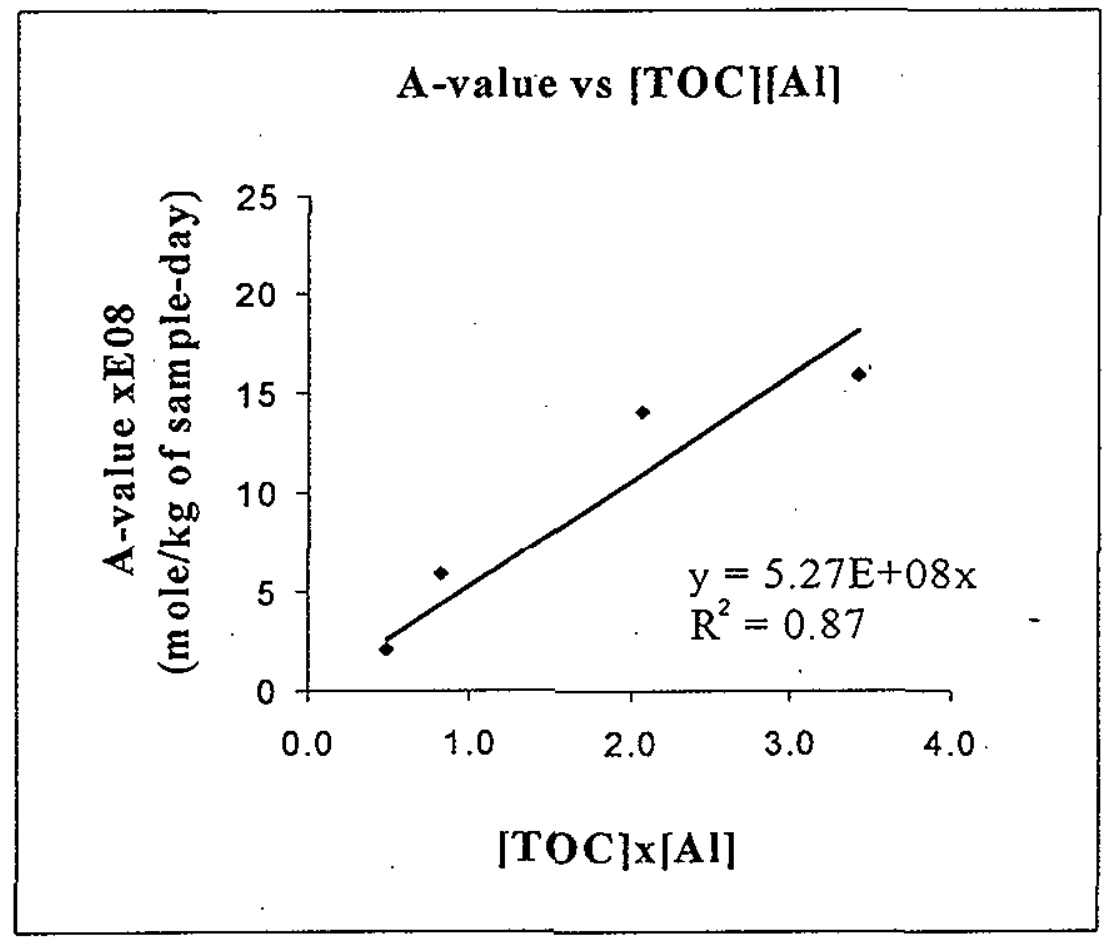

The organic complexants used at the Hanford Site are extremely soluble in aqueous alkaline solution. Experiments with waste simulants and analyses of tank waste samples indicate that most of the organic complexants and energetic chelator fragments remain in the tank supernatants and interstitial liquid. Meisel et al. (1993) also pointed out that the gas generation reactions occur most efficiently in the liquid phase. Therefore, the TOC concentrations used in this report are 
taken only from liquid sample measurements, which eliminate a large portion of non-reactive organic species such as oxalate which is very water insoluble. As shown in Table 4-3, the samples used in the gas generation studies have different water contents. The samples from the convective layer are almost all liquid, but the core composite samples, which contain saltcake and sludge, are heterogeneous. In order to compare the rate as a function of the waste constituents in the liquid, the generation rate should be converted to moles of hydrogen generated per kilogram of liquid in the sample per day, instead of per kilogram of total waste sample per day as reported. The way to estimate the liquid fraction of the waste is discussed in the next paragraph.

Assuming all water in the sample is contained in the liquid, then the liquid weight fraction, $\mathbf{L}_{r}$, of a sample can be estimated by the moisture content:

$$
\begin{aligned}
\mathbf{L}_{\mathbf{f}} & =\mathbf{W}_{\text {liquid in sample }} / \mathbf{W}_{\text {total sample }} \\
& =\left(\mathbf{W}_{\mathrm{H} 2 \mathrm{O}} / \mathbf{W}_{\text {total__ample }}\right) /\left(\mathbf{W}_{\mathrm{H} 2 \mathrm{O}} / \mathbf{W}_{\text {liquid_in_sample }}\right) \\
& =\left(\mathbf{H}_{2} \mathbf{O}_{\text {wt } \%)}\right)_{\text {total sample }} /\left(\mathbf{H}_{\mathbf{2}} \mathbf{O}_{\text {wt\% } \%}\right)_{\text {liquid in sample }}
\end{aligned}
$$

Where $\left(\mathrm{H}_{2} \mathrm{O}_{\text {wt\% }}\right)_{\text {total sample }}$ and $\left(\mathrm{H}_{2} \mathrm{O}_{\mathrm{w} \%}\right)_{\text {liquid in sample }}$ are the weight percent water in total sample and liquid of the sample, respectively.

$\mathrm{W}_{\mathrm{H} 2 \mathrm{O}}, \mathrm{W}_{\text {total_sample, }}$ and $\mathrm{W}_{\text {liquid_in_sample }}$ are the weight of water, total sample and liquid in sample, respectively.

Table 4-3 lists the estimated liquid fractions using Equation 4-3. Since the generation rate is proportional to the reported $\mathrm{A}$-value, this unit conversion of generation rate from per kilogram of total sample to liquid is equivalent to normalize the reported A-value with liquid weight fraction. Therefore, the reported A-value can be normalized with liquid weight fraction as following,

$$
\mathbf{A}_{\mathrm{Liq}}=\mathbf{A} / \mathbf{L}_{\mathbf{f}}
$$

Where $\mathrm{A}$ is from thermal rate measurement (mole/kg of total sample per day) $L_{\mathrm{f}}$ is the liquid weight fraction in the sample

The $\mathbf{A}_{\mathrm{Liq}}$-value has the desired units of moles of hydrogen per kilogram liquid in the sample per day. The $\mathbf{A}_{\mathrm{Liq}}$-values are listed in Table 4-3.

An effort to refine the relationship between normalized $A_{L i q}$-values and the waste constituents was made. The dilution study of the waste sample from tank 241-SY-101 (Person, 1996) suggests that the combined order of the reactants of the thermal rate is about 1.3 to 1.5. The measured TOC values for the liquid portions of the waste provide the organic concentrations. The organic solutes are presumed to have first-order dependent for gas generation from many simulant studies (e.g., Delegard 1980, Meisel et al. 1991c, 1993, Ashby et al. 1994). To meet the combined reaction order of 1.4 , this leaves the aluminate dependence as the $0.4^{\text {th }}$ power. 
HNF-3851 Rev. 0

Table 4-3. Water Content of Samples and Calculated $A_{L i q}$ Values

\begin{tabular}{|c|c|c|c|c|c|c|}
\hline Tanks & $\begin{array}{l}\text { Sample } \\
\text { Type }\end{array}$ & (inoledkg-day) & $\begin{array}{l}\mathrm{H}_{2} \mathrm{O} \\
\text { of liquidi } \\
\text { in sample }\end{array}$ & $\begin{array}{l}\mathrm{H}_{2} \mathrm{O}_{* 1} \% \\
\text { of total } \\
\text { sample }\end{array}$ & $\begin{array}{l}\text { Ir } \\
\text { of total } \\
\text { sample }\end{array}$ & (mole/kg-day) \\
\hline $241-S Y-101^{1}$ & Core Composite & $1.58 \mathrm{E}+09$ & 45.0 & 35.0 & 0.78 & $2.03 E+09$ \\
\hline $241-S Y-103^{2}$ & Convective Layer & $1.40 \mathrm{E}+09$ & 48.8 & 48.8 & 1.00 & $1.40 \mathrm{E}+09$ \\
\hline $241-\mathrm{AN}-105^{3}$ & Convective Layer & $5.88 \mathrm{E}+08$ & 50.7 & 50.7 & 1.00 & $5.88 \mathrm{E}+08$ \\
\hline $241-S-102^{4}$ & Core Composite & $2.10 \mathrm{E}+08$ & 49.4 & 27.4 & 0.56 & $3.78 E+08$ \\
\hline
\end{tabular}

Using the data listed in Table 4-3, a linear fit of the reported $\mathrm{A}_{\mathrm{iq}}$-values with the product of $[\mathrm{TOC}]$ and $[\mathrm{Al}]$ raised to various exponents was carried out. The analysis shows that the use of liquid-fraction normalized $\mathrm{A}_{\mathrm{Liq}}$-values has dramatically improved the correlation with the correlation coefficient increased to 0.98 compared to 0.86 for the unmodified $A$ values. This improvement is realized for all trial exponents for [TOC] and [Al]. This improvement is compatible with the concept that gas generation occurred primarily in liquid phase.

Furthermore, the analysis shows that the best correlation is obtained for a first-order dependence on total organic carbon and a zero-order dependence on Al. The correlation coefficient decreases as the power of [TOC] decreases further; for example, it drops to 0.96 for [TOC] to the $0.8^{\text {th }}$ power and to 0.41 at [TOC] to the $0.5^{\text {th }}$ power. The analysis found that the fits to the product of $[\mathrm{TOC}]^{\mathrm{m}}$ and $[\mathrm{All}]^{\mathrm{n}}$ are less sensitive to the exponent of each species. For example, when [TOC] is first-order, the fit quality ranges from 0.996 to 0.984 for [Al] to the power of 0 to 1 . For a given $\mathrm{m}^{\text {th }}$ power of [TOC], an $\mathrm{n}^{\text {th }}$ power of [Al] can be found to give a reasonable fit, although the correlation is reduced when the power of [TOC] decreases from 1 . For example, the best fit of the product of $[\mathrm{TOC}]^{\mathrm{m}}$ and $[\mathrm{AI}]^{\mathrm{n}}$ for $\mathrm{m}=0.5$ is when $\mathrm{n}=2.1$, which has $\mathrm{R}^{2}$ of 0.95 . In general, the lower the [TOC] power, the higher the [Al] power is needed to get the best correlation with the product of $[\mathrm{TOC}]^{\mathrm{m}}$ and $\left.[\mathrm{Al}]\right]^{\mathrm{n}}$.

This analysis shows that the data favors a first-order rate-dependence for [TOC]. However, the choice of the exponent for [A] is less obvious. Considering the results of the dilution study of SY-101 waste (Person 1996) and the simulant waste studies mentioned above, the best choice seems to be for the reaction order to be first-order for [TOC] and $0.4^{\text {th }}$ order for [Al]. The correlation coefficient $\mathrm{A}_{\mathrm{Liq}}$-values to the product of [TOC] and [Al] ${ }^{0.4}$ is 0.996 (Figure 4-3), which is almost the same as [TOC] of first-order alone. Using a rate-dependence of TOC of firstorder and aluminate of $0.4^{\text {th }}$-order, the rate for the diluted 241-SY-101 waste would be expected to be 55 percent of the rate for undiluted waste, i.e., $(0.65) \times(0.65)^{04}=0.55$. This agrees very well with the range of 52 to 58 percent from the dilution study (Person 1996). 
Figure 4-3. Preliminary Thermal Analysis: The Fit of $A_{\text {liquid }}$ with the [TOC] $\times$ [Al] $]^{0.4}$ from Tanks 241-SY-101, 241-SY-103, 241-AN-105, and 241-S-102 Data

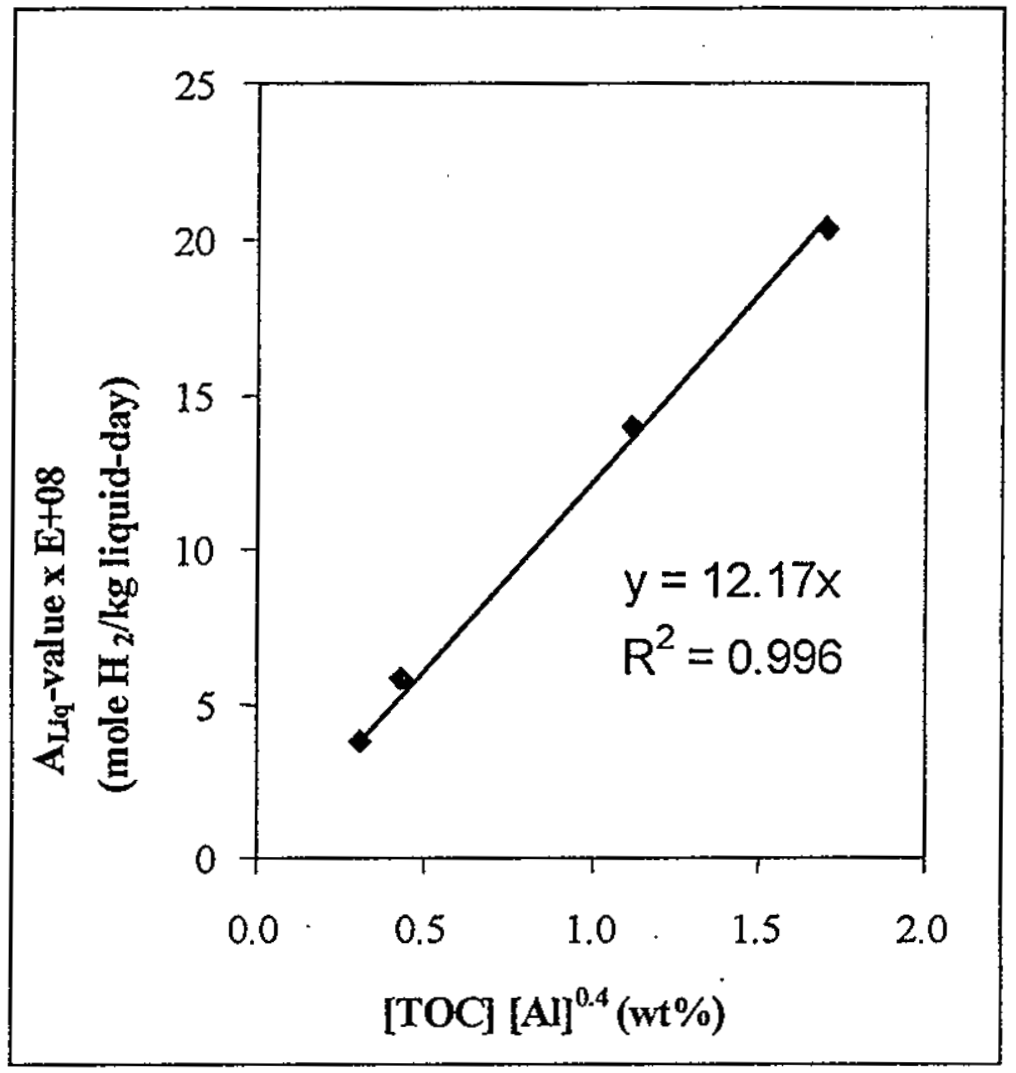

The relationship between the $\mathrm{A}, \mathrm{A}_{\mathrm{Liq}},[\mathrm{TOC}],[\mathrm{Al}]$, and $\left[\mathrm{H}_{2} \mathrm{O}\right]$ is expressed in Equation 4-5:

$$
\mathbf{A}_{\mathrm{Liq}}=\mathrm{A} / \mathrm{L}_{\mathrm{f}}=\mathrm{a} \times[\mathrm{TOC}]_{\mathrm{wt} \%} \times[\mathrm{Al}]_{\mathrm{wt} \%}{ }^{0.4}
$$

Where $\mathrm{a}$ is the pre-exponential factor (in the unit of moles of $\mathrm{H}_{2}$ per $\mathrm{kg}$ of liquid in samples per day)

Table 4-4 lists the pre-exponential a value obtained from the slope of the regression equations, and the measured and calculated values of $A_{\text {Liq. }}$. 
HNF-3851 Rev. 0

Table 4-4. Fitting Results of $A_{\text {Liq }}$ with $[\mathrm{TOC}][\mathrm{AI}]^{0.4}$

\begin{tabular}{|c|c|c|c|}
\hline \multirow[t]{2}{*}{ Tanks } & \multicolumn{3}{|c|}{ 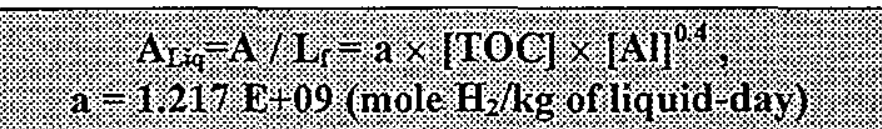 } \\
\hline & Measured & Calculated & \% Difference \\
\hline 241-SY-101 & 2.03 & 2.07 & 1.9 \\
\hline 241-SY-103 & 1.40 & 1.36 & 2.9 \\
\hline 241-AN-105 & 0.59 & 0.52 & 12.5 \\
\hline $241-S-102$ & 0.38 & 0.37 & 2.6 \\
\hline
\end{tabular}

To summarize, in this study, the Arrhenius pre-exponential factor a is determined based on the rate data for several tanks having similar activation energies. As shown in Table 4-2, the values of activation energies for four tanks are $89,91.3,91.7$, and $94.0 \mathrm{~kJ} / \mathrm{mole}$ with the mean value of $91.5 \mathrm{~kJ} / \mathrm{mole}$. With the activation energy of $91.5 \mathrm{~kJ} / \mathrm{mole}$, a thermal rate equation may be expressed as follows,

$$
\begin{aligned}
& \text { HGR }_{\text {Therm }}=\mathbf{a} \times[\mathrm{TOC}] \times[\mathrm{Al}]^{0.4} \times \mathrm{e}^{-(\mathrm{E} a / \mathrm{RT})} \times \mathrm{L}_{\mathrm{f}} \\
& \text { With } \quad \begin{array}{l}
\mathrm{a}=1.217 \mathrm{E}+09\left(\mathrm{~mole} \mathrm{H}_{2} / \mathrm{kg}\right. \text { of liquid-day) } \\
\mathrm{E}_{\mathrm{a}}=91.5 \mathrm{~kJ} / \mathrm{mole} \\
\mathbf{R}=8.314 \mathrm{~J} / \mathrm{mole} / \mathrm{K}
\end{array}
\end{aligned}
$$

Where HGR $_{\text {Therm }}$ is the thermal rate, moles of hydrogen generated per kilogram of liquid waste per day

[TOC] is total organic carbon concentration in the liquid waste (wt\%)

$[\mathrm{Al}]$ is aluminum concentration in liquid waste (wt\%)

$\mathrm{L}_{\mathrm{f}}$ is the weight fraction of liquid in the waste

$T$ is the temperature of waste $(\mathrm{K})$

$\mathrm{E}_{\mathrm{a}}$ and a are the activation energy and pre-exponential factor of $\mathrm{H}_{2}$ generation.

This thermal rate equation provides an estimated rate for given [TOC], [Al], liquid fraction, and temperature of the waste. 


\subsubsection{Final Global Thermal Rate Equation Analysis}

In the preliminary analysis of the thermal rate equations, it was shown that the liquid weight fraction normalized pre-exponential A-value is linearly dependent on the product of [TOC] and $[\mathrm{Al}]^{0.4}$ for those tanks having a similar thermal activation energy, Ea. One is able to derive an empirical thermal rate equation, characterized by its rate constant $\mathrm{k}$ and activation energy $\mathrm{Ea}$, as shown in Equation 4-6. This preliminary analysis establishes a framework for global analysis. To date, the thermal rates for seven tanks have been studied. As shown in Table 3-2, the activation energies range from 74 to $101 \mathrm{~kJ} / \mathrm{mole}$.

Since the A-value is very sensitive to the $\mathrm{Ea}$, the activation energy, a universal activation energy that would accommodate the thermal rate data was sought. In the analysis, the observed thermal rates were divided by the liquid fraction of the waste sample, total organic concentration, [Al] ${ }^{0.4}$, according to Equation 4-6, and labeled as "normalized thermal rates, $R_{\text {nor". The universal a_and }}$ Ea values were obtained by the linear relationship between $\ln \left(R_{\text {nor }}\right)$ and $1 / T$. Table 4-5 lists the parameters used for normalization for each tank, including weight fraction of liquid and the weight percent of TOC and Al.

Table 4-5. Input Variables for Normalized Thermal Rates Analysis

\begin{tabular}{|c|c|c|c|}
\hline Tanks. & Viquid Fraction & Measurred: & $\begin{array}{l}\text { Measured } \\
4(w t \%)\end{array}$ \\
\hline 241-A-101 & 0.59 & 0.22 & 2.52 \\
\hline 241-S-102 & 0.56 & 0.14 & 2.14 \\
\hline $241-S-106$ & 0.59 & 0.09 & 2.14 \\
\hline $241-A N-105$ & 1.0 & 0.28 & 2.61 \\
\hline $241-S Y-103$ & 1.0 & 0.74 & 2.80 \\
\hline 241-AW-101 & 1.0 & 0.34 & 1.94 \\
\hline
\end{tabular}

Table 4-6 lists the slopes and intercepts of the linear relationship with as reported and normalized thermal rates versus temperatures. As shown in Table 4-6, the errors of both slope and intercept are improved significantly by normalization of the thermal rates with $[\mathrm{TOC}],[\mathrm{Al}]^{0.4}$, and $\mathrm{L}_{\mathrm{f}}$. The second part of the table gives the thermal activation energy and pre-exponential $\mathrm{k}$ value. The activation energies of 88.6 and $89.1 \mathrm{~kJ} / \mathrm{mole}$ differ modestly, but the pre-exponential A-value shifts from $2.25 \mathrm{E}+08$ to the a-value of $9.11 \mathrm{E}+08$. The observations in Table $4-6$ show that the normalization of thermal rates does not change the thermal activation energy, but improves the concentration by accounting for differences in the reactions. 


\section{Error}

An error occurred while processing this page. See the system log for more details. 
Figure 4-4. The Relationship Between Logarithm of Reported Thermal Rates and the Inverse of Temperature (1/T ) for Tanks 241-A-101, 241-AN-105, 241-AW-101, 241-SY-103, 241-S-102, and 241-S-106

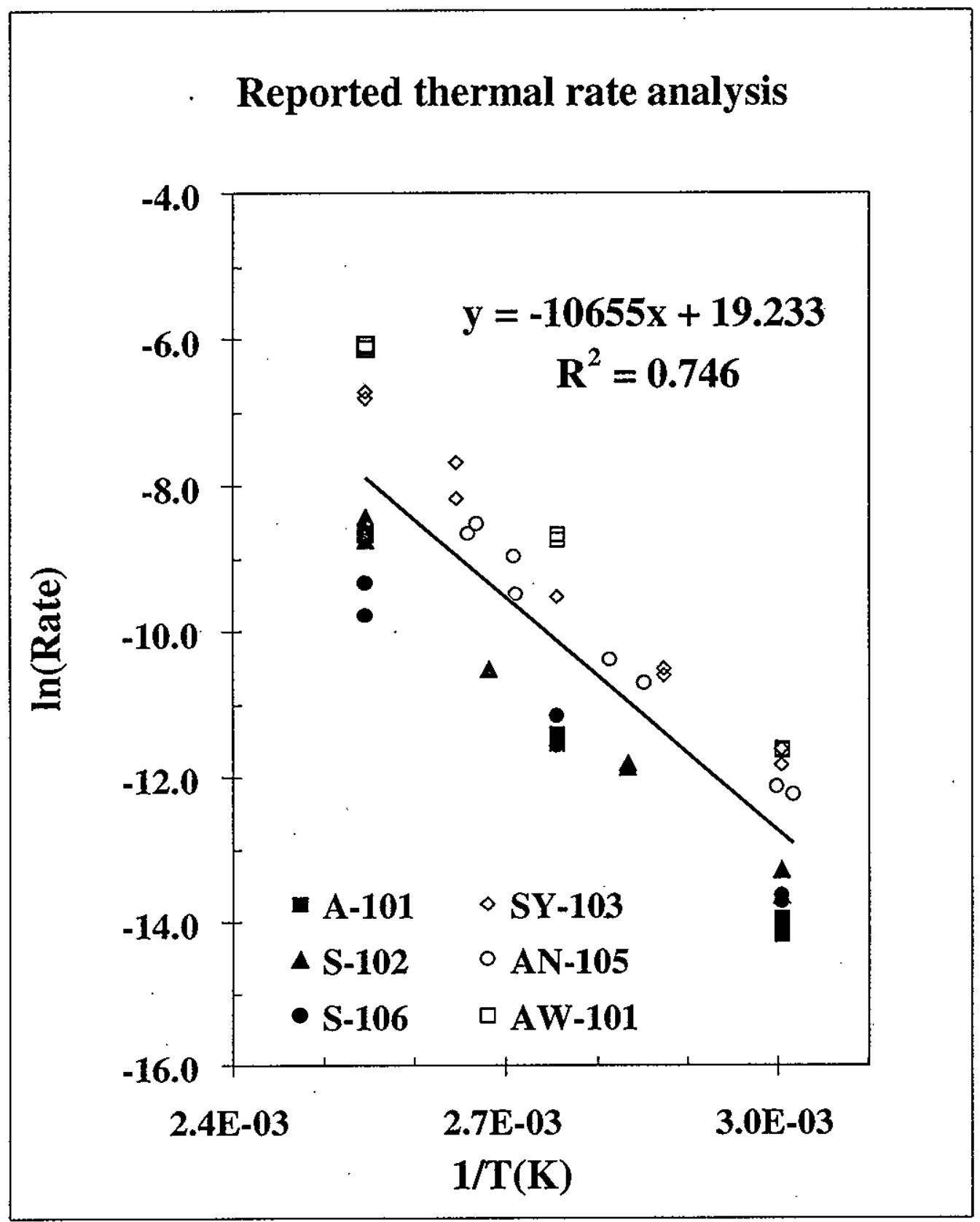


Figure 4-5. The Relationship of Logarithm of Normalized Thermal and the Inverse of Temperature (1/T) for Tanks 241-A-101, 241-AN-105, 241-AW-101, 241-SY-103, 241-S-102, and 241-S-106

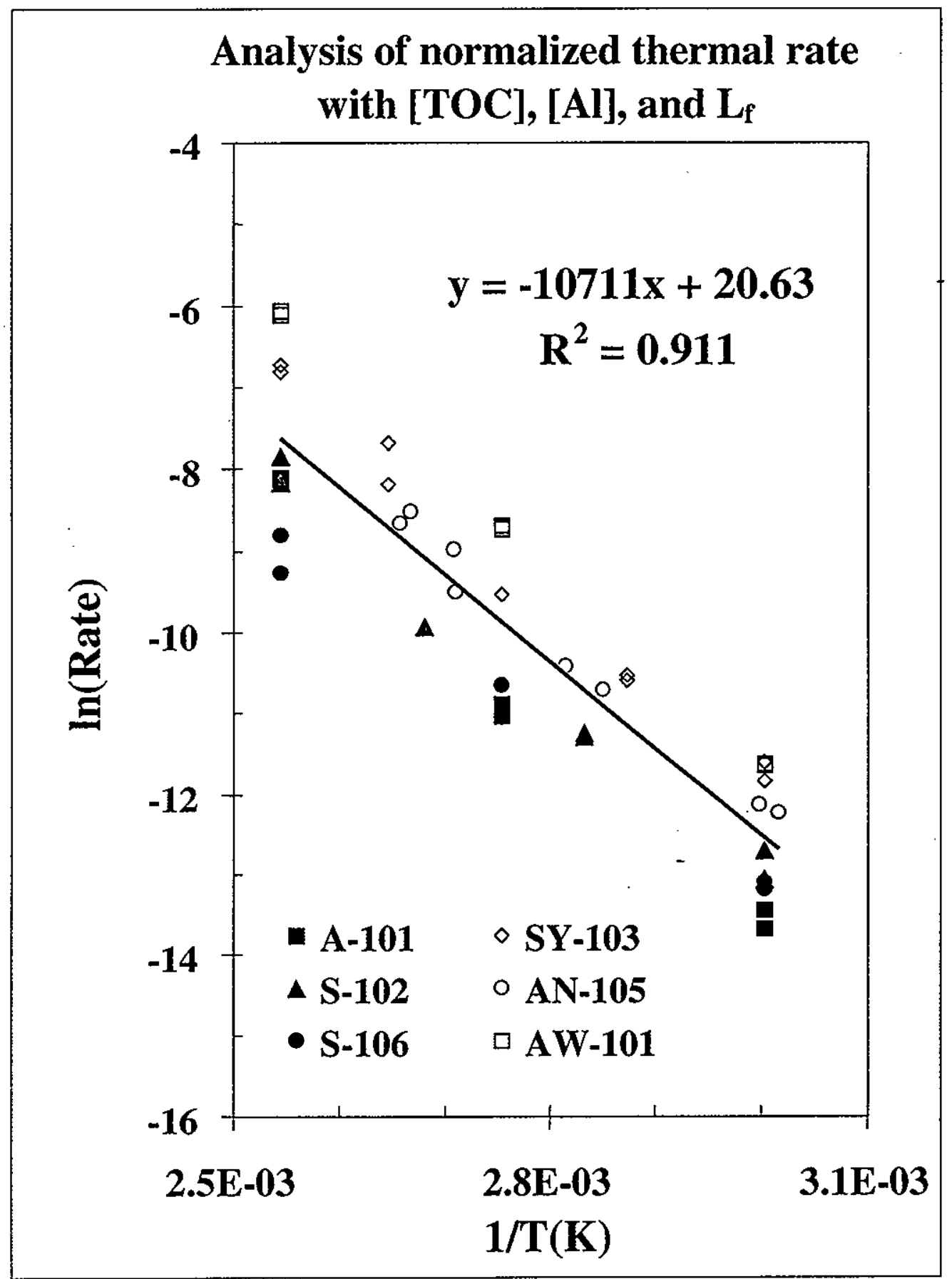


HNF-3851 Rev. 0

Table 4-7. Normalized Thermal Rates With or Without Reactivity Coefficient $r_{f}$ (2 Sheets)

\begin{tabular}{|c|c|c|c|c|c|c|}
\hline tanks: & (? & $\begin{array}{l}\text { Iaboratory } \\
\text { Obs: Rate: } \\
\text { (molenglaay) }\end{array}$ & 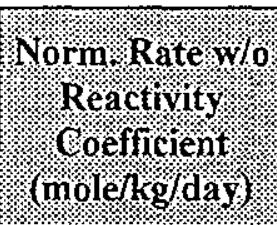 & 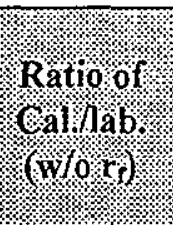 & 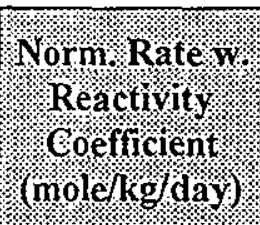 & 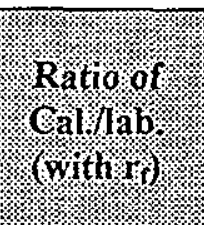 \\
\hline \multirow{6}{*}{$241-A-101$} & 60 & $6.90 \mathrm{E}-07$ & $1.85 \mathrm{E}-06$ & 2.68 & $8.92 \mathrm{E}-07$ & 1.29 \\
\hline & 60 & $8.70 \mathrm{E}-07$ & 1.85E-06 & 2.13 & $8.92 \mathrm{E}-07$ & 1.03 \\
\hline & 90 & $9.60 \mathrm{E}-06$ & $2.64 \mathrm{E}-05$ & 2.75 & $1.28 \mathrm{E}-05$ & 1.34 \\
\hline & 90 & 1:10E-05 & $2.64 \mathrm{E}-05$ & 2.40 & $1.28 \mathrm{E}-05$ & 1.17 \\
\hline & 120 & $1.70 \mathrm{E}-04$ & $2.51 \mathrm{E}-04$ & 1.48 & $1.23 \mathrm{E}-04$ & 0.72 \\
\hline & 120 & $1.80 \mathrm{E}-04$ & 2.51E-04 & 1.39 & $1.23 \mathrm{E}-04$ & 0.68 \\
\hline \multirow{8}{*}{$241-S-102$} & 60 & $1.20 \mathrm{E}-06$ & $1.04 \mathrm{E}-06$ & 0.87 & $1.17 \mathrm{E}-06$ & 0.97 \\
\hline & 60 & $1.70 \mathrm{E}-06$ & $1.04 \mathrm{E}-06$ & 0.61 & $1.17 \mathrm{E}-06$ & 0.69 \\
\hline & 80 & $7.00 \mathrm{E}-06$ & $6.43 \mathrm{E}-06$ & 0.92 & 7.27E-06 & 1.04 \\
\hline & 80 & $7.30 \mathrm{E}-06$ & $6.43 \mathrm{E}-06$ & 0.88 & $7.27 \mathrm{E}-06$ & 1.00 \\
\hline & 100 & $2.70 \mathrm{E}-05$ & $3.27 \mathrm{E}-05$ & 1.21 & $3.72 \mathrm{E}-05$ & 1.38 \\
\hline & 100 & $2.70 \mathrm{E}-05$ & $3.27 \mathrm{E}-05$ & 1.21 & 3.72E-05 & 1.38 \\
\hline & 120 & $1.60 \mathrm{E}-04$ & $1.41 \mathrm{E}-04$ & 0.88 & $1.61 \mathrm{E}-04$ & 1.01 \\
\hline & 120 & $2.20 \mathrm{E}-04$ & $1.41 \mathrm{E}-04$ & 0.64 & $1.61 \mathrm{E}-04$ & 0.73 \\
\hline \multirow{6}{*}{$241-S-106$} & 60 & $1.10 \mathrm{E}-06$ & $7.07 \mathrm{E}-07$ & 0.64 & $8.00 \mathrm{E}-07$ & 0.73 \\
\hline & 60 & $1.20 \mathrm{E}-06$ & $7.07 \mathrm{E}-07$ & 0.59 & $8.00 \mathrm{E}-07$ & 0.67 \\
\hline & 90 & $9.40 \mathrm{E}-06$ & $1.01 \mathrm{E}-05$ & 1.07 & $1.15 \mathrm{E}-05$ & 1.22 \\
\hline & 90 & $1.40 \mathrm{E}-05$ & $1.01 \mathrm{E}-05$ & 0.72 & $1.15 \mathrm{E}-05$ & 0.82 \\
\hline & 120 & $5.50 \mathrm{E}-05$ & $9.60 \mathrm{E}-05$ & 1.75 & $1.10 \mathrm{E}-04$ & 2.00 \\
\hline & 120 & 8.70E-05 & $9.60 \mathrm{E}-05$ & 1.10 & $1.10 \mathrm{E}-04$ & 1.27 \\
\hline \multirow{6}{*}{ 241-AN-105 } & 58 & $4.79 \mathrm{E}-06$ & $3.45 \mathrm{E}-06$ & 0.72 & $3.83 \mathrm{E}-06$ & 0.80 \\
\hline & 61 & $5.34 \mathrm{E}-06$ & $4.25 \mathrm{E}-06$ & 0.80 & $4.71 \mathrm{E}-06$ & 0.88 \\
\hline & 82 & $3.01 \mathrm{E}-05$ & $3.03 \mathrm{E}-05$ & 1.01 & $3.39 \mathrm{E}-05$ & 1.13 \\
\hline & 78 & $2.23 \mathrm{E}-05$ & $2.04 \mathrm{E}-05$ & 0.92 & $2.28 \mathrm{E}-05$ & 1.02 \\
\hline & 102 & $1.97 \mathrm{E}-04$ & $1.47 \mathrm{E}-04$ & 0.75 & $1.65 \mathrm{E}-04$ & 0.84 \\
\hline & 96 & $1.25 \mathrm{E}-04$ & $9.48 \mathrm{E}-05$ & 0.76 & $1.06 \mathrm{E}-04$ & 0.85 \\
\hline
\end{tabular}


Table 4-7. Normalized Thermal Rates With or Without Reactivity Coefficient $r_{f}$ (2 Sheets)

\begin{tabular}{|c|c|c|c|c|c|c|}
\hline 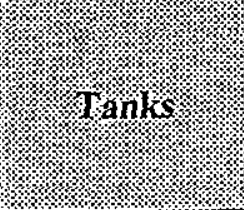 & (2) & $\begin{array}{l}\text { Iaboratory } \\
\text { obs. Rate } \\
\text { (noletrgg/day) }\end{array}$ & 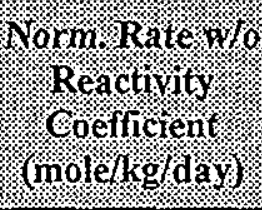 & 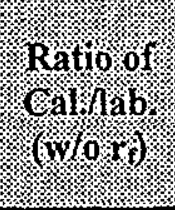 & 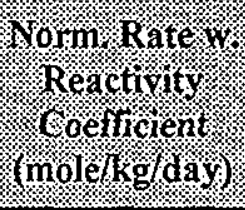 & 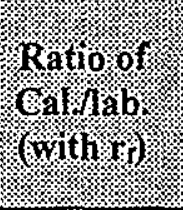 \\
\hline \multirow{2}{*}{ 241-AN-105 } & 103 & 1.72E-04 & $1.64 \mathrm{E}-04$ & 0.95 & $1.84 \mathrm{E}-04$ & 1.07 \\
\hline & 96 & $7.38 \mathrm{E}-05$ & $9.34 \mathrm{E}-05$ & 1.27 & $1.05 \mathrm{E}-04$ & 1.42 \\
\hline \multirow{10}{*}{ 241-SY-103 } & 60 & $7.20 \mathrm{E}-06$ & $1.09 \mathrm{E}-05$ & 1.52 & $6.96 \mathrm{E}-06$ & 0.97 \\
\hline & 60 & $9.10 \mathrm{E}-06$ & $1.09 \mathrm{E}-05$ & 1.20 & $6.96 \mathrm{E}-06$ & 0.76 \\
\hline & 75 & $2.50 \mathrm{E}-05$ & $4.37 \mathrm{E}-05$ & 1.75 & $2.80 \mathrm{E}-05$ & 1.12 \\
\hline & 75. & $2.70 \mathrm{E}-05$ & 4.37E-05 & 1.62 & $2.80 \mathrm{E}-05$ & 1.04 \\
\hline & 90 & $7.20 \mathrm{E}-05$ & $1.56 \mathrm{E}-04$ & 2.17 & $1.00 \mathrm{E}-04$ & 1.39 \\
\hline & 90 & $7.30 \mathrm{E}-05$ & $1.56 \mathrm{E}-04$ & 2.14 & $1.00 \mathrm{E}-04$ & 1.37 \\
\hline & 105 & $2.80 \mathrm{E}-04$ & $5.03 \mathrm{E}-04$ & 1.80 & $3.24 \mathrm{E}-04$ & 1.16 \\
\hline & 105 & $4.60 \mathrm{E}-04$ & $5.03 \mathrm{E}-04$ & 1.09 & $3.24 \mathrm{E}-04$ & 0.70 \\
\hline & 120 & $1.10 \mathrm{E}-03$ & $1.48 \mathrm{E}-03$ & 1.35 & $9.60 \mathrm{E}-04$ & 0.87 \\
\hline & 120 & $1.20 \mathrm{E}-03$ & $1.48 \mathrm{E}-03$ & 1.24 & 9.60E-04 & 0.80 \\
\hline \multirow{6}{*}{ 241-AW-101 } & 60 & $8.80 \mathrm{E}-06$ & 4.33E-06 & 0.49 & $1.18 \mathrm{E}-05$ & 1.35 \\
\hline & 60 & $9.00 \mathrm{E}-06$ & $4.33 \mathrm{E}-06$ & 0.48 & $1.18 \mathrm{E}-05$ & 1.32 \\
\hline & 90 & $1.60 \mathrm{E}-04$ & $6.18 \mathrm{E}-05$ & 0.39 & $1.70 \mathrm{E}-04$ & 1.07 \\
\hline & 90 & $1.70 \mathrm{E}-04$ & $6.18 \mathrm{E}-05$ & 0.36 & $1.70 \mathrm{E}-04$ & 1.00 \\
\hline & 120 & $2.20 \mathrm{E}-03$ & $5.88 \mathrm{E}-04$ & 0.27 & $1.63 \mathrm{E}-03$ & 0.74 \\
\hline & 120 & $2.30 \mathrm{E}-03$ & $5.88 \mathrm{E}-04$ & 0.26 & $1.63 \mathrm{E}-03$ & 0.71 \\
\hline
\end{tabular}

The tanks with large fractions of the TOC present as species that rapidly produce hydrogen, will have above average rates (e.g., the rate of DSTs in Figure 4-5). The present state of our knowledge of the TOC speciation data in each tank and of the rate constants for the important reaction steps does not provide an obvious way to accurately predict the rate constant (per amount of TOC) for production of hydrogen for the different tanks. Thus, we shall empirically introduce a parameter to address this feature. This parameter which is called reactivity coefficient, $\mathrm{r}_{\mathrm{f}}$, represents the differences in the nature of the TOC in different tanks. The reactivity coefficient, $r_{f}$, is determined empirically by adjusting $r_{f}$ to minimize the scatter in the Arrhenius plot. There are different ways to normalize; here $r_{f}$ is set equal to $I$ for the tank where the fastest rate was observed (241-AW-101). 
The equivalent rate equation of Equation 4-6 for each tank is given as

$$
\text { Rate }=\left(k \times \mathbf{r}_{\mathrm{r}} \times[\mathrm{TOC}] \times[\mathrm{Al}]^{0.4}\right) \times \mathrm{L}_{\mathrm{r}}
$$

Where $\mathrm{k}$ is the rate constant (in moles $\mathrm{H}_{2}$ per $\mathrm{kg}$ liquid per day) which follows

Arrhenius behavior $r_{f}$ is the reactivity coefficient (unitless)

[TOC] and [Al] is the concentration of TOC and $\mathrm{Al}$ ions (in weight percent) $\mathrm{L}_{\mathrm{f}}$ is the liquid fraction of waste (unitless)

The reactivity coefficient, $r_{f}$, is then used to maximize the correlation coefficient for the normalized thermal rates and inverse of temperature. The input data are taken from Table 4-5. The parameters of the thermal rate equations and the reactivity coefficient, $r_{f}$, are listed in Table 4-8. The relationship with the highest correlation coefficient, 0.98 (compared to 0.91 in Figure 4.5) is shown in Figure 4-6.

The calculated thermal rates using these two procedures are shown in the last two columns of Table 4-7. A plot of ratios for calculated versus laboratory thermal rates, whether with or without the reactivity coefficient, $r_{f}$, for tanks 241-AW-101, 241-SY-103, 241-A-101, 241-S-102, and 241-S-106, is given in Figure 4-6. The y-axis gives the ratio on a log scale, and the $x$-axis is the consecutive number for the measurement. The ratios ranged from 0.25 to 3 when reactivity coefficients were not used. The ratio was improved to be 1.5 when the reactivity coefficient was considered. The reactivity coefficient brings the off-set Arrhenius lines together, when comparing Figures 4-5 and 4-6, and leads to the best set of thermal activation energies and the pre-exponential a-values. As shown in Table 4-8, the reactivity coefficient, $\mathrm{r}_{\mathrm{f}}$, used in the fit ranged from 0.18 to 1 . In general, the reactivity coefficients are larger for DSTs than for SSTs, and reflect the trend that the rates are above the average lines for DSTs and below the lines for SSTs as shown in both Figures 4-4 and 4-5. A similar case is observed for radiolysis rates. By - considering both sets $\mathrm{r}_{\mathrm{f}}$ from thermal rates (Table 4-8) and radiolysis rates analysis (Table 4-10), an average $r_{f}$ of 0.7 and 0.4 for DSTs and SSTs, respectively, are used in both thermal and radiolysis rate equations.

As a comparison, the analyses of the measured thermal rates, normalized thermal rates with or without reactivity coefficient provide very similar activation energies of $88.6,89.3$, and $89.1 \mathrm{~kJ} / \mathrm{mole}$, respectively. The correlation coefficient improves from 0.75 to 0.91 by normalizing the measured thermal rate; which depends on the differences of [TOC], [Al], and $\mathrm{L}_{\mathrm{f}}$ among tanks. The correlation coefficient is further enhanced from 0.91 to 0.98 by recognizing the differences of the TOC reactivity among tanks. The data for [TOC], [Al], and liquid fraction $\mathrm{L}_{\mathrm{f}}$ are available for each tank, while the reactivity coefficients lead to the best empirical relationship. 
Figure 4-6. Plot of the Relationship of the Logarithm of Normalized Thermal Rates with Reactivity Coefficient Per [TOC] Versus the Inverse of Temperature From Tanks 241-AW-101, 241-AN-105, 241-SY-103, 241-A-101, 241-S-102, and 241-S-106

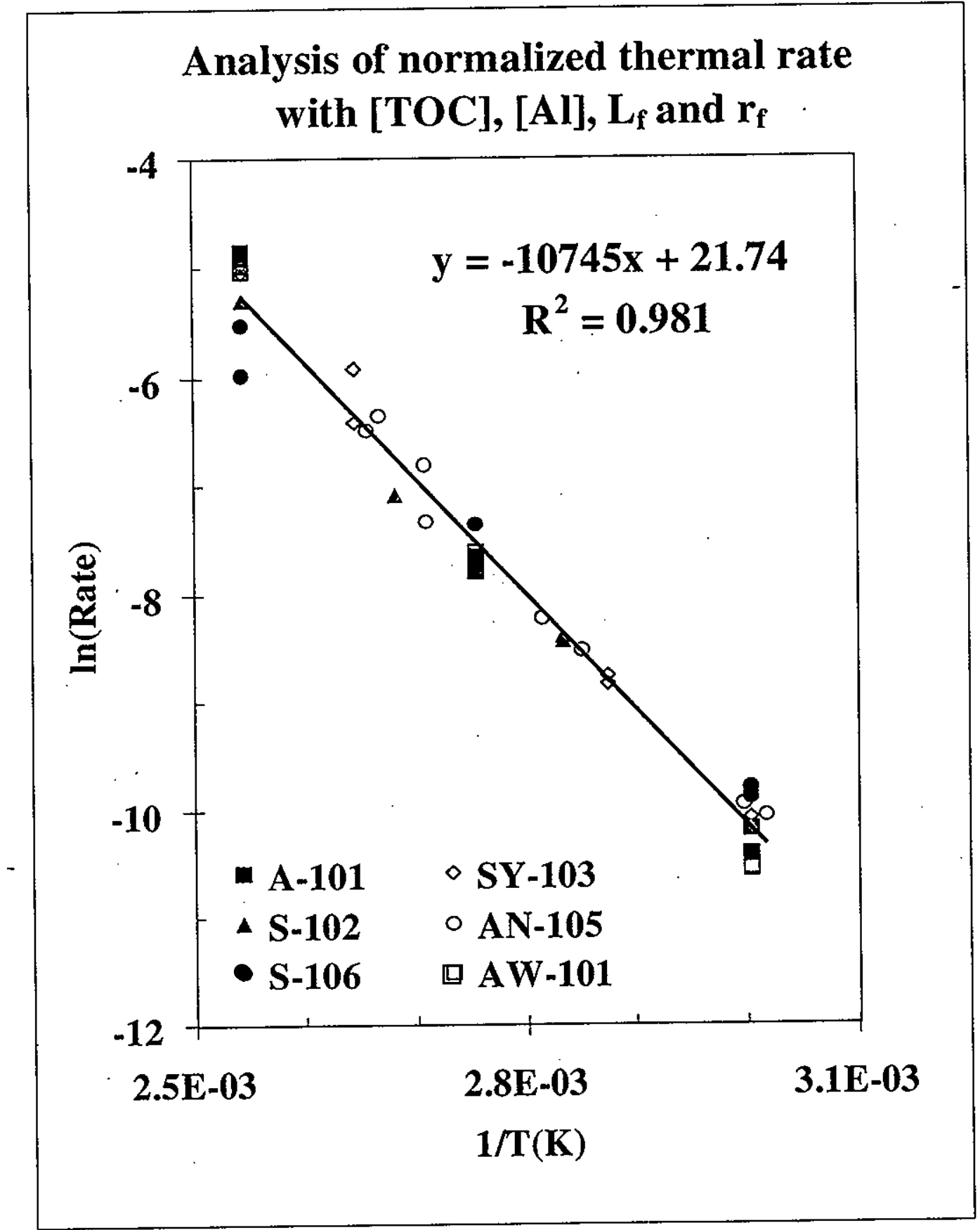


Table 4-8. The Parameters for The Thermal Rate Equation from The Global Fit of The Normalized Thermal Rate Analysis

\begin{tabular}{|c|c|c|}
\hline tranks: & $\begin{array}{l}\text { Measured } \\
\text { ThOC) }(\mathrm{wr} \% \text { ) }\end{array}$ & IReactivity \\
\hline 241-A-101 & 0.22 & 0.18 \\
\hline 241-S-102 & 0.14 & 0.41 \\
\hline $241-S-106$ & 0.09 & 0.41 \\
\hline 241-AN-105 & 0.28 & 0.41 \\
\hline 241-SY-103 & 0.74 & 0.23 \\
\hline 241-AW-101 & 0.34 & 1.00 \\
\hline Parameters of Thermal Rate Equation & .. 10 Yalues? & Uncertainty \\
\hline Thermal Activation Energy (mole/ko) & 89.3 & 1.93 \\
\hline Thermal Pre-exponential a (molenkg/day) & $2.76 E+09$ & N/A \\
\hline
\end{tabular}

The final empirical thermal rate equation includes [TOC], [Al], $\mathrm{L}_{f}$, and temperature with newly revised $\mathbf{E}_{\text {thm }}$ and $\mathbf{a}_{\text {thm }}$-values, and the parameter, $\mathbf{r}_{\mathbf{f}}$.

$$
\begin{aligned}
& \mathbf{H G R}_{\mathrm{Thm}}=\mathbf{a}_{\mathrm{thm}} \times \mathbf{r}_{\mathrm{f}} \times[\mathrm{TOC}] \times[\mathrm{Al}]^{0.4} \times \mathrm{L}_{\mathfrak{f}} \times \mathrm{e}^{-(E \mathrm{Ethm} / R T)} \\
& \text { With } \quad a_{\text {thm }}=2.76 \mathrm{E}+09 \text { (mole } / \mathrm{kg} \text { liquid-day) } \\
& \mathrm{E}_{\mathrm{thm}}=89.33 \mathrm{~kJ} / \mathrm{mole} \\
& \mathrm{R}=8.314 \mathrm{~J} / \mathrm{mole} / / \mathrm{K} \\
& \overline{\mathrm{r}}_{\mathrm{f}}=0.7 \text { for DSTs and } 0.4 \text { for SSTs }
\end{aligned}
$$

Where $\mathrm{HGR}_{\mathrm{thm}}$ is moles of $\mathrm{H}_{2}$ generated per kilogram of waste per day

$\mathrm{T}$ is the temperature of waste

- $a_{t h m}$ is the thermal rate pre-exponential factor of $\mathrm{H}_{2}$ generation

$E_{t h m}$ is the activation energy of $\mathrm{H}_{2}$ generation

$\mathrm{r}_{\mathrm{f}}$ is the reactivity coefficient.

[TOC] is total organic carbon concentration in the liquid waste (wt $\%)$

[Al] is aluminum concentration in liquid waste (wt\%)

$\mathrm{L}_{\mathrm{f}}$ is the weight fraction of liquid in the waste.

The liquid weight fraction of the waste can be obtained using Equation 4-3. 
Figure 4-7. Comparison of the Ratio of Calculated to Laboratory Thermal Rates With and Without Reactivity Coefficients $r_{f}$ for Tanks 241-AW-101, 241-SY-103, 241-A-101, 241-S-102, and 241-S-106.
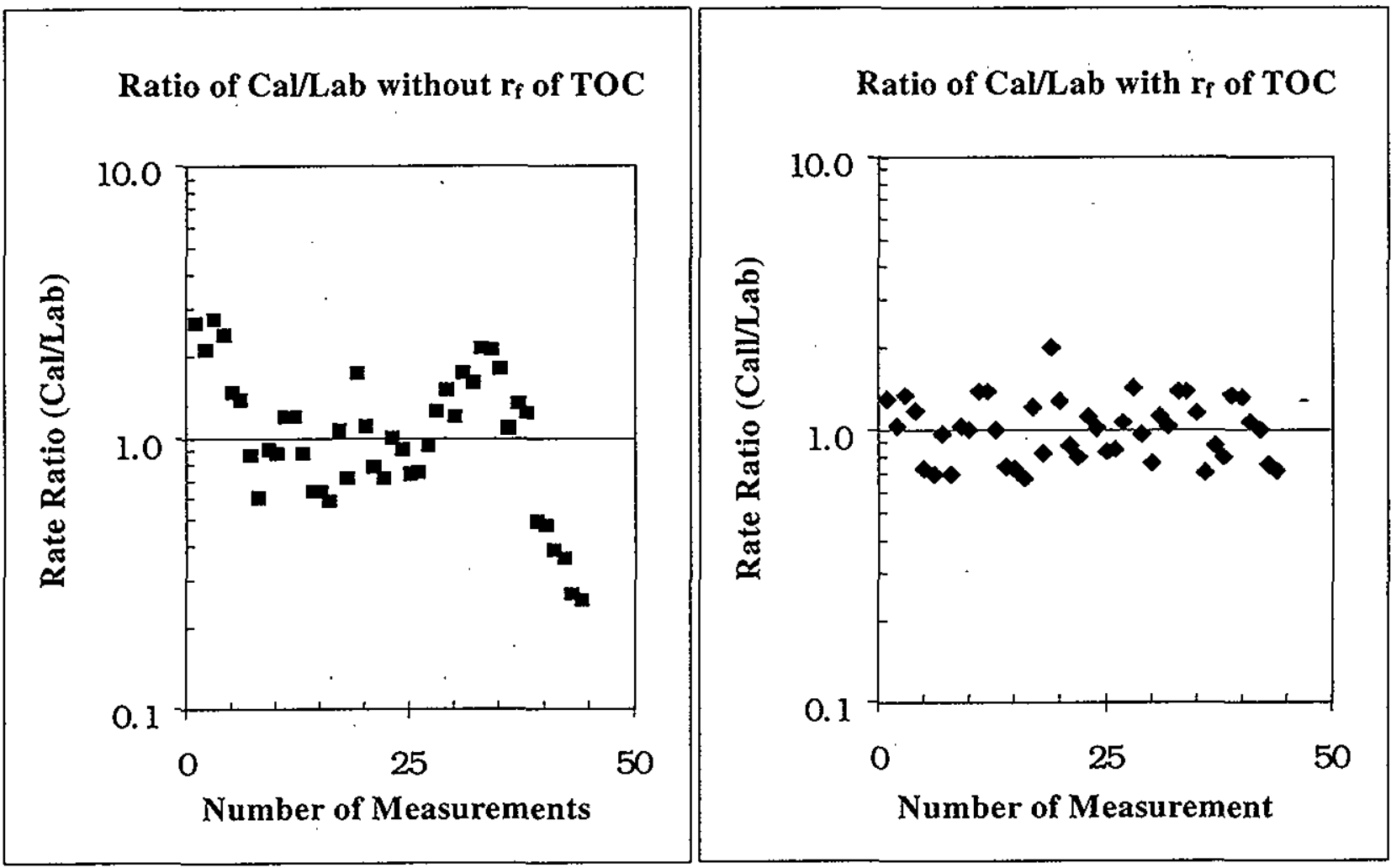

\subsection{RATE EQUATION FOR RADIOLYSIS}

The key parameter to calculate the hydrogen generation rate by radiation is the G-value. The $\mathrm{G}$-value is defined as the molecules of hydrogen produced per $100 \mathrm{eV}$. For Hanford waste, hydrogen arises from the radiolysis of water and organic waste. Once the G-value is estimated for each process, the radiolysis rate is simply the product of the $\mathrm{G}$-value and the radiation dose-rate. The derivation of the G-value calculation are given in the next section.

\subsubsection{Water Radiolysis}

For pure water, the G-value is 0.45 hydrogen molecules per 100 electron volts (Spinks and Woods 1990). As discussed in Section 2, hydrogen atoms from water radiolysis are scavenged by nitrate and nitrite ions. The effect of nitrite and nitrate ions in solution on water radiolysis, $\left(\mathrm{G}_{H 2 O}\right)$, is given in an empirical formula by Tabta et al. (1991) as 


$$
\begin{aligned}
& \mathrm{G}_{\mathrm{H} 2 \mathrm{O}}=0.45-0.41 \times\left[\mathrm{NO}_{3}\right]^{1 / 3}-0.31 \times\left[\mathrm{NO}_{2}\right]^{1 / 3} \\
& \text { Where, }\left[\mathrm{NO}_{3}^{-}\right] \text {is the nitrate ion concentration in solution }(\mathrm{moles} / \mathrm{L}) \\
& {\left[\mathrm{NO}_{2}^{-}\right] \text {is the nitrite ion concentration in solution }(\mathrm{moles} / \mathrm{L})}
\end{aligned}
$$

As shown in Table 5-1, 96\% of the hydrogen generation rate of tank 241-AY-102 comes from radiolysis of water because of the low [TOC], low salt content, and low temperature. Using Equation $4-9$, the calculated rate is $40 \%$ higher than what has been observed in the field. Since the observed field rate is quite accurate, as discussed Section 5.2, the coefficients in front of nitrate and nitrite ions of water radiolysis scavenging in Equation 4-9 are linearly re-scaled to reflect the observed rate of $691 \mathrm{~L} /$ day, assuming the same type of salts and mechanism of scavenging. The parameters in Equation 4-9 are adjusted using these measurements as follows.

$$
\mathrm{G}_{\mathrm{H} 2 \mathrm{O}}=0.45-0.56 \times\left[\mathrm{NO}_{3}^{-}\right]^{1 / 3}-0.43 \times\left[\mathrm{NO}_{2}^{-}\right]^{1 / 3}
$$

The $\mathrm{G}_{\mathrm{H} 2 \mathrm{O}}$ value for water radiolysis can approach zero for high concentrations of $\mathrm{NO}_{2}{ }^{\circ}$ and $\mathrm{NO}_{3}{ }^{\circ}$. A computer model (Meisel et al. 1993) shows that when $\left[\mathrm{NO}_{3}{ }^{-}\right.$] exceeds approximately $1 \mathrm{M}$, and $\left[\mathrm{NO}_{2}{ }^{-}\right]$exceeds $2 \mathrm{M}$, no additional chemical scavenger will significantly diminish the yield of hydrogen over the suppression already achieved by nitrate and nitrite ions. Meisel et al. (1993) found $\mathrm{G}_{\mathrm{H} 2 \mathrm{O}}$ to be 0.031 in simulated waste containing concentrated salt solutions without any organic material. Since the lowest observed G-value is 0.001 (per kg liquid waste from tank 241-S-106) at high salt conditions, the default water radiolysis of the actual waste may be much lower than 0.031 suggested by simulated waste study (Meisel et al. 1993). A non-zero water radiolysis G-value for high salt conditions will be determined in the global analysis of the observed radiolysis rates. Although the measured total radiolysis rate is temperature-dependent, as shown in Section 3, the water radiolysis G-value of the waste in this model is not explicitly temperaturedependent. As shown in Equation 4-10, for pure water, the G-value holds as a constant of 0.45 $\mathrm{H}_{2} / 100 \mathrm{eV}$ over a large range of temperatures (Spinks and Woods 1990), and the salt scavenging part is a function of the nitrate and nitrite ions concentration.

\section{2,2. Organic Radiolysis}

When organic compounds are present, Meisel et al. (1993) found that $G_{\text {ORG }}$ value is proportional to the molar concentration of organic species $[\mathrm{RH}]$ and the number of $\mathrm{C}-\mathrm{H}$ and N-H bonds of organic species $\eta_{\mathrm{R}-\mathrm{H}}$, and can be calculated as

$$
\mathrm{G}_{\mathrm{ORG}}=0.013 \times \eta_{\mathrm{R} \cdot \mathrm{H}} \times[\mathrm{RH}]
$$

Using Equation 4-11 and organic speciation data from tank 241-SY-103, Pederson and Bryan (1996) found that the calculated $\mathrm{G}_{\mathrm{ORG}}$ of tank 241-SY-103 waste is 0.011 . This value is ten times smaller than the G-value derived from the radiolysis rate measurements at 60 and $75^{\circ} \mathrm{C}$ for waste 
from tank 241-SY-103 (Table 3-4). To resolve this difference, they derived an equation based on the radiolysis rate of tank 241-SY-103 to calculate the G-value for organic radiolysis as follows,

$$
\mathrm{G}_{\mathrm{ORG}}=\left(\mathrm{G}_{\mathrm{ORG}} /[\mathrm{TOC}]\right)_{\mathrm{SY}-103} \times[\mathrm{TOC}]=0.15 \times[\mathrm{TOC}]
$$

Where $\mathrm{G}_{\mathrm{ORG}}$ is the $\mathrm{G}$-value of organic radiolysis (molecules/100 eV)

$\left(\mathrm{G}_{\text {org }} /[\mathrm{TOC}]\right)_{\mathrm{SY}-103}$ is the ratio of organic radiolysis yield and TOC from tank 241-SY-103, which is 0.15

$[\mathrm{TOC}]$ is the total organic carbon concentration in liquid waste (wt\%)

Note that the GorG value of tank SY-103 is 0.11 , which is the difference between the measured radiolysis G-value of 0.14 of tank 241-SY-103 (Table 3-4) and the water radiolysis G-value of 0.031 (Meisel et al. 1993). The scaling factor 0.15 is the ratio of $\mathrm{G}_{O R G}$ of 0.11 and the TOC content, 0.74, from tank 241-SY-103.

As discussed in Section 3.0, the effective radiolysis rate is temperature-dependent and follows Arrhenius behavior. Equations 4-11 and 4-12 are temperature-independent. Temperaturedependent radiolysis rate equations will be established later based on the global analysis of the radiolytic rate data.

\subsubsection{Global Radiolysis Rate Equation Analysis}

The discussion in Section 2 and the above section showed that a model of radiolysis rate for Hanford waste should have two parts, one for water radiolysis and the other for organic radiolysis. The water radiolysis is temperature-independent, and the organic radiolysis is temperature-dependent and follows Arrhẹnius behavior.

In general, the radiolysis rate is characterized by the G-value and is linearly dependent on the radiation dose. Assuming the total heat load is absorbed equally by the weight fraction of solid and liquid in the samples, the radiolysis rate in moles hydrogen generated per day per kilogram of waste can be expressed as follows,

$$
\begin{aligned}
\text { HGR }_{\text {radiolysis }}= & \mathbf{G}_{\mathrm{L}} \times \mathbf{H}_{\text {load }} \text { absorbed by Liquid }+ \\
& \mathbf{G}_{\mathbf{S}} \times \mathbf{H}_{\text {load }} \text { absorbed by Solid }
\end{aligned}
$$

Where $\mathrm{HGR}_{\text {radiolysis }}$ is the hydrogen generation rate of radiolysis (mole $/ \mathrm{kg}$-day) $\mathrm{H}_{\text {load }}$ is total heat load of the tank (Watt $/ \mathrm{kg}$ )

$\mathrm{G}_{\mathrm{L}}$ and $\mathrm{G}_{\mathrm{S}}$ are the total yield of $\mathrm{H}_{2}$ per $100 \mathrm{eV}$ from liquid and solid portion

The water radiolysis occurs in the liquid phase, and the organic radiolysis also occurs effectively in the liquid phase because the most energetic organic compounds are soluble (Barney 1994, 1995, 1996, and 1997). Organic speciation (Campbell et al. 1995 and 1996) of the waste liquid 
and solid (separated by centrifugation) samples from tanks with the highest TOC corroborates that the energetic complexants are contained in the aqueous phase. Thus, only radiation absorbed by the liquid portion denoted as liquid fraction $\mathrm{L}_{f}$ is responsible for hydrogen generation, and $\mathrm{G}_{s}$ can be set to zero. Equation 4-13 can be further developed as follows,

$$
\mathbf{H G R}_{\text {radiolysis }}=\mathbf{G} \times \mathbf{H}_{\text {load }} \times \mathbf{L}_{\mathrm{f}}
$$

The G-value has two parts, water and organic radiolysis, and can be expressed as follows,

$$
\mathbf{G}=\mathbf{G}_{\mathrm{H} 2 \mathrm{O}}+\mathbf{G}_{\mathrm{ORG}}=\mathbf{G}_{\mathrm{H} 2 \mathrm{O}}+\mathbf{a}_{\mathrm{rad}} \times \mathbf{e}^{-(\mathrm{Rrad} / \mathrm{RT})} \times[\mathrm{TOC}]
$$

The G-value for water radiolysis can be calculated using Equation 4-10, as a function of [ $\mathrm{NO}_{2}{ }^{-}$] and $\left.\mathrm{NO}_{3}{ }^{-}\right]$. As mentioned previously, it has a non-zero default value at high salt conditions (Meisel et al. 1993). The G-value for organic radiolysis is proportional to the concentration of organic species and follows Arrhenius behavior. Therefore, the second term in Equation 4-15 is temperature-dependent and depends on the [TOC] content.

A global analysis of the measured radiolysis rates from waste samples was conducted to determine the default value of $\mathrm{G}_{\mathrm{H} 2 \mathrm{O}}$, the pre-exponential a-value term, and the activation energy. In this analysis, total $\mathrm{G}$-values were calculated from each radiolysis rate using Equation 4-14. Since all available tanks have high salt concentrations, the values of the natural log of (GORG $/[T O C])$ can be calculated by assuming a default value of $\mathrm{G}_{\mathrm{H} 2 \mathrm{O}}$, and then examined for adherence to an Arrhenius relationship. Total organic carbon (TOC) is an indicator of the amount of organic compounds in the waste. However, some compounds, such as oxalate, make little or no contribution to hydrogen generation. The reactivity coefficient, $\boldsymbol{r}_{\boldsymbol{i}}$, was used to differentiate the differences in reactivity of TOC among tanks. The variables used in the analysis, such as the liquid weight fraction, the external radiation applied to the samples, and the TOC concentrations in the liquid phase are listed in Table 4-9. The global slope and intercept will determine the activation energy $\mathrm{E}_{\mathrm{a}}$ and the pre-exponential term a-value.

\begin{tabular}{|c|c|c|c|}
\hline . Tanks & Fraction & (kxtrar) & $(w+\%)$ \\
\hline $241-A-101$ & 0.59 & 36500 & 0.22 \\
\hline $241-S-102$ & 0.56 & 37400 & 0.14 \\
\hline $241-S-106$ & 0.59 & 36800 & 0.09 \\
\hline $241-S Y-103$ & 1.0 & 5300 & 0.74 \\
\hline 241-AW-101 & 1.0 & 36800 & 0.34 \\
\hline
\end{tabular}

Table 4-9. Radiolysis Rates Analysis Parameters 


\section{Error}

An error occurred while processing this page. See the system log for more details. 
Figure 4-8. Normalized Radiolysis Rate Analysis with $\mathrm{G}_{\mathrm{H} 2 \mathrm{O}}=\mathbf{0 . 0 0 5}$ for the Data from Tanks 241-AW-101, 241-SY-103, 241-A-101, 241-S-102, and 241-S-106.

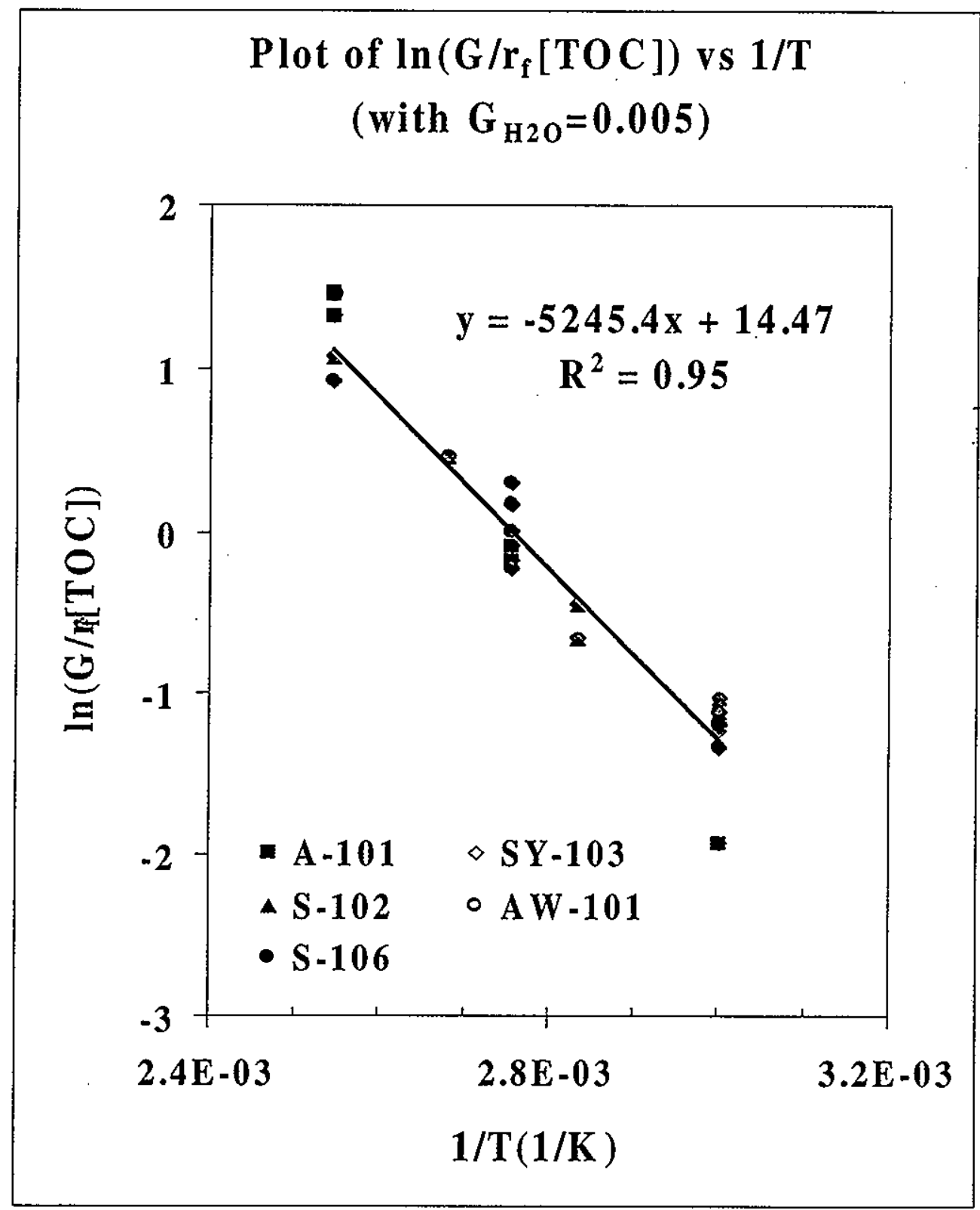

Table 4-11 lists the results of radiolysis analysis by setting $\mathrm{G}_{\mathrm{H} 2 \mathrm{O}}=0.005$, including the calculated total G-value, the observed radiolysis rates, the calculated radiolysis rate and the ratio of the calculated rate versus the observed rate. Note that the observed radiolysis rate used in the analysis is the difference between the rates measured under external radiation and the calculated thermal rates from the thermal reactions. Also, a large discrepancy between two measured rates at $60^{\circ} \mathrm{C}$ for A-101, thus the rate data with the ratio of 2.17 in Table 4-11 is not included in the fit. 
HNF-3851 Rev. 0

Table 4-11. Calculated Radiolysis $\mathrm{G}$-value and Rate at $\mathrm{G}_{\mathrm{H} 2 \mathrm{O}}=0.005$

\begin{tabular}{|c|c|c|c|c|c|}
\hline TIanks & (1) & 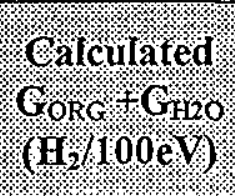 & $\begin{array}{l}\text { observed } \\
\text { Rad. Rate } \\
(\mathrm{mol} / \mathrm{hg} / \mathrm{day})\end{array}$ & $\begin{array}{l}\text { Galculated } \\
\text { Rad. Rate- } \\
\text { (mole/kg/day) }\end{array}$ & (Caliobs) \\
\hline \multirow{6}{*}{$241-A-101$} & 60 & 0.024 & $5.91 \mathrm{E}-06$ & $1.28 \mathrm{E}-05$ & 2.17 \\
\hline & 60 & 0.024 & $8.01 \mathrm{E}-06$ & $1.28 \mathrm{E}-05$ & 1.60 \\
\hline & 90 & 0.075 & 3.32E-05 & $4.06 \mathrm{E}-05$ & 1.23 \\
\hline & 90 & 0.075 & $3.62 \mathrm{E}-05$ & 4.06E-05 & 1.12 \\
\hline & 120 & 0.221 & $1.37 \mathrm{E}-04$ & $1.19 \mathrm{E}-04$ & 0.87 \\
\hline & 120 & 0.221 & $1.57 \mathrm{E}-04$ & $1.19 \mathrm{E}-04$ & $0.76^{-}$ \\
\hline \multirow{8}{*}{$241-S-102$} & 60 & 0.023 & $1.48 \mathrm{E}-05$ & $1.20 \mathrm{E}-05$ & 0.81 \\
\hline & 60 & 0.023 & $1.38 \mathrm{E}-05$ & $1.20 \mathrm{E}-05$ & 0.87 \\
\hline & 80 & 0.050 & $2.47 \mathrm{E}-05$ & $2.59 \mathrm{E}-05$ & 1.05 \\
\hline & 80 & 0.050 & $2.07 \mathrm{E}-05$ & $2.59 \mathrm{E}-05$ & 1.25 \\
\hline & 100 & 0.105 & $5.88 \mathrm{E}-05$ & $5.49 \mathrm{E}-05$ & 0.93 \\
\hline & 100 & 0.105 & $5.78 \mathrm{E}-05$ & $5.49 \mathrm{E}-05$ & 0.95 \\
\hline & 120 . & 0.213 & $1.09 \mathrm{E}-04$ & $1.11 \mathrm{E}-04$ & 1.02 \\
\hline & 120 & 0.213 & $1.09 \mathrm{E}-04$ & $1.11 \mathrm{E}-04$ & 1.02 \\
\hline \multirow{6}{*}{ 241-S-106 } & 60 & 0.016 & $9.10 \mathrm{E}-06$ & 8.51E-06 & 0.94 \\
\hline & 60 & 0.016 & $9.20 \mathrm{E}-06$ & $8.51 \mathrm{E}-06$ & 0.93 \\
\hline & 90 & 0.045 & $2.45 \mathrm{E}-05$ & $2.45 \mathrm{E}-05$ & 1.00 \\
\hline & 90 & 0.045 & $3.15 \mathrm{E}-05$ & $2.45 \mathrm{E}-05$ & 0.78 \\
\hline & 120 & 0.128 & $5.97 \mathrm{E}-05$ & $6.95 \mathrm{E}-05$ & 1.16 \\
\hline & 120 & 0.128 & $5.97 \mathrm{E}-05$ & $6.95 \mathrm{E}-05$ & 1.16 \\
\hline 241-SY-103 & 60 & 0.129 & $1.77 \mathrm{E}-05$ & $1.71 \mathrm{E}-05$ & 0.96 \\
\hline \multirow{4}{*}{ 241-AW-101 } & 60 & 0.099 & $1.08 \mathrm{E}-04$ & $9.11 \mathrm{E}-05$ & 0.84 \\
\hline & 60 & 0.099 & $8.82 \mathrm{E}-05$ & $9.11 \mathrm{E}-05$ & 1.03 \\
\hline & 90 & 0.360 & $3.90 \mathrm{E}-04$ & $3.29 \mathrm{E}-04$ & 0.85 \\
\hline & 90 & 0.360 & $2.70 \mathrm{E}-04$ & $3.29 \mathrm{E}-04$ & 1.22 \\
\hline
\end{tabular}


Note that the G-values in Table 4-11 are extrapolated from the normalized radiolysis rates with liquid weight fraction. Therefore, the values will be scaled by the liquid weight percent when compared to the measured G-values (Table 3-4). As shown in Table 4-11, the ratio between calculated and observed is within a factor of two. In summary, the radiolysis rate equations for hydrogen generation are

$$
\begin{aligned}
& \mathrm{HGR}_{\mathrm{rad}}=\left(\mathrm{G}_{\mathrm{H} 2 \mathrm{O}}+\mathrm{G}_{\mathrm{ORG}}\right) \times \mathbf{H}_{\text {load }} \times \mathrm{L}_{\mathrm{f}} \\
& \text { With } G_{O R G}=\left[a_{r a d} \times e^{-(\mathrm{Rrad} / \mathrm{RT})}\right] \times\left(\mathrm{r}_{\mathrm{f}} \times([\mathrm{TOC}])\right. \\
& \mathrm{G}_{\mathrm{H} 2 \mathrm{O}}=0.45-0.56 \times\left[\mathrm{NO}_{3}\right]^{-1 / 3}-0.43 \times\left[\mathrm{NO}_{2}\right]^{-1 / 3}
\end{aligned}
$$

\subsection{RATE EQUATIONS FOR CORROSION}

The design specification limit for the corrosion of DSTs is $1 \mathrm{mil} / \mathrm{year}$. The rate of $1 \mathrm{mil} / \mathrm{year}$ corresponds to the production of $4000 \mathrm{ft}^{3}$ of hydrogen (Ashby et al. 1992). However, a study of simulated DST waste (with $\mathrm{pH}>13$ ) showed that the corrosion rate was about 0.02 to 0.03 mil/year (Strachan 1994). Also recent electrochemical measurements in liquid waste from tank 241-AZ-101 indicate that the corrosion rate is less than 0.1 mil/year (Anantatmula 1999 and associated references). Anantatmula (1999) recently assessed the corrosion rate of SSTs and found that current maximum uniform corrosion rate is around $0.16 \mathrm{mil} / \mathrm{year}$.

In this work, the corrosion rate will be assigned as $0.1 \mathrm{mil} /$ year for DSTs and $0.2 \mathrm{mil} /$ year for SSTs, which correspond to hydrogen generation rates of $0.6 \mathrm{E}-7$ and $1.2 \mathrm{E}-7 \mathrm{ft}^{3} / \mathrm{min} / \mathrm{ft}^{2}$, respectively. The hydrogen generation rate $\mathrm{HGR}_{\text {corr }}$ in the tank can be expressed as

$$
\mathbf{H G R}_{\text {corr }}=\mathbf{R}_{\text {corr }} \times \mathbf{A}_{\text {wetted }}
$$

Where $R_{\text {corr }}=6.0 \mathrm{E}-08$ for DSTs and 1.2E-07 for SSTs $\left(\mathrm{ft}^{3} / \mathrm{min} / \mathrm{ft}^{2}\right)$ $A_{\text {wetted }}$ is the area of steel exposed to moisture-containing waste $\left(\mathrm{ft}^{2}\right)$. 
As shown in Table 5-1, corrosion makes only a minor contribution for the active hydrogen generating tanks, but for those tanks with low [TOC] and low Cs and Sr concentrations, the corrosion process becomes dominant.

\subsection{SUMMARY AND DISCUSSION OF EMPIRICAL RATE EQUATIONS}

The empirical rate equation for hydrogen generation of Hanford waste developed above contains the simulation of thermal reaction $H_{G} R_{\text {thm }}$, radiolysis of water and organic $H_{G R}$ rad, and the corrosion process $\mathrm{HGR}_{\text {corr }}$. This rate equation is function of waste composition of TOC, $\mathrm{Al}$, $\mathrm{NO}_{3}^{-}, \mathrm{NO}_{2}^{-}$, radiation dose, temperature, liquid fraction, and tank wetted area. Both thermal and radiolysis rate follows the Arrhenius behavior with a derived activation energy. The equation for hydrogen generation rate (HGR) can be summarized as follows.

$\mathbf{H G R}=\mathrm{HGR}_{\mathrm{thm}}+\mathrm{HGR}_{\mathrm{rad}}+\mathrm{HGR}_{\mathrm{corr}}$

Where $\mathbf{H G R}_{\text {thm }}=\mathbf{a}_{\text {thm }} \times \mathbf{r}_{\mathrm{f}} \times[\mathrm{TOC}] \times[\mathrm{Al}]^{0.4} \times \mathrm{L}_{\mathrm{f}} \times \mathrm{e}^{-(\mathrm{Ethm} / \mathrm{RT})}$

$\mathrm{HGR}_{\mathrm{rad}}=\left(\mathrm{G}_{\mathrm{H} 2 \mathrm{O}}+\mathbf{G}_{\mathrm{ORG}}\right) \times \mathbf{H}_{\text {load }} \times \mathbf{L}_{\mathrm{r}}$

$\mathbf{H G R}_{\text {corr }}=\mathbf{R}_{\text {corr }} \times \mathbf{A}_{\text {wetted }}$

With GoRG $_{\text {OR }}=\left[a_{\mathrm{rad}} \times \mathrm{e}^{\left(-\mathrm{Erad} / \mathrm{R}^{\prime} \mathrm{r}\right)} \times\left(\mathrm{r}_{\mathrm{f}} \times([\mathrm{TOC}])\right.\right.$

$\mathrm{G}_{\mathrm{H} 2 \mathrm{O}}=0.45-0.56 \times\left[\mathrm{NO}_{3}^{-}\right]^{1 / 3}-0.43 \times\left[\mathrm{NO}_{2}^{-}\right]^{1 / 3}$.

And $\quad E_{t h m}=89.3 \mathrm{~kJ} / \mathrm{mole}$, the activation energy for thermal reaction

$a_{t h m}=2.76 \mathrm{E}+09 . \mathrm{mole} / \mathrm{kg}$-day, pre-exponential factor of the thermal rate

$\mathrm{E}_{\mathrm{rad}}=44.3(2.0) \mathrm{kJ} / \mathrm{mole}$, activation energy for organic radiolysis

$a_{\mathrm{rad}}=2.49 \mathrm{E}+6 \mathrm{~mole} / \mathrm{kg}$-day, pre-exponential factor of organic radiolysis rate

$\mathrm{r}_{\mathrm{f}}=0.7$ for DSTs and 0.4 for SSTs (unitless), the TOC reactivity coefficient

$\mathrm{R}=8.314 \mathrm{~J} / \mathrm{mole} /{ }^{\circ} \mathrm{K}$, gas constant

$\left(\mathrm{G}_{\mathrm{H} 2 \mathrm{O}}\right)_{\mathrm{sat}}=0.005 \mathrm{~mole}_{2} / 100 \mathrm{eV}$, the default water radiolysis $\mathrm{G}$ under high salts

$\mathrm{R}_{\text {corr }}=6.0 \mathrm{E}-08$ for DSTs and 1.2E-07 for SSTs $\left(\mathrm{ft}^{3} / \mathrm{min} / \mathrm{ft}^{2}\right)$, corrosion coefficient

[TOC] is total organic carbon concentration in the liquid waste (wt $\%$ )

[Al] is aluminum concentration in liquid waste (wt\%)

$\left[\mathrm{NO}_{3}{ }^{-}\right]$is the nitrate ion concentration in the liquid waste (moles/L)

$\left[\mathrm{NO}_{2}{ }^{-}\right]$is the nitrite ion concentration in the liquid waste (moles/L)

$\mathrm{H}_{\text {load }}$ is total heat load of the tank (Watt $/ \mathrm{kg}$ )

$\mathrm{L}_{\mathrm{f}}$ is the liquid weight fraction in the waste (unitless)

$\mathrm{T}$ is the temperature of waste $(\mathrm{K})$

$A_{\text {wetted }}$ is the area of steel exposed to moisture-containing waste $\left(\mathrm{ft}^{2}\right)$.

In general, the overall rate analysis shows better correlation by normalizing the rates with liquid fraction. This feature strongly supports that all reactions for hydrogen generation occur most 
effectively in the liquid phase. Since the liquid fraction can be estimated by the moisture content and, fortunately, almost all tanks waste have the moisture content measurement, this factor is available for most tanks. Secondly, the reactivity coefficient of TOC further improves the correlation of the rate analysis. As discussed in Section 4.2, the reactivity coefficient reflects the reactivity of TOC from each tank in the hydrogen generation reaction. However, there are currently no organic speciation data to derive this coefficient. In this work, $r_{f}$ values were empirically determined to minimize the off-set of rates along the average value. Two sets of reactivity coefficients are obtained, one from thermolysis analysis and the other from radiolysis analysis. Both sets show that the $\mathrm{r}_{\mathrm{f}}$ for DSTs is larger than for SSTs, which reflects the fact that the observed rates from DSTs are higher than those from SSTs. An average value of 0.7 for DSTs and 0.4 for SSTs are used for both thermal and radiolysis rate equations.

The thermal rate equation is derived based on laboratory rate measurements without external radiation. The rates follow Arrhenius behavior very closely for all available measurements. The self-dose of the samples are in the order of a few hundred $\mathrm{R} / \mathrm{hr}$ which contributes less than $1 \%$ of the thermal rate at the temperature ranges of the rate measurement. No self-dose correction was made on the rate analysis. The rate-dependent constituents are TOC and $\mathrm{Al}$, as suggested by several simulant studies (e.g., Meisel et al. 1993). The reaction order of the rate dependent constituents is concluded from the rate analysis. The laboratory rates of tank waste strongly show the first-order dependence on TOC; however, they are really not sensitive to the aluminate concentration to help determine the reaction order of aluminate. Aluminate concentrations, ranging from 2.8 to 1.9 weight percent, are very similar among tanks; the amount of aluminate of these tanks could be all super saturate to the rate reactions since it plays a role of catalysis (Ashby et al. 1994). As discussed in Section 4.1, the 0.4 power for aluminate is determined by the results of dilution study on tank 241-SY-101 (Person 1996). The reaction order of aluminate can be further analyzed by studying the rate of tank waste which has very different aluminate content; for example, tanks 241-AN-107 and 241-AN-106 have low aluminate concentration (around 0.2 $\mathrm{wt} \%)$, but very high TOC concentration. Predicted rates for these two tanks would be very high compared to the field observed rate if considering TOC as the only rate-dependent. However, the calculated rates become comparable to the field data when including $\mathrm{Al}$ concentration as one of rate-dependent constituents in the rate equation.

For the radiolysis rate equation, the water radiolysis G-value was formulated with the G-value of 0.45 from pure water minus the scavenging effect from nitrate and nitrite. The coefficients of scavenging effect were re-scaled to reflect the field observed hydrogen generation rate of tank 241-AY-102, in which the hydrogen generation in a very diluted waste is believed to come mainly from water radiolysis. The scavenger effect and its coefficients can be further improved by studying the very dilute tank wastes, such as $\mathrm{AP}$ or $\mathrm{AW}$ tanks; which have low TOC, low salts, and low temperature. Most Hanford tank waste, particularly the SSTs, contains high concentration salts, and, thus, in water radiolysis the scavenging occurs very rapidly. As Meisel et al. (1993) point out, there is a minimum water radiolysis $G$-value even with excessive amount of salts. The minimum water radiolysis $\mathrm{G}$-value is determined to be 0.005 by evaluating the observed rates from tank waste hydrogen generation data. This value is much smaller than the value of 0.031 suggested by the simulant study (Meisel et al 1993). 
Hydrogen generation from organic radiolysis is one of the results of degradation of organic species in the waste by radiation. Gas generation studies of tank waste show that the radiation effect on the hydrogen generation is also temperature-dependent and follows Arrhenius behavior. The organic radiolysis $G_{O G R}$ in the rate equation is formulated as linear dependent on the concentration of TOC and as a function of temperature and activation energy exponentially. The radiolysis rates used in the analysis are the net rates of the rates measured with and without external radiation which contain the uncertainty from both measured data, and thus the fit quality was not as good as the thermolysis analysis. For the analysis with the normalized rates without $r_{f}$, the correlation of data analysis $\left(R^{2}\right)$ is 0.8 in the radiolysis analysis versus 0.92 in the thermolysis analysis. In the final radiolysis analysis, $T O C$ reactivity coefficients $\mathrm{r}_{\mathrm{f}}$ are used and determined to bring the off-set Arrhenius lines (from different tanks) together and improve the overall correlation of the analysis $\left(\mathrm{R}^{2}\right)$ to 0.95 .

One of the major differences between the previous model (Hu 1997) and the current study is that the current radiolysis term is temperature-dependent; while the previous one ratio the $\mathrm{G}$-vatue of SY-103 waste at $60^{\circ} \mathrm{C}$ with TOC. For most tanks, the waste temperatures are about 30 to $40^{\circ} \mathrm{C}$, and thus, the $\mathrm{G}$-values determined from the current study are smaller than the previous values (Hu 1997) by a factor of 3 to 4 , in general: Using the current temperature-dependent radiolysis rate equation, the calculated $G_{O R G}$ shows good agreement with the simulant study. As mentioned in Section 4.2.2, the Gorg of tank 241-SY-103 was 0.011 using Equation 4-11 suggested by the simulant study (Meisel et al 1993). Equation 4-11 is derived from the radiolysis rate study of simulant at $30^{\circ} \mathrm{C}$. The current model calculated $\mathrm{G}_{\mathrm{ORG}}$ value at $30^{\circ} \mathrm{C}$ for tank $241-\mathrm{SY}-103$ is 0.035 , which is not too far from 0.011 . 
HNF-3851 Rev. 0

This page intentionally left blank 


\subsection{COMPARISON OF FIELD OBSERVED AND MODEL CALCULATED RATES}

In this section, the hydrogen generation rates for some of the most active hydrogen generation tanks, including 13 DSTs and 20 SSTs, are calculated using the model developed in Section 4. For these tanks; field monitoring data, such as waste level measurements, airflow rates, and hydrogen concentrations in the tank dome space, are available to estimate the hydrogen generation rate; thus, the model calculated rate can be compared with the field-estimated rate. Note that the calculated rates provided in the following tables provide a first-cut calculation to get an overall idea how the model predicts the rate as a general equation. The calculation is based on the data available at this point, and any complex on-going operations on individual tanks are not considered; for example, waste in tank C-106 is undergoing slucing operations and transfer to tank SY-102. The rates provided here are only for model comparison, and any rate used for waste operations should be re-examined based on the complexity of waste condition, and the updated characterization and surveillance data.

\subsection{MODEL CALCULATED HYDROGEN GENERATION RATES OF TANK WASTE}

Hydrogen generation rates (HGRs) were calculated for 13 DSTs and 20 SSTs using a Microsoft EXCEL spreadsheet. The HGRs in the crust (top thin solid layer), convective (liquid layer), and non-convective (solid layer) were calculated separately and summed to give the total HGRs for each tank. The work sheets were organized in three parts: direct input data, derived terms from input data, and the generation rate.

Chemical properties include the concentration of total organic carbon [TOC], aluminate [Al], nitrate $\left[\mathrm{NO}_{3}{ }^{-}\right]$, nitrite $\left[\mathrm{NO}_{2}{ }^{-}\right]$, cesium [Cs], and strontium [Sr]. Physical properties include bulk density, liquid density, waste volume, weight percent water, tank waste temperature, and tank dome space temperature. As mentioned in Section 4, hydrogen generation occurs most effectively in the liquid phase. Thus, the concentrations of $\mathrm{TOC}, \mathrm{Al}, \mathrm{NO}_{3}$, and $\mathrm{NO}_{2}$ are taken from the liquid sample in each layer. If no liquid sample data are available, the convective layer data are also used for the crust and non-convective layers. The bulk concentration of [Cs] and [Sr] for each layer are used to estimate the heat load. As described in Section 3.1, it is necessary to calculate liquid weight fractions so that the rate can be expressed per kilogram of liquid.

These data are collected from the latest tank characterization report (TCR) for each DST. If no laboratory sampling data are available, the best estimated value was used as given in the BestBasis Inventory section in Appendix D of the TCR. This information is available in the Tank Characterization and Safety Resource Center at Tank Waste Remediation System (TWRS) and can also be accessed electronically through the tank characterization database (TCD), which is a tank waste database managed by TWRS (Schaffer 1997).

The derived terms are calculated from the TCR input data using convenient units; for example, the chemical constituents units of $\mu \mathrm{g} / \mathrm{mL}$ were converted to weight percent or moles. The heat load is estimated by the inventory of cesium and strontium. The wetted area in the tank was 
calculated from waste level data, including the tank walls and the tank bottom. The calculated water radiolysis $G_{\mathrm{H} 2 \mathrm{O}}$ and total $\mathrm{G}_{\text {tot }}$ values are also provided. Tanks such as 241-AY-102 and most AP and AW Farms' tanks have low, less than 0.5 molar, nitrate and nitrite ion concentrations, resulting in less scavenging. As a result, $\mathrm{G}_{\mathrm{H} 2 \mathrm{O}}$ is much higher than the default value 0.005 assumed for the model. The highest $\mathrm{G}_{\mathrm{H} 2 \mathrm{O}}$ is 0.24 from tank $241-\mathrm{AY}-102$, which contains less than 0.02 molar nitrite and nitrate. The highest organic $G_{o r g}$ is 0.12 from tank 241-AN-107, which has a very high [TOC] value.

Table 5-1 summarizes the calculated hydrogen generation rates and the percentage of the total rates from each of the three gas generation mechanisms. For the most active gas generating DSTs and SSTs, the thermolysis and radiolysis play the major role. Whether radiolysis or thermolysis is the leading term is dependent on the [TOC] and radiation dose rate. For those tanks with low TOC and aluminate, such as tanks 241-AN-101, 241-SY-102, and several SSTs, hydrogen generation occurs at a reduced rate and corrosion becomes the main contributor to hydrogen generation.

Table 5-1. The Model-Calculated Hydrogen Generation Rate (2 Sheets)

\begin{tabular}{|c|c|c|c|c|c|c|c|}
\hline \multirow{2}{*}{ Wank Name } & \multicolumn{2}{|c|}{ Radiolysis Rate } & \multicolumn{2}{|c|}{ Thermolysis Rate } & \multicolumn{2}{|c|}{ Gorrosion Rate. } & \multirow{2}{*}{$\begin{array}{l}\text { Fotaldor } \\
\text { (molerkg }\end{array}$} \\
\hline & (molerkg d) & Percent & (mole/kg d) & Percent & (molerkg-d) & Percents & \\
\hline 241-AN-101 & $3.96 \mathrm{E}-08$ & $4.4 \%$ & $4.82 \mathrm{E}-08$ & $5.4 \%$ & $8.10 \mathrm{E}-07$ & $90.2 \%$ & $8.98 \mathrm{E}-07$ \\
\hline 241-AN-103 & $3.37 \mathrm{E}-07$ & $26.7 \%$ & $7.39 \mathrm{E}-07$ & $58.6 \%$ & $1.84 \mathrm{E}-07$ & $14.6 \%$ & $1.26 \mathrm{E}-06$ \\
\hline 241-AN-104 & $3.72 \mathrm{E}-07$ & $26.0 \%$ & $8.67 \mathrm{E}-07$ & $60.6 \%$ & $1.91 \mathrm{E}-07$ & $13.3 \%$ & $1.43 \mathrm{E}-06$ \\
\hline 241-AN-105 & $3.02 \mathrm{E}-07$ & $23.5 \%$ & $7.96 \mathrm{E}-07$ & $61.9 \%$ & $1.87 \mathrm{E}-07$ & $14.6 \%$ & $1.28 \mathrm{E}-06$ \\
\hline 241-AN-107 & $2.46 \mathrm{E}-06$ & $64.5 \%$ & $1.15 \mathrm{E}-06$ & $30.0 \%$ & $2.09 \mathrm{E}-07$ & $5.5 \%$ & $3.82 \mathrm{E}-06$ \\
\hline 241-AW-101 & $3.93 \mathrm{E}-07$ & $31.4 \%$ & $6.65 \mathrm{E}-07$ & $53.2 \%$ & $1.92 \mathrm{E}-07$ & $15.4 \%$ & $1.25 \mathrm{E}-06$ \\
\hline 241-AY-101 & $1.59 \mathrm{E}-05$ & $95.3 \%$ & $4.54 \mathrm{E}-08$ & $0.3 \%$ & $7.43 \mathrm{E}-07$ & $4.4 \%$ & $1.67 \mathrm{E}-05$ \\
\hline 241-AY-102 & $9.07 \mathrm{E}-06$ & $96.5 \%$ & $5.55 \mathrm{E}-10$ & $0.0 \%$ & $3.33 \mathrm{E}-07$ & $3.5 \%$ & $9.40 \mathrm{E}-06$ \\
\hline 241-AZ-101 & 4.92E-06 & $64.0 \%$ & $2.54 \mathrm{E}-06$ & $33.0 \%$ & $2.32 \mathrm{E}-07$ & $3.0 \%$ & $7.70 \mathrm{E}-06$ \\
\hline 241-AZ-102 & $3.24 \mathrm{E}-06$ & $74.2 \%$ & $8.70 \mathrm{E}-07$ & $19.9 \%$ & $2.55 \mathrm{E}-07$ & $5.8 \%$ & $4.36 \mathrm{E}-06$ \\
\hline 241-SY-101 & $1.04 \mathrm{E}-06$ & $20.6 \%$ & $3.83 \mathrm{E}-06$ & $76.0 \%$ & $1.69 \mathrm{E}-07$ & $3.3 \%$ & $5.04 \mathrm{E}-06$ \\
\hline 241-SY-102 & $1.82 \mathrm{E}-08$ & $5.5 \%$ & $3.54 E-09$ & $1.1 \%$ & $3.07 \mathrm{E}-07$ & $93.4 \%$ & $3.28 \mathrm{E}-07$ \\
\hline 241-SY-103 & $4.63 \mathrm{E}-07$ & $28.5 \%$ & $9.41 \mathrm{E}-07$ & $57.9 \%$ & $2.22 \mathrm{E}-07$ & $13.6 \%$ & $1.63 \mathrm{E}-06$ \\
\hline 241-A-101 & $1.92 \mathrm{E}-07$ & $13.6 \%$ & $8.60 \mathrm{E}-07$ & $60.8 \%$ & $3.62 \mathrm{E}-07$ & $25.6 \%$ & $1.41 \mathrm{E}-06$ \\
\hline 241-A-102 & $5.08 \mathrm{E}-07$ & $12.0 \%$ & $2.00 \mathrm{E}-07$ & $4.7 \%$ & $3.52 \mathrm{E}-06$ & $83.3 \%$ & 4.22E-06 \\
\hline 241-C-104 & $4.19 \mathrm{E}-07$ & $35.3 \%$ & $9.49 \mathrm{E}-08$ & $8.0 \%$ & $6.71 \mathrm{E}-07$ & $56.6 \%$ & $1.18 \mathrm{E}-06$ \\
\hline
\end{tabular}


HNF-3851 Rev. 0

Table 5-1. The Model-Calculated Hydrogen Generation Rate (2 Sheets)

\begin{tabular}{|c|c|c|c|c|c|c|c|}
\hline \multirow{2}{*}{ Tank Nime } & \multicolumn{2}{|c|}{ Radiolysis Rate } & \multicolumn{2}{|c|}{ Thermolysis Rate } & \multicolumn{2}{|c|}{ Conrosion Rate } & \multirow{2}{*}{ 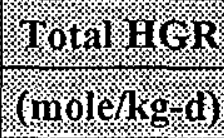 } \\
\hline & (nole/kg-d) & Percent & (moleng-d) & Percent & (moles) d) & Percent & \\
\hline 241-C-105 & $9.88 \mathrm{E}-07$ & $42.6 \%$ & $7.53 \mathrm{E}-09$ & $0.3 \%$ & $1.32 \mathrm{E}-06$ & $57.1 \%$ & $2.32 \mathrm{E}-06$ \\
\hline 241-C-106 & 2.15E-05 & $93.7 \%$ & $6.46 \mathrm{E}-07$ & $2.8 \%$ & 7.87E-07 & $3.4 \%$ & $2.29 \mathrm{E}-05$ \\
\hline 241-S-102 & $1.08 \mathrm{E}-07$ & $12.1 \%$ & $3.26 \mathrm{E}-07$ & $36.6 \%$ & $4.58 \mathrm{E}-07$ & $51.3 \%$ & $8.91 \mathrm{E}-07$ \\
\hline 241-S-106 & 3.63E-08 & $6.4 \%$ & $2.04 \mathrm{E}-08$ & $3.6 \%$ & $5.12 \mathrm{E}-07$ & $90.0 \%$ & $5.68 \mathrm{E}-07$ \\
\hline 241-S-111 & $3.58 \mathrm{E}-08$ & $6.5 \%$ & $2.49 \mathrm{E}-08$ & $4.5 \%$ & 4.87E-07 & $88.9 \%$ & $5.47 \mathrm{E}-07$ \\
\hline $241-S X-101$ & $7.25 \mathrm{E}-08$ & $11.7 \%$ & $5.41 \mathrm{E}-08$ & $8.7 \%$ & 4.93E-07 & $79.6 \%$ & $6.19 \mathrm{E}-07$ \\
\hline 241-SX-103 & $2.49 \mathrm{E}-07$ & $17.4 \%$ & $7.75 \mathrm{E}-07$ & $54.4 \%$ & $4.02 \mathrm{E}-07$ & $282 \%$ & \\
\hline 241-SX-104 & $1.23 \mathrm{E}-07$ & $14.7 \%$ & $2.29 \mathrm{E}-07$ & $27.5 \%$ & $4.82 \mathrm{E}-07$ & $57.8 \%$ & 8.34E-07 \\
\hline 241-SX-105 & $3.77 \mathrm{E}-07$ & $15.9 \%$ & $1.60 \mathrm{E}-06$ & $67.3 \%$ & 4.01E-07 & $16.9 \%$ & $2.38 \mathrm{E}-06$ \\
\hline 241-SX-106 & 1.53E-07 & $15.4 \%$ & $3.54 \mathrm{E}-07$ & $35.5 \%$ & 4.91E-07 & $49.2 \%$ & 9.98E-07 \\
\hline $241-U-102$ & $2.40 \mathrm{E}-07$ & $21.4 \%$ & $2.86 \mathrm{E}-07$ & $25.4 \%$ & $5.97 \mathrm{E}-07$ & $53.2 \%$ & $1.12 \mathrm{E}-06$ \\
\hline $241-U-103$ & $2.36 \mathrm{E}-07$ & $21.4 \%$ & $3.55 \mathrm{E}-07$ & $32.2 \%$ & $5.12 \mathrm{E}-07$ & $46.4 \%$ & $1.10 \mathrm{E}-06$ \\
\hline 241-U-105 & $3.80 \mathrm{E}-07$ & $28.6 \%$ & $3.95 \mathrm{E}-07$ & $29.7 \%$ & $5.54 \mathrm{E}-07$ & $41.7 \%$ & $1.33 \mathrm{E}-06$ \\
\hline 241-U-106 & $6.08 \mathrm{E}-07$ & $29.3 \%$ & $5.82 \mathrm{E}-07$ & $28.1 \%$ & $8.82 \mathrm{E}-07$ & $42.6 \%$ & $2.07 \mathrm{E}-06$ \\
\hline 241-U-107 & 4.07E-08 & $5.8 \%$ & $3.17 \mathrm{E}-08$ & $4.5 \%$ & $6.33 \mathrm{E}-07$ & $89.7 \%$ & $7.05 \mathrm{E}-07$ \\
\hline 241-U-108 & $1.06 \mathrm{E}-07$ & $13.5 \%$ & $1.71 \mathrm{E}-0.7$ & $21.8 \%$ & $5.08 \mathrm{E}-07$ & $64.7 \%$ & $7.86 \mathrm{E}-07$ \\
\hline 241-U-109 & $6.03 \mathrm{E}-08$ & $9.3 \%$ & $4.36 \mathrm{E}-08$ & $6.7 \%$ & $5.48 \mathrm{E}-07$ & $84.0 \%$ & $6.51 \mathrm{E}-07$ \\
\hline
\end{tabular}

\subsection{FIELD OBSERVED HYDROGEN GENERATION RATES OF TANK WASTE}

The hydrogen generation rates of Hanford tanks can be estimated from surveillance and waste characterization data, such as waste level measurements, hydrogen monitoring data, gas composition data, etc. The total generation rate is the sum of the steady release rate and the rate of gas retention in the tank waste.

The steady release rate can be estimated by the hydrogen concentration in the dome space and the ventilation rate.

$R_{\mathrm{H} 2}=\mathbf{V}_{\mathbf{r}} /\left[\left(1 /\left[\mathrm{H}_{2}\right]\right)-1\right]$

Where $V_{r}$ is the airflow rate in $\mathrm{cfm}$. 
$R_{r}$ is the hydrogen release rate in the dome space in $\mathrm{cfm}$.

$\left[\mathrm{H}_{2}\right]$ is the concentration in volume percent.

Ideally, the release rate should be estimated with both airflow rate and hydrogen concentration measurements taken simultaneously. Tank 241-AY-102 has been equipped with continuous hydrogen concentration monitoring and airflow rate monitoring system, and the release rates derived from these field data demonstrate this feature.

As shown in Figure 5-1, the thick background line, ranging from 18 and $28 \mathrm{cfd}$, is the steady release rate from 8,000 hydrogen concentration measurements and the vent rate measurements from June 1998 to December 1998. To demonstrate the relationships among these variables, the monthly averaged hydrogen concentration and vent rate, as well as the release rate, are listed in Table 5-2 and plotted in Figure 5-2. The averaged release rate is $23.7 \pm 3 \mathrm{cfd}$. As shown in Figure 5-2, the hydrogen concentration data and vent rate are precisely $180^{\circ}$ out of phase, and the product of these two curved lines gives a straight line of hydrogen release rate in the middle.

However, simultaneous data are not available for most tanks. Thus, the release rate is estimated using the average values of hydrogen concentration and airflow rate from the available data. As demonstrated for tank 241-AY-102, the product of average values of vent rate and hydrogen concentration should provide a reliable estimate of the release rate. The air flow rates are obtained in different ways, including the direct measurement using pito-tubes (tank farm operational datasheet), the tracer gas study in tank headspace (Huckaby et al. 1997 and 1998), and estimated rate from the Gas Release Event (GRE) SHMS data (McCain and Bauer 1998).

Table 5-2. Tank 241-AY-102 Hydrogen Concentration, Vent Rate, and Hydrogen Release Rate

\begin{tabular}{|c|c|c|c|}
\hline Monith : & {$\left[\mathrm{H}_{2}\right](\mathrm{ppm})$} & Vent Rate (cfin) & Y Releass Rater(cfd) \\
\hline Jun-98- & 62.8 & 267 & 23.8 \\
\hline Jul-98 & 58.6 & 258 & 23.3 \\
\hline Áug-98 & 72.6 & 215 & 22.3 \\
\hline Sep-98 & 63.7 & 266 & 23.5 \\
\hline Oct-98 & 47.9 & 361 & 24.9 \\
\hline Nov-98 & 49.7 & 348 & 24.7 \\
\hline Dec-98 & 55.4 & 277 & 21.9 \\
\hline Average & 58.7 & 284 & 23.5 \\
\hline
\end{tabular}

Note: $\quad c f m=$ cubic feet per minute, $c f d=$ cubic feet per day, $\mathrm{ppm}=$ parts per million 
Figure 5-1. The Hydrogen Release Rate of Tank 241-AY-102 From Continuous Field Monitoring Data of Hydrogen Concentration and Headspace Vent Rate

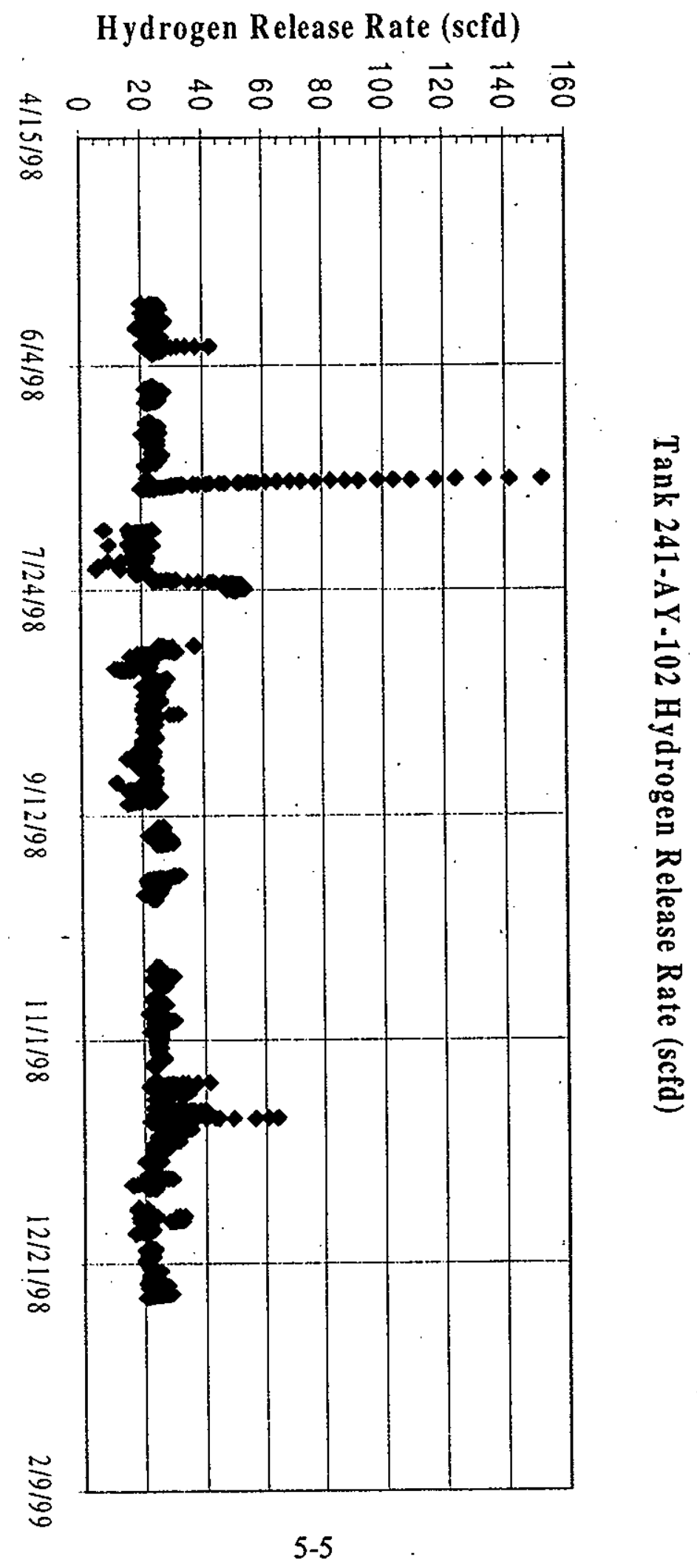


HNF-3851 Rev. 0

Figure 5-2. The Hydrogen Release Rate, Hydrogen Concentration, and Vent Rate in the Headspace of Tank 241-AY-102.

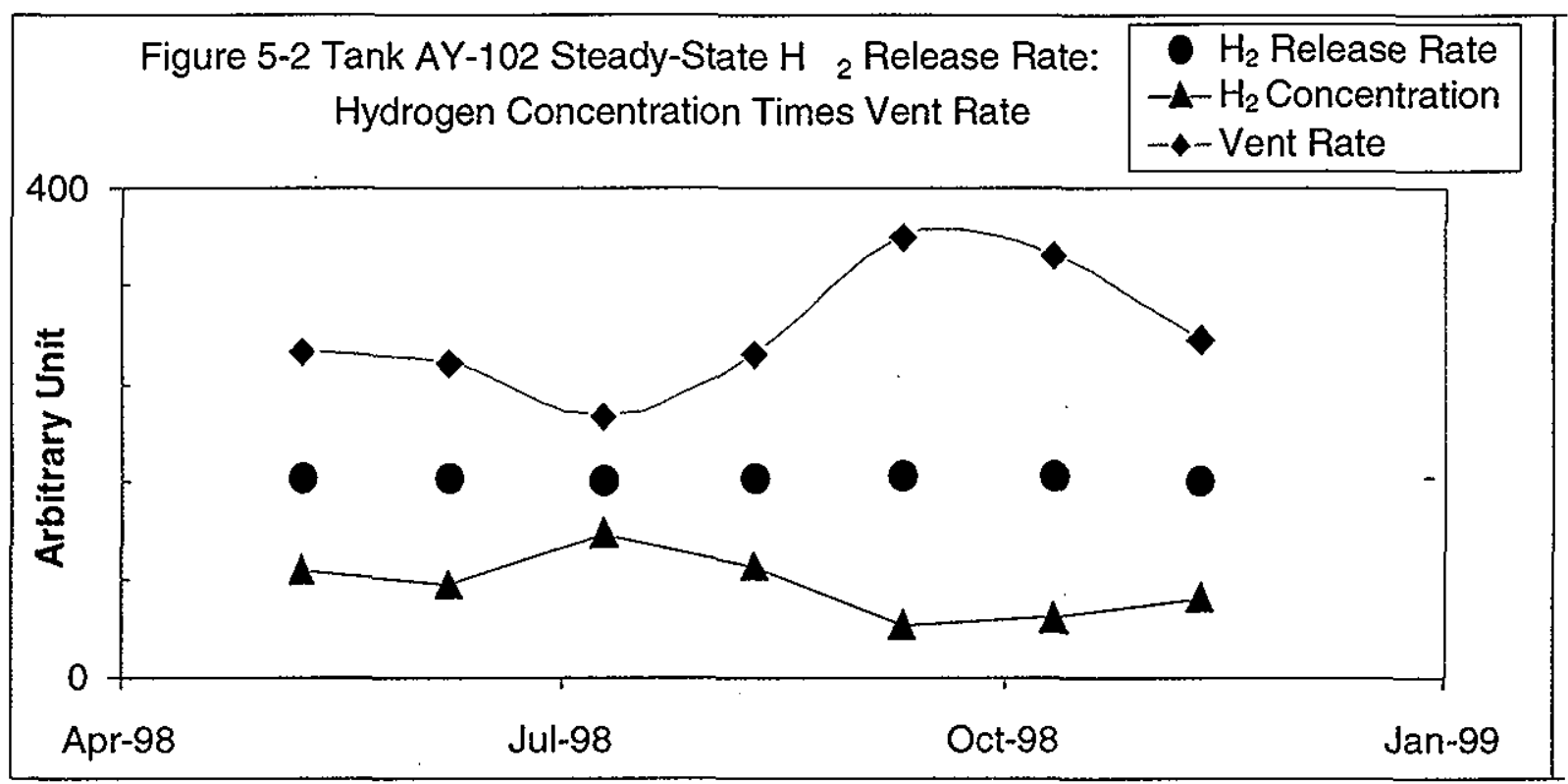

Hydrogen trapped in the waste will cause the waste level to increase. The hydrogen accumulation rate, therefore, can be estimated by knowing the waste level growth rate and hydrogen fraction of the trapped gas, and can be expressed as follows,

$$
\mathbf{A}_{\mathbf{H} 2}=\left(\mathbf{L}_{\mathrm{g}} \times \mathbf{A}\right) \times\left[(\mathbf{P} / \mathbf{T})_{\text {waste }} \times(\mathbf{T} / \mathbf{P})_{\text {headspace }}\right] \times\left[\mathbf{H}_{2}\right]
$$

Where $A_{H 2}$ is the hydrogen accumulation rate $\left(\mathrm{ft}^{3} / \mathrm{min}\right.$ or $\left.\mathrm{cfm}\right)$ $\mathrm{L}_{\mathrm{g}}$ is the growth rate of waste level ( $\mathrm{ft} / \mathrm{min}$ ) $A$ is the surface area (pi $x r^{2}$ ) of the tank. $(\mathrm{P} / \mathrm{T})_{\text {waste }}$ is the ratio of gas pressure $\mathrm{P}$ and temperature $\mathrm{T}$ within the waste. $(\mathrm{T} / \mathrm{P})_{\text {headspace }}$ is the ratio of temperature and pressure at the tank headspace. $\left[\mathrm{H}_{2}\right]$ is the hydrogen volume fraction in the trapped gas

The first term of the equation evaluates the rate of total gas volume increase within the confined waste, and this volume is then converted to the tank headspace condition using the ideal gas law. The growth rate of waste level can be obtained from tank waste level measurements. The pressure of trapped gas is the sum of atmospheric and hydrostatic pressures. An effective hydrostatic pressure of the trapped gas can be obtained from the retained gas sampler (RGS) data (Shekarriz et al. 1997, Mahoney et al. 1997). Otherwise, the hydrostatic pressure of the trapped gas is calculated using half of the solid waste weight plus the liquid weight above it. The average 


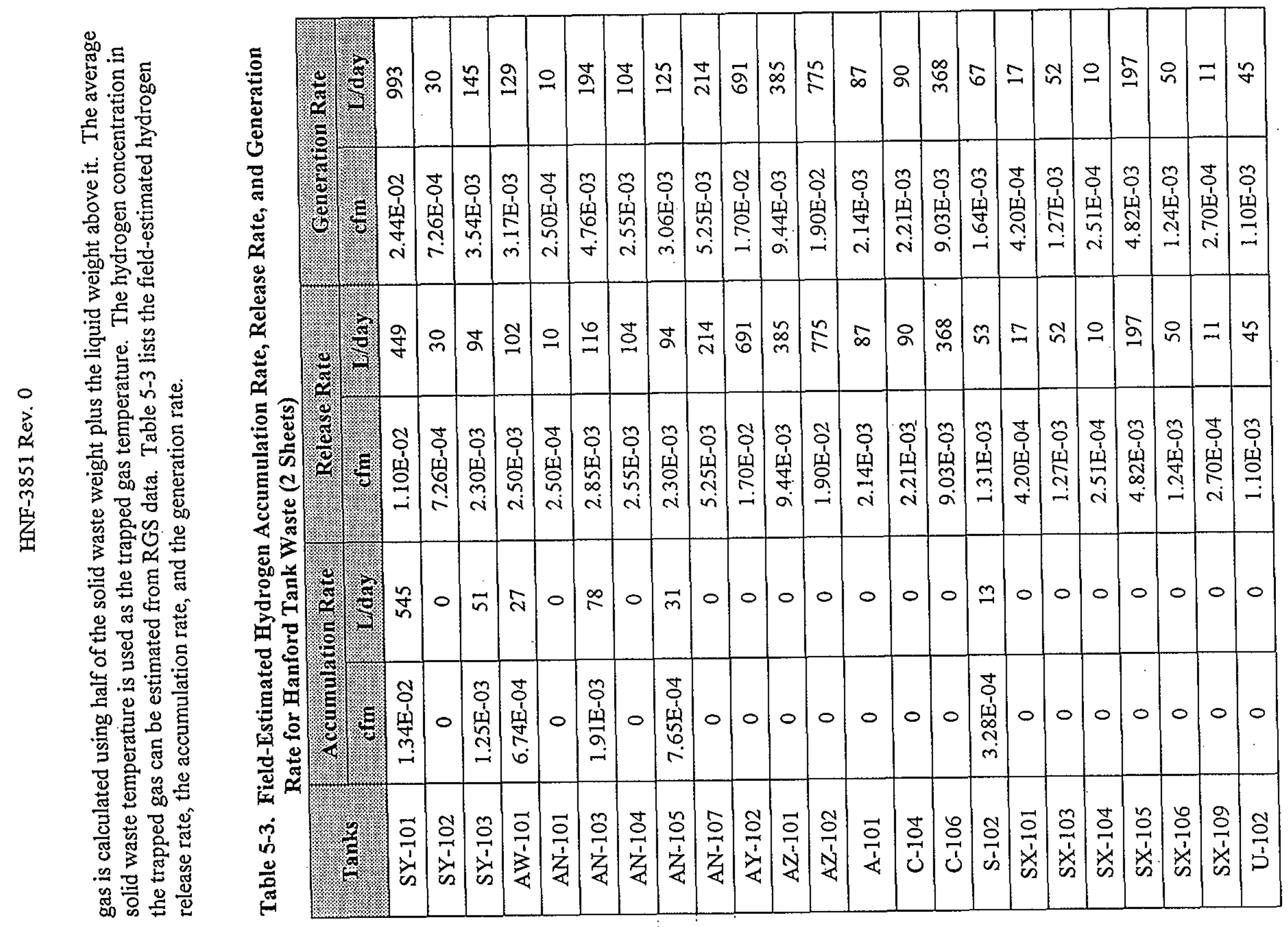


Table 5-3. Field-Estimated Hydrogen Accumulation Rate, Release Rate, and Generation Rate for Hanford Tank Waste (2 Sheets)

\begin{tabular}{|c|c|c|c|c|c|c|}
\hline \multirow{2}{*}{ ranks } & \multicolumn{2}{|c|}{ Accumulation Rate } & \multicolumn{2}{|c|}{ Release Rate. } & \multicolumn{2}{|c|}{ Generation. Rate } \\
\hline & cfin & Wofay. & cfin. & toray & cfm. & 1/ay \\
\hline U-103 & $6.73 \mathrm{E}-05$ & 3 & $1.41 \mathrm{E}-03$ & 58 & $1.48 \mathrm{E}-03$ & 60 \\
\hline U-105 & $2.56 \mathrm{E}-04$ & 10 & $1.35 \mathrm{E}-03$ & 55 & $1.61 \mathrm{E}-03$ & 65 \\
\hline U-106 & 0 & 0 & $6.62 \mathrm{E}-04$ & 27 & $6.62 \mathrm{E}-04$ & 27 \\
\hline U-107 & $1.58 \mathrm{E}-04$ & 6 & $6.69 \mathrm{E}-04$ & 27 & 8.27E-04 & 34 \\
\hline U-108 & $2.96 \mathrm{E}-04$ & 12 & 8.15E-04 & 33 & $1.11 \mathrm{E}-03$ & 45 \\
\hline U-109 & lo & 0 & $6.16 \mathrm{E}-04$ & 25 & $6.16 \mathrm{E}-04$ & 25 \\
\hline U-111 & 0 & 0 & $7.11 \mathrm{E}-04$ & 29 & $7.11 \mathrm{E}-04$ & 29 \\
\hline
\end{tabular}

For comparison, Table 5-4 lists the field-observed and model-calculated total hydrogen generation rates, and the ratio between these values for more than 25 tanks. For most tanks, the ratios are between 0.5 and 2.5, but for tank $241-\mathrm{SX}-104$, the ratio is 6.7 . There may be two explanations for this higher ratio. One possibility is that the field-estimated generation rate of tank $241-\mathrm{SX}$ 104 is lower than the actual value, because the estimated field rate assumes zero accumulation rate while the other surveillance data indicate the gases are trapped in the waste. Another possible reason is that the temperature used in the calculation may be lower than the true temperature in the waste because there is quite a wide range of temperature gradient vertically in. this tank as discussed below.

Several tanks have a wide temperature distribution throughout the tank. For example, tank 241-C-106 has a wide temperature distribution, ranging from 72 to $214^{\circ} \mathrm{F}$, and the temperature gradient appears not only vertically but also radially. For the rate equations developed above, both thermolysis and radiolysis rates are a function of temperature exponentially; therefore, temperature information is critical in the calculation. The model calculated rate for tank 241-C-106 listed in Table 5-4 uses an average temperature and may be underestimated. An appropriate way to take care of this temperature distribution is to calculate the generation rate by a finite volume then integrate to the whole tank.

Another issue regarding tank 241-C-106 is the organic oil was found in the core samples when centrifuging solid samples. Tanks having dispersed oil, such as tank 241-C-106, produce hydrogen by the radiolysis of oil. The estimated waste volume containing oil in tank 241-C-106 can be as much as of $84 \mathrm{kgal}$ with the concentration of 3 vol\% oil (Schreiber 1996; Reynolds 1997). This oil material may be responsible for the model calculated rates for C-104 and C-106 being lower than the field observed data because the model did not account for the radiolysis of oil. The $\mathrm{G}$-value of oil radiolysis can be as large as $5.0 \mathrm{H}_{2} / 100 \mathrm{eV}$ (Holroyd 1964), thus the estimated hydrogen contribution from 3 vol\% oil waste material is $17 \mathrm{~L} /$ day. 
HNF-3851 Rev. 0

Table 5-4. Comparison of Rates Between Model-Calculated and Field-Observed

\begin{tabular}{|c|c|c|c|c|}
\hline mankvames & Fotal hor rrom & Model(GiDay) & $\begin{array}{l}\text { Model Gield } \\
\text { Ratios from } \\
\text { This Work }\end{array}$ & $\begin{array}{l}\text { yodelfield } \\
\text { matros fom } \\
\text { grewous Hodel }\end{array}$ \\
\hline 241-AN-101 & 15 & 10 & 1.47 & \\
\hline 241-AN-103 & .183 & 180 & 1.02 & 1.18 \\
\hline 241-AN-104 & 220 & 209 & 1.05 & 1.36 \\
\hline 24l-AN-105 & 205 & 150 & 1.37 & 1.46 \\
\hline 241-AN-107 & 529 & 214 & 2.47 & \\
\hline 241-AW-101 & 193 & 157 & 1.23 & 0.74 \\
\hline 241-AY-102 & 727 & 665 & 1.09 & 1.70 \\
\hline 241-AZ-101 & 934 & 385 & 2.43 & - \\
\hline $241-\mathrm{AZ}-102$ & 897 & 775 & 1.16 & \\
\hline 241-SY-101 & 782 & 604 & 1.30 & 1.25 \\
\hline $241-S Y-102$ & 25 & 30 & 0.83 & \\
\hline 241-SY-103 & 163 & 145 & 1.12 & 1.15 \\
\hline 241-A-101 & 185 & 103 & 1.79 & \\
\hline $241-C-104$ & 47 & 90 & 0.53 & \\
\hline 241-C-106 & 337 & 368 & 0.92 & \\
\hline $241-S-102$ & 71 & 66 & 1.08 & 1.2 \\
\hline $241-S X-101$ & 43 & 17 & 2.55 & \\
\hline 241-SX-103 & 132 & 52 & 2.54 & 6.1 \\
\hline $241-S X-104$ & 66 & 10 & 6.64 & . \\
\hline 241-SX-105 & 228 & 197 & 1.16 & 14.6 \\
\hline $241-\mathrm{SX}-106$ & 77 & 50 & 1.54 & 2 \\
\hline 241-U-102 & 59 & 45 & 1.32 & . \\
\hline 241-U-103 & 75 & 60 & 1.25 & 1.26 \\
\hline 241-U-105 & 72 & 65 & 1.11 & 0.75 \\
\hline 241-U-106 & 63 & 27 & 2.37 & \\
\hline 241-U-107 & 39 & 34 & 1.14 & 1.11 \\
\hline 241-U-108 & 55 & 45 & 1.22 & 1.47 \\
\hline 241-U-109 & 43 & 25 & 1.71 & \\
\hline
\end{tabular}

Note: "Ratios of DSTs from Hu (1997) and SSTs from Peurrung et al. (1998). 
Further consideration of C-106 is that the water soluble TOC in the oil layer (Reynolds 1997) is much more reactive in hydrogen generation than other SSTs. If using reactivity coefficient $r_{f}$ as 1.0 rather than the 0.4 (for SST in Equation 4-16) for the aqueous phase part in the oil-containing waste, the hydrogen generation rate can gain extra $35 \mathrm{~L} /$ day. This will increase the total hydrogen generation from $285 \mathrm{~L} /$ day to $337 \mathrm{~L} /$ day, and the ratio of model versus field increases from 0.77 to 0.92 .

Comparison of the model-calculated and field-estimated hydrogen generation rates (Table 5-4) shows that the results for those tanks dominated by the corrosion process are in good agreement (within a factor of 1.5). This consistency suggests that the rate equation of corrosion in Equation 4-17 accurately model what is observed in the field.

Also listed in Table 5-4 are the ratios between model and field data for tanks using the previous model (Hu 1997). It appears that the ratio for SSTs varies from 0.75 to 30 using the old model. Part of the reason for the ratio of SSTs being so high is that the temperature used in the calculation may be the highest temperature instead of the average temperature. In contrast, this work provides a better consistency between model predictions and the field observed data. 


\subsection{SUMMARY AND CONCLUSION}

As long as the radioactive waste exists, hydrogen and other flammable gases will be generated, retained, and released. The existence of these gases will need to be addressed during waste handling operations. The model developed in this work can be a useful tool to estimate the hydrogen generation rate. Since the model considers waste composition and related variables, it can be used to calculate the rate for storage conditions so it can also predict the rates for newly created mixed wastes.

This work began with the analysis of the laboratory generation rates. It was discovered that both the observed thermal and effective radiolysis rates are temperature-dependent and follow Arrhenius behavior. A global analysis of the available data led to an empirical hydrogen generation rate model for Hanford tank waste in general. The hydrogen generation rate model contains empirical kinetic rate equations to simulate the generation from the thermal and radiolytic reactions on the waste. The model also includes hydrogen from liner corrosion.

The thermal rate is proportional to the total organic carbon and aluminate ion concentrations. The thermal process exhibits Arrhenius behavior. The reaction order for each reactant is determined by the rate analysis, and the results of a dilution study of tank 241-SY-101 waste. A radiolysis rate equation is used to simulate the enhanced rate in the presence of radiation. The radiation-enhanced rate is a combination of radiolytic and thermal reactions. A reactivity coefficient, $\mathrm{r}_{\mathrm{f}}$, which reflects differences in reactivity of the different $T O C$ distributions is introduced in the global fit of both thermolytic and radiolytic rates.

The effective radiolysis rate is the product of the radiation dose and the hydrogen $\mathrm{G}$-value. The $\mathrm{G}$-value is formulated to calculate the contribution from water radiolysis and organic radiolysis. The water radiolysis $G$-value is reduced by nitrate and nitrite salt in the waste, and is assumed to be temperature independent. The default water radiolysis $\mathrm{G}$-value is 0.005 for wastes with high salt $\left(\mathrm{NO}_{3} / \mathrm{NO}_{2}\right.$ ions). The organic radiolysis $\mathrm{G}$-value is proportional to the concentration of total organic carbon, and follows Arrhenius behavior. The radiolysis rate is the product of radiation dose and $G$, and $G$ is a function of temperature. Finally, the contribution from liner corrosion is determined by the product of liner corrosion rate and the wetted area in the tank. The liner corrosion rate is specified for SSTs and DSTs. The parameters in the rate equations are derived from 200 gas generation measurements from waste samples from four DSTs and three SSTs.

Finally, the model is tested by comparing the model calculated rate with the field observed data for twenty-eight DSTs and SSTs. For most tanks compared between model and field HGRs the calculated generation rate is within a factor of three, except for tank 241-SX-104 which has a factor of 6.7. In addition, tank 241-C-106 has lower prediction value than the field observed rate. Notice that this tank has disperse oil in the sludge layer contains appreciable amount of dissolved organic and produce hydrogen by the radiolysis of oil. The typical $\mathrm{G}$-value can be as high as 1 and will responsible for the discrepancy between the predicted value and observed value. Similar situation may occurred in tank 241-C-104. 
HNF-3851 Rev. 0

Overall, the model is consistent with gas generation mechanism studies of simulants and with laboratory and field investigations of tank waste. The model should provide a scientifically defensible and statistically accurate approach to evaluate hydrogen generation in the Hanford waste. 


\subsection{REFERENCES}

Anantatmula, R. P., 1999, Recommendation of Uniform Corrosion Rates for Double-Shell and Single-Shell Tanks (Internal Memo 74700-99RPA-006 to K. M. Hodgson, January 29), Lockheed Martin Hanford Incorporation, Richland, Washington.

Anantatmula, R. P., E: B. Schwenk, and M. J. Danielson, 1994, Characterization of the Corrosion Behavior of the Carbon Steel Liner in Hanford Site Single-Shell Tanks, WHC-EP-0772, Rev. 0, Westinghouse Hanford Company, Richland, Washington.

Ashby, E. C., E. K. Barefield, C. L. Liotta, H. M. Neumann, F. Doctorovich, A. Konda, K. Zhang, J. Hurley, D. Boatright, A. Annis, G. Pansino, M. Dawson, and M. Juliao, 1992, Mechanistic Studies Related to the Thermal Chemistry of Simulated Wastes Which Mimic Contents of Tank 101-SY, paper presented at American Chemical Society Symposium, "Emerging Technologies for Hazardous Waste Management," Atlanta, Georgia.

Ashby, E. C., R. Doctorovich, C. L. Liotta, H. M. Neuman, E. K. Barefield, A. Konda, K. Zhang, J. Hurley, and D. D. Siemer, 1993, Concerning the Formation of Hydrogen in Nuclear Waste. Quantitative Generation of Hydrogen via a Cannizzaro Intermediate. Journal of. American Chemical Society 115, 1171.

Ashby E. C., D. A. Annis, E. K. Barefield, D. Boatwright, F. Doctorovich, C. L. Liotta, H. M. Neumann, A. Konda, C. F. Yao, K. Zhang, and N. G. McDuffie, 1994, Synthetic Waste Chemical Mechanism Studies, WHC-EP-0823, Westinghouse Hanford Company, Richland, Washington.

Barefield, E. K., D. Boatwright, A. Deshpande, F. Doctorovich, C. L. Liotta, H. M. Neumann, and S. Seymore, 1995, Mechanisms of Gas Generation from Simulated SY Tank Farm Wastes: FY-1994 Progress Report, PNL-10822, Pacific Northwest Laboratory, Richland, Washington.

Barefield, E. K., D. Boatwright, A. Deshpande, F. Doctorovich, C. L. Liotta, H. M. Neumann, and S. Seymore, 1996, Mechanisms of Gas Generation from Simulated SY Tank Farm Wastes: FY 1994 Progress Report, PNL-11247, Pacific Northwest National Laboratory, Richland, Washington.

Barney, G. S., 1994, The Solubilities of Significant Organic Compounds in HLW Tank Supernate Solutions, WHC-SA-2565-FP, Westinghouse Hanford Company, Richland, Washington.

Barney, G. S., 1995, The Solubilities of Significant Organic Compounds in HLW Tank Supernate Solutions-FY 1995 Progress Report, WHC-EP-0899, Westinghouse Hanford Company, Richland, Washington. 
Barney, G. S., 1996, The Solubilities of Significant Organic Compounds in HLW Tank Supernate Solutions-FY 1996 Progress Report, WHC-EP-0899-1, Westinghouse Hanford Company, Richland, Washington.

Barney, G. S., 1997, The Solubilities of Significant Organic Compounds in HLW Tank Supernate Solutions-FY 1996 Progress Report, WHC-EP-0899-2, Westinghouse Hanford Company, Richland, Washington.

Bryan, S. A., L. R. Pederson, J. L. Ryan, R. D.Scheele, and J. M: Tingey, 1992, Slurry Growth, Gas Retention, and Flammable Gas Generation by Hanford Radioactive Waste Tanks, PNL-8169, Pacific Northwest National Laboratory, Richland, Washington

Bryan, S. A., and L. R. Pederson, 1994, Composition, Preparation, and Gas Generation Results from Simulated Wastes of Tank 241-SY-101, PNNL-10075, Pacific Northwest National Laboratory, Richland, Washington.

Bryan, S. A., L. R. Pederson, C. M. King, S. V. Forbes, and R. L. Sell, 1996, Gas Generation from Tank 241-SY-103 Waste, PNNL-10978, Pacific Northwest National Laboratory, Richland, Washington.

Bryan, S. A., and C. M. King, 1998, Thermal and Radiolytic Gas Generation From Tank 241-AW-101 Waste: Status Report, TWRS98.39, Pacific Northwest National Laboratory, Richland, Washington.

Camaioni, D. M., W. D. Samuels, J. C. Linehan, S. A. Clauss, A. K. Sharma, K. L. Wahl, and J. A. Campbell, 1996, FY95 Waste Aging Studies, PNL-11312, Pacific Northwest Laboratory, Richland, Washington.

Campbell, J. A., S. Clauss, K. A. Grant, F. V. Hoopes, B. D. Lerner, R. B. Lucke, G. M. Mong, J. K. Rau, R. T. Steele, and K. L. Wahl, 1995, Organic Analysis and Analytical Methods Development: FY 1995 Progress Report, PNL-10776, Pacific Northwest Laboratory, Richland, Washington.

Campbell, J. A., S. Clauss, K. A. Grant, F. V. Hoopes, G. M. Mong, J. K. Rau, R. T. Steele, and K. L. Wahl, 1996, Flammable Gas Safety Program: Actual Waste Organic Analysis, FY 1996 Progress Report, PNNL-1307, Pacific Northwest National Laboratory, Richland, Washington.

Delegard, C., 1980, Laboratory Studies of Complexed Waste Slurry Volume Growth in Tank 241-SY-101, RHO-LD-124, Rockwell International, Richland, Washington.

Graves, R. D., 1994, Topical Report on Flammable Gases in Non-Burping Waste Tanks, WHC-SD-WM-SARR-015, Westinghouse Hanford Company, Richland, Washington. 
Hopkins, J. D., 1994, Criteria for Flammable Gas Watch List Tanks, WHC-EP-0702, Rev. 0, Westinghouse Hanford Company, Richland, Washington.

Holroyd, R. A., 1964, Radiolysis of Hydrocarbons, Elsevier Publishing Co., New York.

Hu, T. A., 1997, Calculations of Hydrogen Release Rate at Steady State for Double-Shell Tanks, HNF-SD-WM-CN-117, Rev. 0-A, Lockheed Martin Hanford Corporation, Richland, Washington.

$\mathrm{Hu}, \mathrm{T}$ A, W. B. Barton, and K. M. Hodgson, 1998, Validation and Application of the Hydrogen Generation Rate Model Calculations for Hanford Tank Waste, paper presented at American Chemical Society, $53^{\text {rd }}$ Northwest Regional Meeting, June 17-20, 1998, Pasco, Washington.

Huckaby, J. L., J. C. Evans, K. B. Olsen, K. M. Remund, and D. S. Sklarew, 1997, Measurements of Waste Tanks Passive Ventilation Rates Using Tracer Gases, PNNL-11683, Pacific Northwest National Laboratory, Richland, Washington.

Huckaby, J. L., D. S. Sklarew, J. C. Evans, and A. V. Mitroshkov, 1998, Waste Tank Ventilation Rates Measured with a Tracer Gas Method, PNNL-11925, Pacific Northwest National Laboratory, Richland, Washington.

King, C. M., L. R. Pederson, and S. A. Bryan, 1997, Thermal and Radiolytic Gas Generation From Tank 241-S-102 Waste, PNNL-11600, Pacific Northwest National Laboratory, Richland, Washington.

King, C. M. and S. A. Bryan, 1998a, Thermal and Radiolytic Gas Generation From Tank 241-S-106 Waste: Status Report, TWS98.77, Pacific Northwest National Laboratory, Richland, Washington

King, C. M., and S. A. Bryan, 1998b, Thermal and Radiolytic Gas Generation From Tank 241-A-101 Waste: Status Report, TWS98.78, Pacific Northwest National Laboratory, Richland, Washington.

Mahoney, L. A., Z. I. Antoniak, and J. M. Bates, 1997, Composition and Quantities of Retained Gas Measured in Hanford Waste Tanks 241-U-103, S-106, BY-101, and BY-109, PNNL-11777, Pacific Northwest National Laboratory, Richland, Washington.

McCain. D. J., and R. E. Bauer, 1998, Results of Vapor Space Monitoring of Flammable Gas Watch List Tanks, HNF-SD-WM-TI-797, Rev. 3, Lockheed Martin Hanford Corporation, Richland, Washington.

Meisel, D., H. Diamond, E. P. Horowitz, C. D. Jonah, M. S. Matheson, M. C. Sauer, and J. C. Sullivan, 1991a, Radiation Chemistry of Synthetic Waste, ANL-91/40, Argonne National Laboratory, Argonne, Illinois. 
Meisel, D., H. Diamond, E. P. Horowitz, C. D. Jonah, M. S. Matheson, M. C. Sauer, Jr., and J. C. Sullivan, 1991b, Radiation Chemistry of Synthetic Waste, ANL-91/40, Argonne National Laboratory, Argonne, Illinois.

Meisel, D., H. Diamond, E. P. Horowitz, C. D. Jonah, M. S. Matheson, M. C. Sauer, Jr., J. C. Sullivan, F. Barnabas, E. Cerny, and Y. D. Cheng, 1991c, Radiolytic Generation of Gases from Synthetic Waste: Annual Report 1991, ANL-91/41, Argonne National Laboratory, Argonne, Illinois.

Meisel, D., C. D. Jonah, S. Kapoor, M. S. Matheson, and M. C. Sauer, 1993, Radiolytic and Radiolytically Induced Generation of Gases from Synthetic Wastes, ANL-93/43, Argonne National Laboratory, Argonne, Illinois.

Ondrejcin, R. S., S. P. Rideout, and J. A. Donovan, 1979, Control of Stress Corrosion Cracking in Storage Tanks Containing Radioactive Waste, Nuclear Technology, Vol. 44. 297=306.

Pederson, L. R., and S. A. Bryan, 1996, Status and Integration of Studies of Gas Generation in Hanford Wastes, PNNL-11297, Rev. 0, Pacific Northwest National Laboratory, Richland, Washington.

Peurrung, L. M., L. A. Mahoney, C. W. Stewart P. A. Gauglitz, L. R. Pederson, S. A. Bryan, and C. L. Shepard, 1998, Flammable Gas Issues in Double-Contained Receiver Tanks, PNNL-11836, Rev. 2, Pacific Northwest National Laboratory, Richland, Washington.

Person, J. C., 1996, Effects of Oxygen Cover Gas and NaOH Dilution on Gas Generation in Tank 241-SY-101 Waste, WHC-SD-WM-DTR-043, Westinghouse Hanford Company, Richland, Washington.

Person, J. C., 1998, Gas Generation in Tank 241-AN-105 Waste, WHC-SD-WM-DTR-043, Westinghouse Hanford Company, Richland, Washington.

Reynold, D. A., 1997, Chemical and Chemically-Related Considerations Associated with Sluicing Tank C-106 Waste to Tank AY-102, HNF-SD-WM-TI-756, Rev. 2, Lockheed Martin Hanford Corporation, Richland, Washington.

Schaffer, J. B., 1997, Tank Characterization Database, HISI Registration Number 11578, Lockheed Martin Hanford Corporation, Richland, Washington.

Schreiber, R. D., 1996, Tank Characterization Report for Single-Shell Tank 241-C-106, WHCSD-WM-ER-615, Rev. 0, Westinghouse Hanford Company, Richland, Washington. 
Shekarriz, A., D. R. Rector, N. S. Cannon, L. A. Mahoney, C. G. Linschooten, J. M. Bates, F. J. Reitz, R. E. Bauer, E. R. Siciliano, 1997, Composition and Quantities of Retained Gas Measured in Hanford Waste Tanks 241-AW-101, A-101, AN-105, AN-104, and $A N-103$, PNNL-11450, Rev. 1, Pacific Northwest National Laboratory, Richland, Washington.

Spinks, J. W. T., and R. J. Woods, 1990, Introduction to Radiation Chemistry, $3^{\text {rd }}$ edition, John Wiley \& Sons, Inc., New York, New York.

Stauffer, L. A. and L. M. Stock, 1999, Origins of Volatile Organic Compounds Emerging from Tank 241-C-106 during Sluicing, HNF-4261, Lockheed Martin Hanford Corporation, Richland, Washington.

Stock, L. M., and L. R. Pederson, 1997, Chemical Pathways for the Formation of Ammonia in Hanford Wastes, PNNL-11702, Rev. 1, Pacific Northwest National Laboratory, Richland, Washington.

Strachan, D. M., 1994, Status and Integration of the Gas Generation Studies Performed for the Hydrogen Safety Program - FY 1993 Annual Report, PNL-9459, Pacific Northwest Laboratory, Richland, Washington.

Tabta, Y., T. Ito, and S. Tagawa, 1991, Handbook of Radiation Chemistry, CRC Press, Boca Raton, Florida. 
HNF-3851 Rev. 0

This page intentionally left blank. 


\begin{tabular}{|c|c|c|c|c|c|}
\hline To & \multirow{2}{*}{\multicolumn{3}{|c|}{$\begin{array}{l}\text { From } \\
\text { Process Engineering }\end{array}$}} & \multicolumn{2}{|l|}{ Page 1 of 1} \\
\hline Distribution & & & & \multicolumn{2}{|c|}{ Date $05 / 25 / 99$} \\
\hline \multicolumn{4}{|l|}{ Project Title/Work Order } & \multicolumn{2}{|c|}{ EDT No. 626581} \\
\hline \multicolumn{4}{|c|}{$\begin{array}{l}\text { HNF-3851, Rev. 0, "Empirical Rate Equation Model and Rate } \\
\text { Calculations of Hydrogen Generation for Hanford Tank Waste" }\end{array}$} & \multicolumn{2}{|l|}{ ECN No. NA } \\
\hline Name & MSIN & $\begin{array}{c}\text { Text } \\
\text { With All } \\
\text { Attach. }\end{array}$ & Text Only & $\begin{array}{l}\text { Attach./ } \\
\text { Appendix } \\
\text { Only }\end{array}$ & $\begin{array}{l}\text { EDT/ECN } \\
\text { Only }\end{array}$ \\
\hline
\end{tabular}

\section{ONSITE}

Fluor Daniel Northwest

D. T. Vladimiroff

$\$ 7-20 \quad X$

Lockheed Mart in Hanford, Corp.
S. A. Barker
W. B. Barton
C. DeFigh-Price
K. M. Hodgson
T. A. Hu
N. W. Kirch
G. D. Johnson
D. A. Reynolds
T.C.S.R.C

$\begin{array}{ll}\text { R2-11 } & X \\ \text { R2-12 } & X \\ \text { R2-12 } & X \\ \text { R2-11 } & X \\ \text { R2-11 } & X \\ \text { R2-11 } & X \\ \text { S7 }-73 & X \\ \text { R2-11 } & X \\ \text { R1-10 } & X\end{array}$

Lockheed Mart in Services, Inc.

Central Files

A3-88 $\quad X$

Numatec Hanford, Corp.

A. F. Choho

R3-73

R3 -73

J. S. Garfield

D. L. Herting

R. A. Kirkbride

J. C. Person

T6-07

R3-73

T6-07

\section{Other}

H. Babad

J. M. Grigsby

L. M. Stock

S7-14

$S 7-73$

$$
\begin{aligned}
& X \\
& X \\
& X
\end{aligned}
$$

Pacific Northwest National Laboratory

J. W. Brothers

$\mathrm{K} 9-20$

$\mathrm{P} 7-25$

K2-44

L. R. Pederson

C. W. Stewart

$\mathrm{K} 7-15$

$X$
$X$
$X$
$X$ 